\title{
Overcoming Challenges: Pacific students' experiences of being resilient through tertiary education
}

A thesis submitted in partial fulfilment of the requirements for the degree of

Master of Arts in Education

at

The Victoria University of Wellington

2015

by

Arden Raymond Dujon Perrot 


\section{Dedication}

This thesis is dedicated to my Dad who passed away suddenly on 17 December 2013. He was my fearless leader, my guru, my friend, and a big piece of my world. When I share my story to the world Dad, I talk about one of the greatest moments in my life. It is not any of my rugby achievements even though there were many. It was the proud look on your face when I received the academic medal of excellence. As I sat back down, you shook my hand with both pride and disbelief, as you did not think the award was going to be that prestigious and presented with such high esteem. After sharing dinner, you hugged me to say goodbye and as you always did, squeezed me tight. You told me how proud you were of me, and how much you loved me. Nearly two years on dad and I still miss you every day, they say time heals all things but maybe what is more true is time reveals all things. Time reveals how precious life is, time reveals the importance of moments, time reveals the importance of family, time reveals our gratitude for life, and time reveals the depth of love. I dedicate this thesis to you Dad, I love you and I will always miss you.

Manuia lou Malaga

Arden

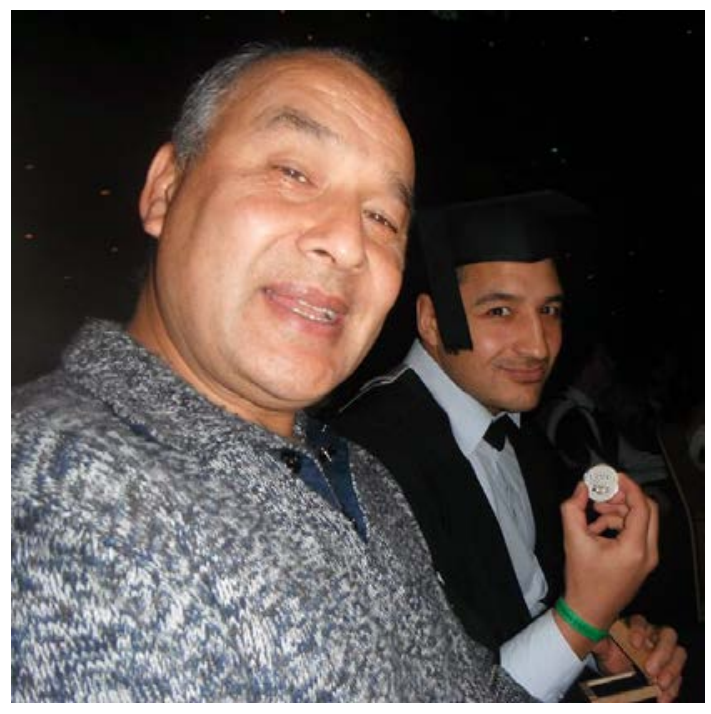




\section{Acknowledgements}

Firstly, I would like to thank our Heavenly Father for continuing to bless me every day. A massive thank you goes out to my leader, my mentor, my friend, my hero, my supervisor Dr Cherie Chu. I thank you for your care, your strength, your understanding, and guidance both in life and in academia. Your leadership over the years has helped to shape me become a better person and leader. This thesis would not be possible without you and was an honour to be under your supervision. I need to thank my colleague Dr Fiona Beals, for your belief in me as an academic and your leadership. Your passion for learning and research is contagious. You made believe I could do it and that I needed to do this research. I also need to thank Dr Maria Ulloa for your research experience and helping me understand my research better. I must thank Mumtaz Dalwa for allowing me the time to get this thesis finished. Thank you to Laura Van Peer for helping me "smooth" the edges of this rough diamond your help has been invaluable. I would also like to extend my gratitude to my participants. Without your inspiring stories of hope, this research would have never been possible.

A special and sincere thank you to the love of my life Emma Tevita, your unconditional love, support and understanding has been vital in getting me across the line, I thank you for spending late nights and weekends in the office with me, for doing the little things that made my life a little easier this year. I need to thank my Mum, my sisters and brothers for always being there for me. Lastly, to my wider family and friends I thank you all for your encouragement throughout the years. To everyone above I am honoured and blessed to have a connection with you all. 


\begin{abstract}
The issue of raising Pasifika achievement levels in New Zealand has been at the forefront of Pasifika research as early as 1996 in the AIMHI report from the Ministry of Education. Nearly, 20 years on and the goal remains the same as Pasifika still underperform in education. In the last 19 years, there has been countless research in understanding the issue, with numerous identified areas of concern. However, so many areas need addressing that is can serve the purpose of perpetuating the problem by making it too large to solve. The structural, systemic issues still remain, the lack of Pasifika teachers and teachers that understand Pasifika still remain, the gap between home and school life still exist, as well as the lack of real leaders and governance in schools that want to make a difference to the education realties of Pasifika (Chu et al., 2013).
\end{abstract}

This frustration has led to the rise of "strength based" approached to Pasifika education research in pursuit of solutions. With a focus on appreciating what works for Pasifika and trying to foster that success and replicate it. However, a gap remains, there has been little to no platform for the empowered Pasifika voice on the issue. The Pasifika person that "bucks" the trend and despite the countless education issues were resilient and fought for their educational success.

This thesis provides a platform for this voice. This thesis reveals the stories of eight Pasifika postgraduate students (PPGS) that were deemed academic failures at secondary school. It focuses on their internal and external factors that facilitated their academic progress and resilience. This qualitative study was underpinned by appreciative inquiry as the theoretical framework and a Pacific methodology and method Talanoa. The participants were selected via snowball sampling technique and one on one Talanoa discussions were used to explore their stories. The main finding from the research identified that as the participant's self-concepts changed so did their academic performance. The identified historical and recent education barriers were still present in both their education failure and success. However, through transferable success experiences, deep reflection, visualisation, and goal setting, enabled the participants to see a positive academic result before it eventuated. This helped the participants develop positive self-concepts and attitudes that facilitated their progress and resilience to overcome existing barriers and become successful postgraduate students. 


\section{Table of Contents}

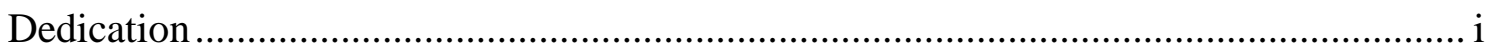

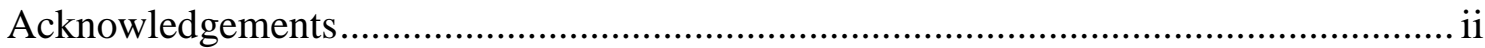

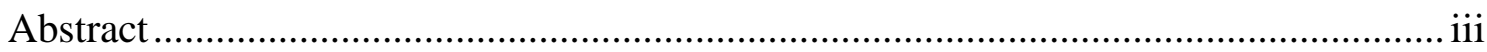

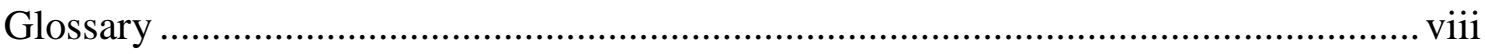

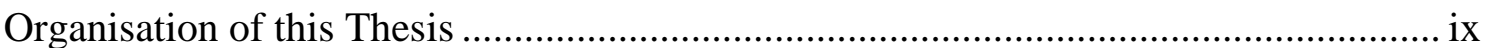

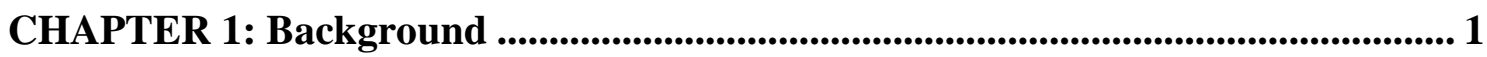

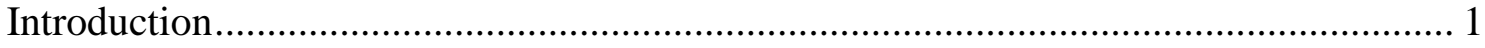

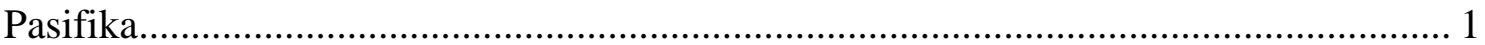

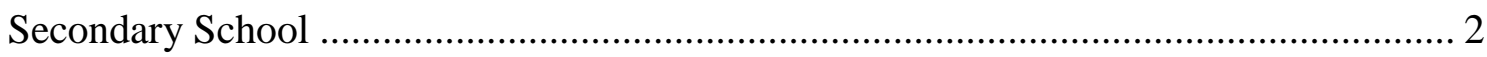

Pasifika in secondary school ............................................................................. 4

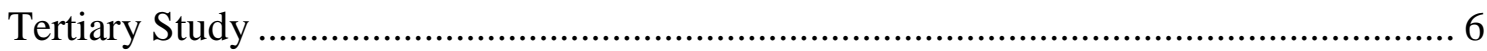

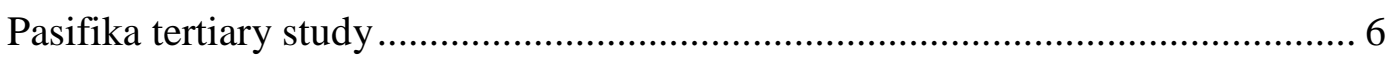

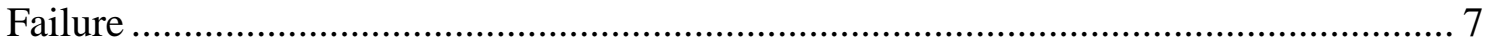

A move to Strength Based for Pasifika in Education ....................................................... 7

Barriers for Pasifika in Education.............................................................................. 9

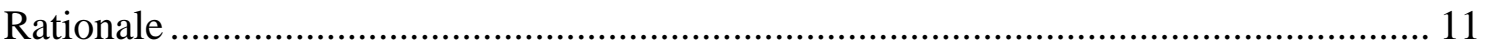

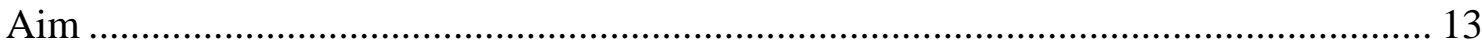

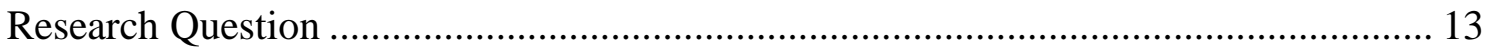

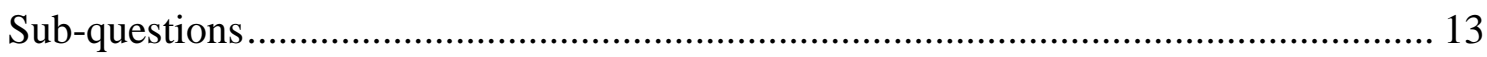

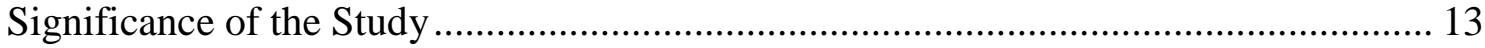

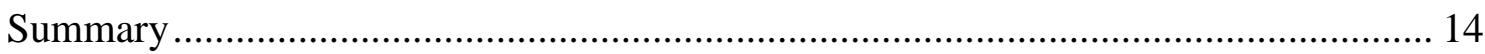

CHAPTER 2: Literature Review ................................................................................ 15

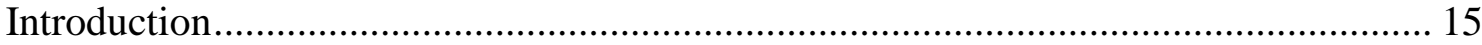

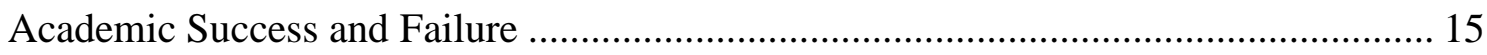

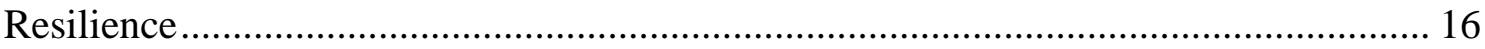

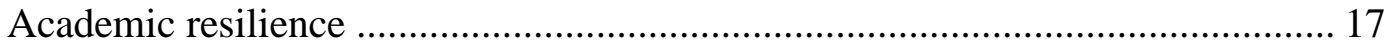

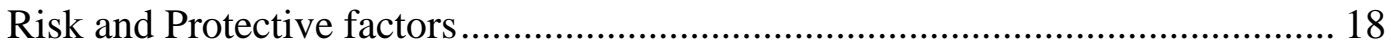

External Factors Affecting Academic Resilience ....................................................... 20

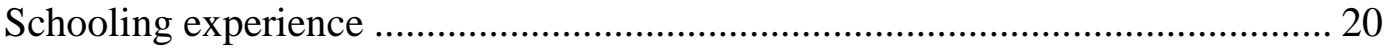

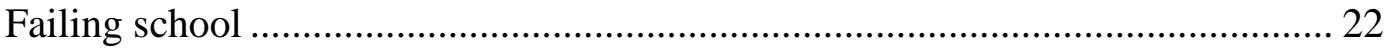




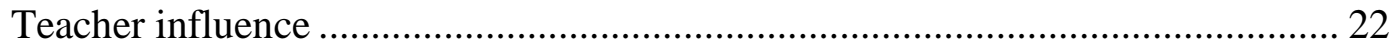

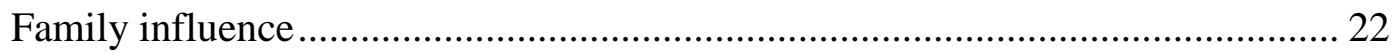

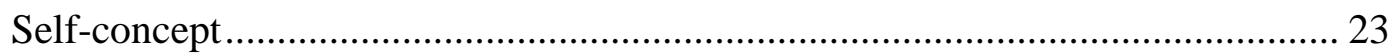

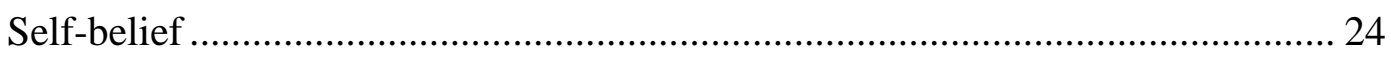

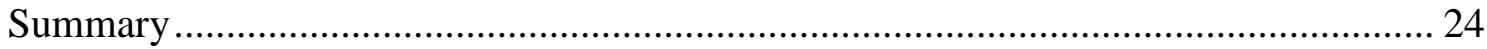

CHAPTER 3: Methodology .............................................................................................. 26

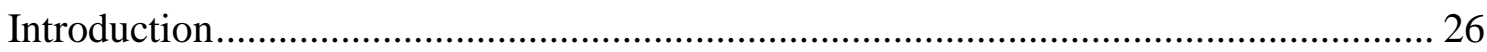

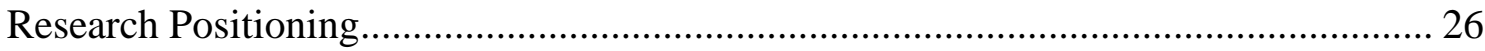

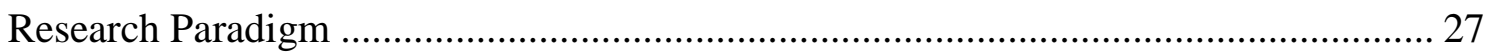

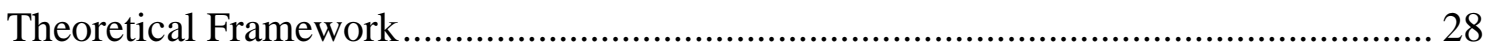

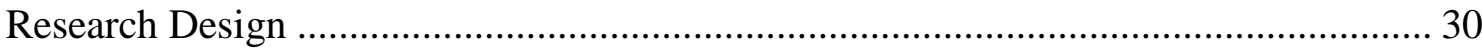

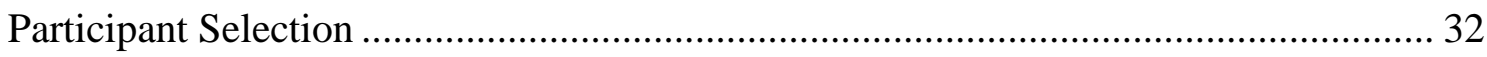

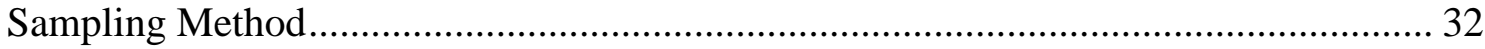

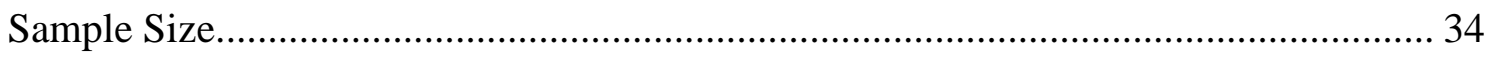

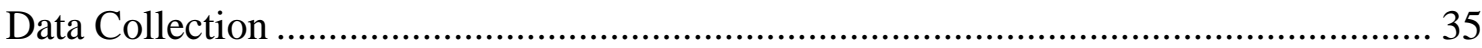

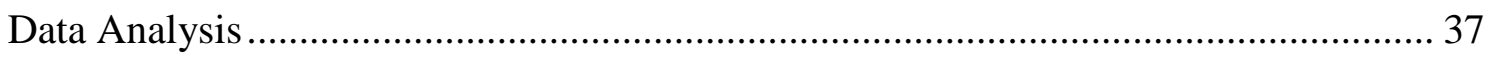

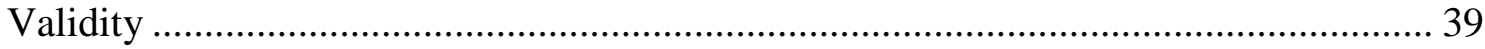

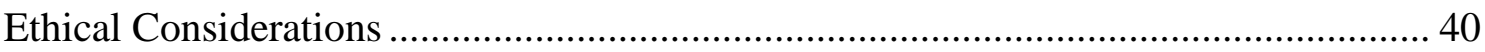

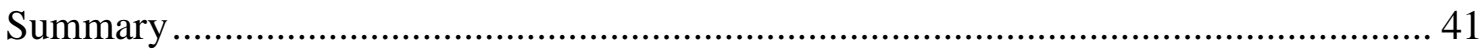

CHAPTER 4: The Findings ......................................................................................... 42

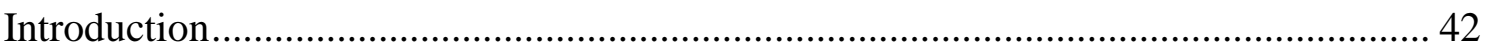

Resilience

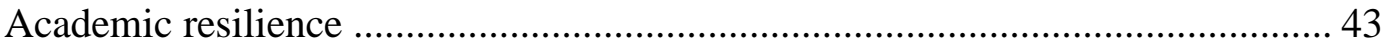

Resilience criteria of the participants .................................................................... 43

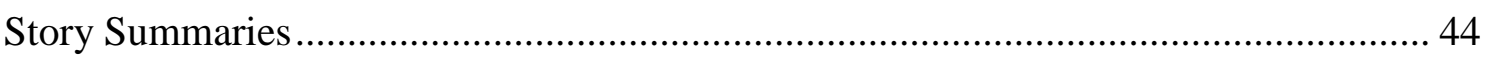

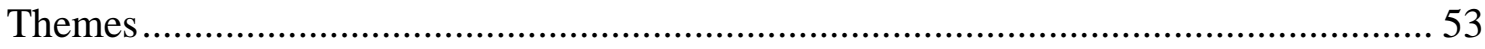

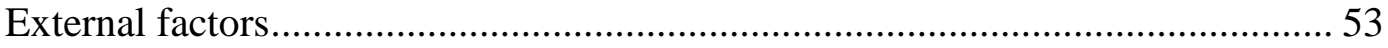

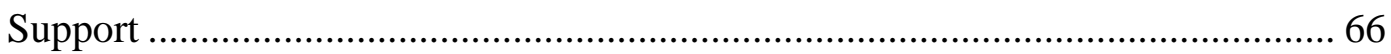

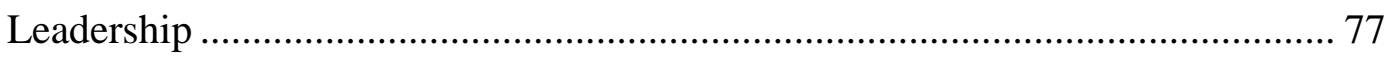

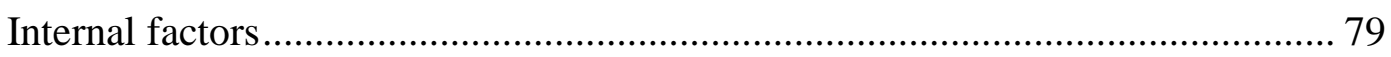

Emotional and motivational aspects influencing learning ................................ 79

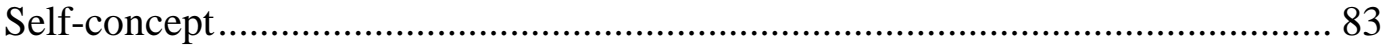


Self-belief

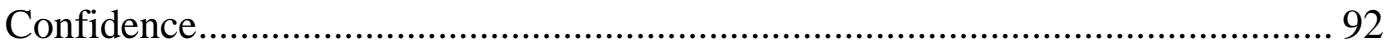

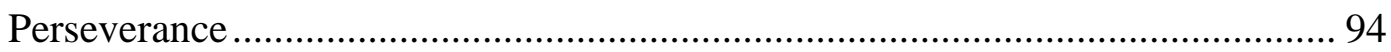

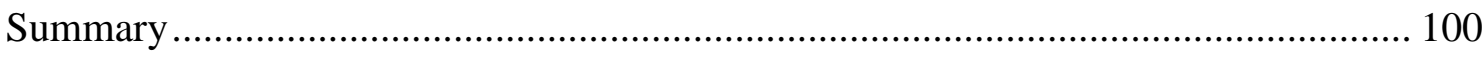

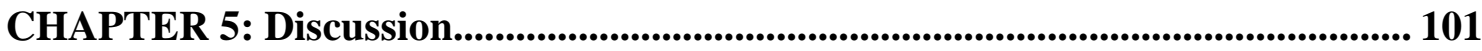

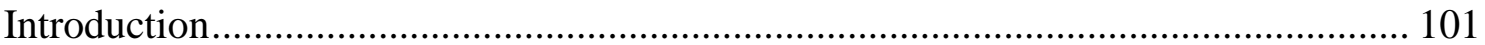

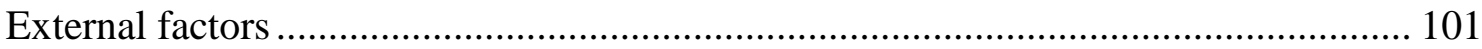

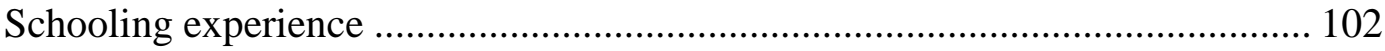

Transferable extracurricular activities (TECA)................................................. 103

Life events that influence education pathway .................................................... 105

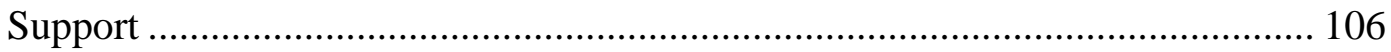

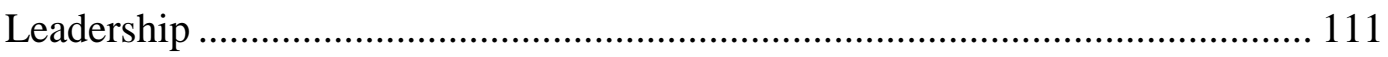

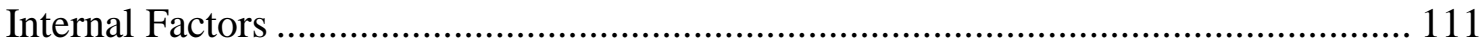

Emotional and motivational aspects that influence learning.............................. 111

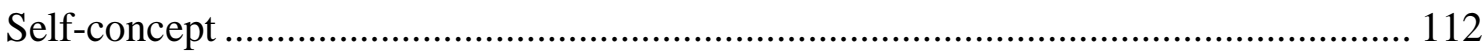

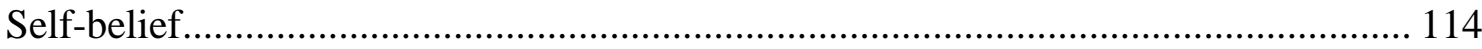

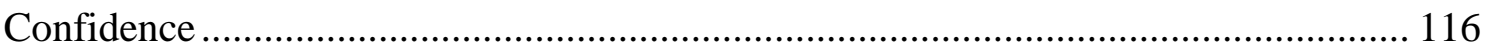

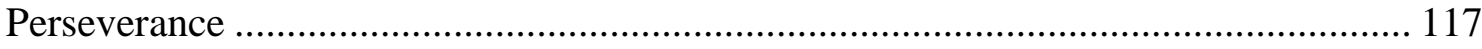

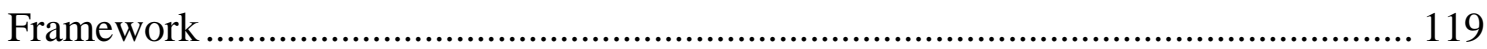

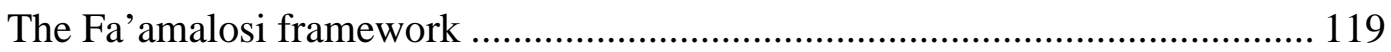

How the Pasifika Resiliency Framework operates........................................... 121

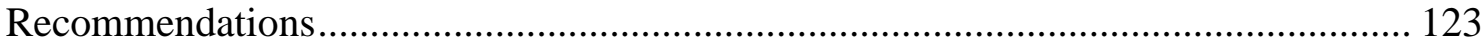

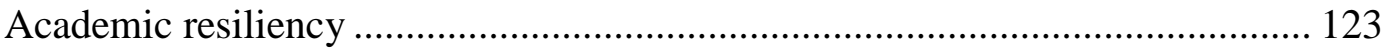

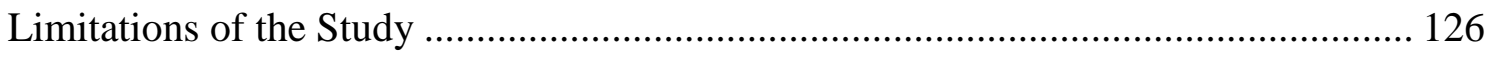

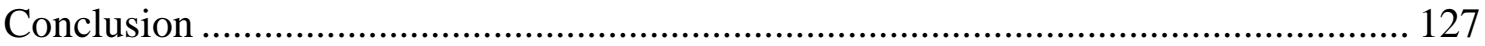

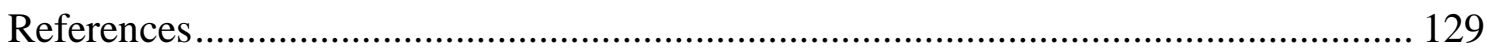

Appendix 1: Participant Information Sheet ............................................................. 142

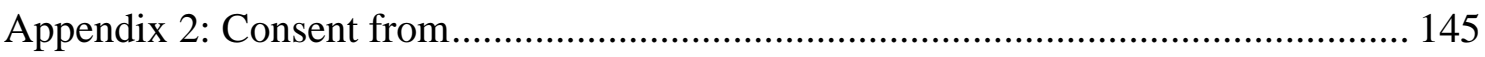

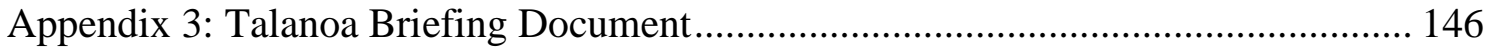

Appendix 4: Victoria University Human Ethics Approval........................................ 147 


\section{List of Tables}

Table 1: $\quad$ NCEA compulsory level (credit) requirements. ........................................ 2

Table 2: $\quad$ University entrance requirements. .......................................................... 3

Table 3: $\quad$ NCEA replaced old national qualification system.................................... 3

Table 4: $\quad$ Participants’ ages, ethnicity, and qualifications......................................... 33

\section{List of Figures}

Figure 1: Year 13 attaining UE by ethnicity in 2014 . ............................................. 5

Figure 2: Completion rates for NCEA level three by ethnicity in $2014 \ldots \ldots \ldots \ldots \ldots \ldots \ldots . . . . . . . .5$

Figure 3: Completion rates in university for domestic students by ethnic group for

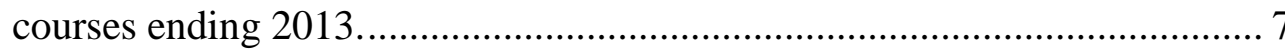




\section{Glossary}

Aiga

Fa’a Samoa

Fa’a Malosi

Māori

Matai

Pakeha/Palangi

Talanoa

Wananga
Family

Traditional Samoan way

Encouragement/Be strong

Indigenous people of New Zealand

High Chief

European/White person

To talk (about anything)

Māori University 


\section{Organisation of this Thesis}

This thesis is divided into five chapters. The first chapter is the background and serves to contextualise the study, exploring some of the current issues Pasifika face in education. Chapter two delves into the theories and literature relevant to the study. Chapter three describes the methodology that was used in this research. Chapter four presents an analysis of the findings. Lastly chapter five offers a detailed discussion around the findings, presents a framework developed from the research, the limitations and the applications of this research and an overall conclusion of the study. 


\section{CHAPTER 1: \\ Background}

\section{Introduction}

The goal of the Ministry of Education's Pasifika Education Plan (PEP) in 2001 was to close the gap between Pasifika and non-Pasifika in 20 years (Ministry of Education, 2002). While there has been changes made and slight improvements, with a little over five years to go in the 20 year vision this goals seems more likely to be "wishful thinking” with Pasifika still underperforming in both secondary and tertiary education. This chapter will look at both the secondary and tertiary context and how Pasifika are performing in these sectors currently, additionally it will delve into some of the education barriers for Pasifika in education, the rationale for this study, the aim of this research, the research questions, and the significance of the study. A summary will be provided at the end of this chapter.

\section{Pasifika}

Pasifika is the term given to a multi-ethnic heterogeneous group of people living in New Zealand. Pasifika people share ancestry, languages, and traditions and due to the small population sizes of these individual Pacific Island nations and the closeness in affiliations between the people, in New Zealand they are often categorised under the general term Pasifika. This is controversial because, although there are shared commonalities, every Pacific Island nation has its own uniqueness, which should not be, ignored (Manu’atu \& Kepa, 2002; Mara, 1999; Nakhid, 2003a). Consequently, while some findings from the proposed research might explain the stories of Pasifika achievement and resiliency, wide-sweeping generalisations will not be made across all Pasifika groups from this research. 


\section{Secondary School}

The official secondary school qualification in New Zealand is the National Certificate of Education Achievement (NCEA) (New Zealand Education, 2015). Generally students first two years of secondary school are preparing them for NCEA and in their last three years is where they sit the NCEA Levels $1-3$. At each level students are required to complete courses and over these courses gain a certain amount of credits to meet the compulsory credit requirements for each level, this is done through a mixture of external and internal assessment (New Zealand Education, 2015).

Table 1: NCEA compulsory level (credit) requirements.

\begin{tabular}{|l|l|}
\hline NCEA & Required Credits \\
\hline Level 1 & $\begin{array}{l}80 \text { credits at level } 1 . \text { (10 of those credits must come from numeracy and } 10 \text { credits } \\
\text { from literacy) }\end{array}$ \\
\hline Level 2 & $\begin{array}{l}60 \text { credits at level } 2+20 \text { at level } 1 \text { or higher (the } 10 \text { numeracy and } 10 \text { literacy from } \\
\text { level } 1 \text { need to be obtained) }\end{array}$ \\
\hline Level 3 & $\begin{array}{l}60 \text { credits at level } 3+20 \text { at level } 2 \text { or higher (the } 10 \text { numeracy and } 10 \text { literacy from } \\
\text { level } 1 \text { need to be obtained) }\end{array}$ \\
\hline
\end{tabular}

Adapted from: (NZQA, 2015a)

University entrance (UE) is the minimum requirement to get into a University in New Zealand (NZQA, 2015b). 
Table 2: University entrance requirements.

\begin{tabular}{|l|l|}
\hline $\begin{array}{l}\text { University } \\
\text { Entrance }\end{array}$ & Prerequisites \\
\hline Achieved & Need to have met the required NCEA Level 3 requirements \\
\hline Subjects & $\begin{array}{l}\text { Three subjects - at Level 3, made up of: } \\
14 \text { credits each, in three approved subjects (certain subjects have been } \\
\text { approved as counting towards UE) }\end{array}$ \\
\hline Literacy & $\begin{array}{l}\text { Literacy - } 10 \text { credits at Level } 2 \text { or above, made up of: } \\
\text { - } 5 \text { credits in reading }\end{array}$ \\
\hline Numeracy & $\begin{array}{l}\text { Numeracy - } 10 \text { credits at Level } 1 \text { or above, made up of: } \\
\text { - achievement standards - specified achievement standards available } \\
\text { through a range of subjects, or } \\
\text { - Unit standards - package of three numeracy unit standards (26623, 26626, } \\
26627 \text { - all three required) }\end{array}$ \\
\hline
\end{tabular}

Adapted from: (NZQA, 2015b)

However, as this table reflects NCEA level 3 does not mean automatic university entrance (UE). This is because only certain subjects at level three are university approved and students must pass a certain proportion of these and also meet the fundamental numeracy and literacy targets set by New Zealand universities' to attain UE.

NCEA was introduced 2002-2004 and replaced the old national qualification system.

Table 3: NCEA replaced old national qualification system.

\begin{tabular}{|l|l|}
\hline NCEA & Old qualification system \\
\hline Level 1 & School certificate \\
\hline Level 2 & Sixth form certificate \\
\hline Level 3 & Bursary \\
\hline
\end{tabular}

Adapted from (NZQA, 2015a) 
Due to its recent introduction, some of the participants could potentially be a mixture of both NCEA students and the old qualification system.

\section{Pasifika in secondary school}

The Education Review Office (ERO) report “Making Connections for Pacific learner's success" (2013) reviewed 25 secondary schools with large Pasifika populations. Pasifika are still underperforming in education compared to the national average. It is also noted that since the previous ERO report in 2012 no major systemic changes had been made with respect to how schools engage with Pasifika students, despite the highlighted disparity in educational outcomes for Pasifika. According to ERO (2013) Pasifika students as a group consistently underperform in NCEA at all levels (Education Review Office, 2013).

Roll based students according to New Zealand Qualification Authority (NZQA) are all the student still on the school roll (attending school) on the 1st of July, secondary schools are required to submit their rolls to Ministry of Education four times a year. Participation cohorts are those students that early behaviours signal they are candidates for NCEA achievement (meeting the NCEA credit requirement). Significantly, Education Counts the ministry of educations statistics webpage only displays the Pasifika participation cohort statistics for 2014 and not the roll based statistics (Education counts, 2015).

The amount of Pasifika School leavers leaving with the university entrance (UE) standard in 2014 was $37.6 \%$ of those in the participating cohort in NCEA and only 28.9\% of all roll based Pasifika students (New Zealand Qualifications Authority, 2015c). Only showing the participating cohort gives the illusion that $37 \%$ of Pasifika will achieve University Entrance (UE), when really it is only $28.9 \%$ of the total Pasifika remaining on the roll on July 1 achieve UE. These stats do not even count the Pasifika students that may have already left before then. Yet, $37 \%$ is not a great number; essentially, it means of those Pasifika students still in the participating cohort the education system fails $60 \%$ of them attaining UE. 


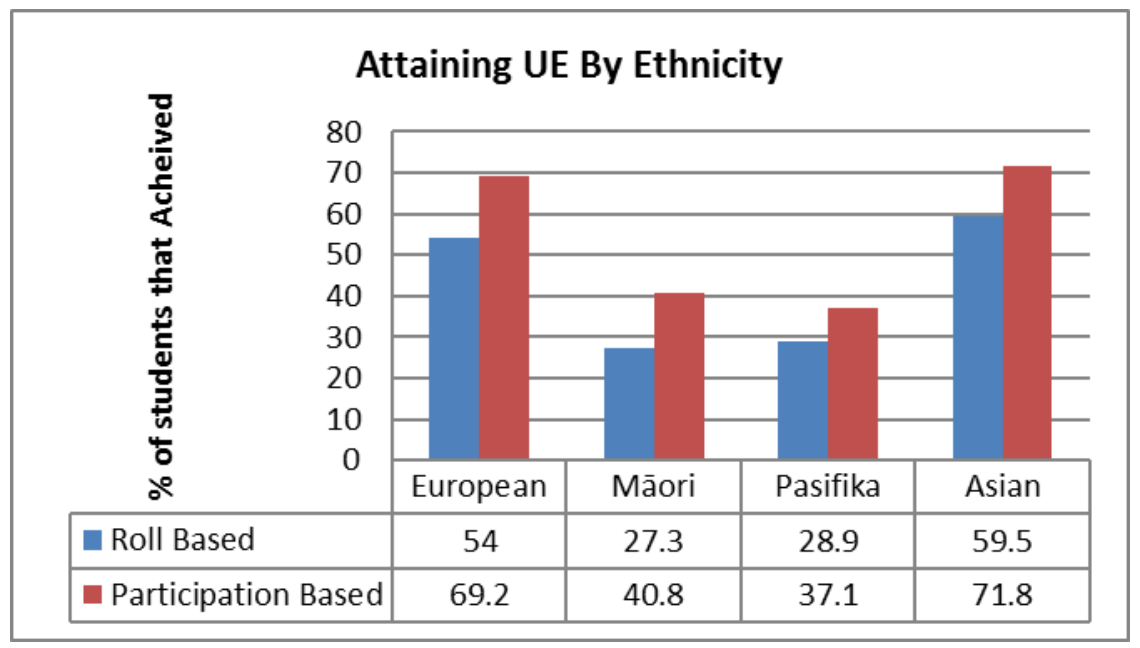

Figure 1: Year 13 attaining UE by ethnicity in 2014. Adapted from: NZQA 2015c.

Currently, the amount of the total roll based Pasifika that leave with at least NCEA level three is at $51.6 \%$ and the participation cohort is $66.4 \%$ these percentages have slowly increased since 2010, although Pasifika still underperform compared to other ethnic groups.

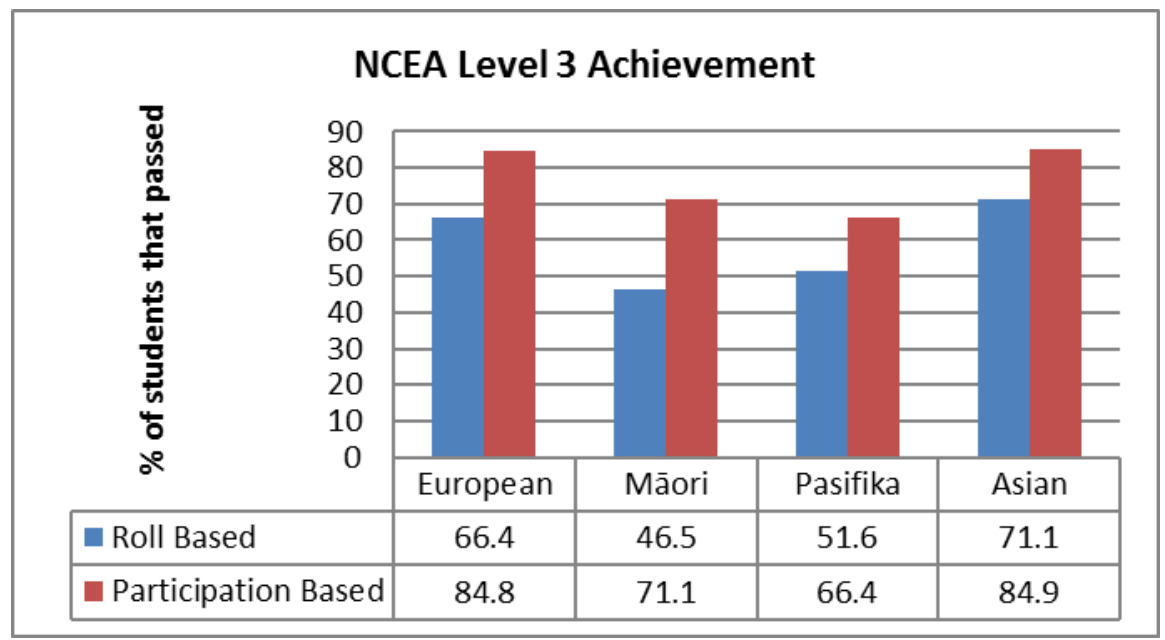

Figure 2: Completion rates for NCEA level three by ethnicity in 2014. Adapted from: NZQA 2015c.

The researcher believes the confusing way that students are counted and measured makes statistics very misleading. As a Pasifika researcher this is very dis-heartening because all Pasifika students are important whether they are deemed to be participating or not and should have a voice or number. This is the equivalent to a teacher only focusing on $70 \%$ of the class and ignoring the "troublesome" $30 \%$ because their behaviour suggest they do not want to be at school. This could be how the MOE and schools try to "pump” up their Pasifika statistics, so they can be perceived as working towards closing the gap between Pasifika and the rest in education. 
The percentages for Pasifika achievement are improving, however there is now this issue of schools putting an uneven amount of Pasifika students in low-streams and unitstandard based course work at secondary school that is limiting their potential choices in the future (Chu et al., 2013b). Therefore, on paper Pasifika peoples may be deemed to be doing better however Chu et al. (2013b) suggest that they may be doing well in courses that do not meet the criteria for university as well as gaining the skills and the learning to be successful lifelong learners, severely limiting their choices postsecondary school.

\section{Tertiary Study}

Tertiary education in New Zealand covers education post-secondary school. There are a variety of options for students to enter into private training establishments (PTEs), institutes of technology and polytechnics (ITPs), wananga (Māori university), universities and workplace training (NZQA, 2015d).

University is the main tertiary provider this study will focus on, as all participants are required to be in or completed postgraduate study. Postgraduate study entry at university usually requires students to have completed a three-year undergraduate degree; some postgraduate programs require a certain grade point average as prerequisite. Additionally, students with no undergraduate degree but have gained the equivalent knowledge through years of experience in their industry can enter into many postgraduate programmes without an undergraduate degree.

\section{Pasifika tertiary study}

There have been successive Tertiary Education Strategies (TES) where they have highlighted the importance of increasing the Pasifika achievement levels (Ministry of Education, 2002, 2010). Completion rates measure whether students complete their level four and above qualification within five years of starting their tertiary qualification. Pasifika completion rates have been slowly increasing from $59.7 \%$ in 2008 to $68.3 \%$ in 2013 however, compared to non-Pasifika rates in 2013 of $76.4 \%$ Pasifika are still underperforming. Comparing the same 2013 statistics by specific ethnic groups Pasifika are again the lowest and this is reflected in figure three. 


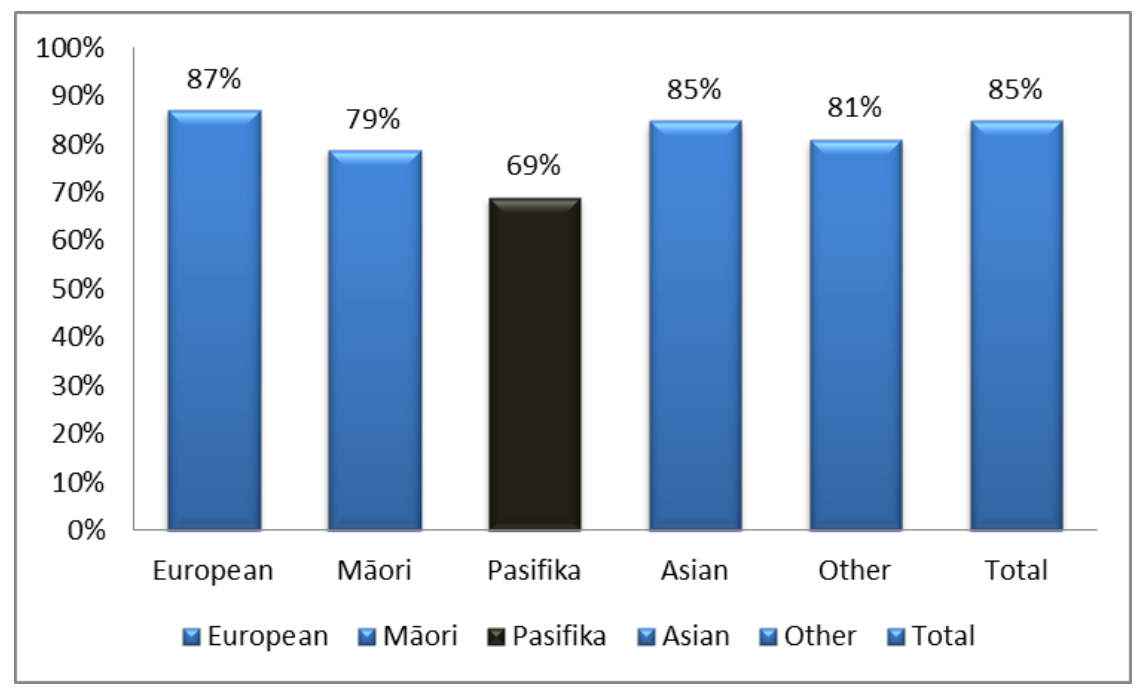

Figure 3: Completion rates in university for domestic students by ethnic group for courses ending 2013. Adapted from: Education counts 2015.

\section{Failure}

This study uses the Ministry of Education's (MOE) definition of failure: that is, lowperforming students, or school leavers that do not complete or pass NCEA level 3 (NZQA, 2015a). However, the question to be asked is, do Pasifika students fail at all, even those that officially meet the criteria of what the MOE deems as failure? Is that not all it is, deemed failure? This label has no real weight other than "on paper”, in the state education system. The stories in this study intend to show Pasifika postgraduate students who are deemed as failures in pre-tertiary education that their experience was more like a "bump" in the road; a temporary obstacle along their journey. Failure only exists, in the hearts and minds of the people that see themselves or others as failures.

As the stories in this study demonstrate, the young student who does not get NCEA is no more a success or a failure in life than a student that attains it. Such "failure" does not mean Pasifika students are not capable academically. The stories of these Pasifika postgraduate students (PPG) students show that "failure" as the state defines is just a label that has no real bearing on a young person's future or destiny in any context, even in education, unless they allow that label to define them as a person.

\section{A move to Strength Based for Pasifika in Education}

There has been a recent push in Pasifika research to focus on strengths rather than predominantly deficit theorising approach in exploring educational underachievement (Gorinski \& Fraser, 2006). This new push predominantly comes from unpublished 
works such as Master's and Doctoral thesis (see Hannant, 2013, Lipene, 2010; Passi, 2011). Predominantly Pasifika education research has identified many issues as to why Pasifika are not achieving, rather than giving possible solutions or strategies to bring about academic success. This new line of thinking is relatively new and still requires further inquiry however, the focus of looking forward may just bring about the change that Pasifika in education are after.

Hannant's (2013) research sought to understand what worked for young Pasifika males in secondary school education that allowed them to achieve NCEA level three. She believed that focusing on what worked and the strengths of these young people opened up new possibilities rather than regurgitating an already dense field of deficit-based research around Pasifika in education. Hannant identified five key recurring themes that influenced students' critical academic pathways and future opportunities. They are family and community support and commitment to education; the impact of a positive relationship between teacher and student; the influences on self-perception that contributed to motivation, attitude, self-belief and ambition; factors within the classroom environment such as teaching practices, curriculum impact; and school structures, systems, policies, practices and beliefs.

While Hannant's (2013) study is based on secondary school success, the research by Chu et al. (2013a) into best practice for Pasifika students in tertiary education noted similarities. The authors used a strengths-based appreciative inquiry approach (AI). Chu et al.'s study (2013a) found three factors that were key to the success of Pasifika tertiary students: appreciative pedagogy, the teaching and learning relationship, and institutional commitment. Appreciative pedagogy consisted of family support, personal commitment to learning, and a learning village. Teaching and learning looked at nurturing and respectful relationships between teacher and student, and institutional commitment focused on the institution's commitment to policy, structure, leadership, and engagement with the Pasifika community.

Hannant's (2013) five key themes assimilate to the three broad areas Chu et al. (2013a) identified. What is of interest in this research is that both Hannant (2013) and Chu et al. (2013a) described similar personal, interpersonal, and structural elements as key for Pasifika students at different levels of education. The experiences of the postgraduate students of this study who failed academically in one context (secondary school) and 
went on to succeed in another (tertiary), show that in one context these key elements were missing and in the next context they were integral to facilitating their academic success.

This research is focused towards appreciating PPGS' resilience to overcome obstacles. However, it is inevitable that the stories must also explore some of their struggles, the obstacles they faced, and their previous failure in education. Morales and Trotman (2004) implied that when you study stories of academic resiliency you are implicitly studying academic failure. Therefore, in the case of this study, it is imperative for the researcher to understand some of the barriers and issues that have been identified already.

\section{Barriers for Pasifika in Education}

One of the major findings to emerge from previous research is that "language" is a major barrier to educational achievement for Pasifika students. According to Bukowski (1979) in Nakhid (2003a), the reason why many Pasifika students underachieved was that they lacked the basic English language skills. In addition, the English literary skills Pasifika students were being taught was considered insufficient to cater to the needs of Pasifika students. Nakhid (2003a) also argues that the language being used is considered boring by Pasifika students, which may be related to students' limited level of understanding so that the effect is like listening to a foreign language. Fletcher, Parkhill, Fa'afoi, Taleni and O'Regan (2009) pointed out that that Pasifika students were actually very good at decoding and could speak English words, but they did not necessarily comprehend the meaning of the words they were reading or speaking. Such a situation can lead to teachers misperceiving the actual literacy levels of Pasifika students in the classroom. Allen, Taleni, and Robertson (2009) looked at strategies for addressing the language barrier, such as acknowledging and drawing on students’ prior knowledge and making it relevant to their lives.

With the over-representation of Pasifika students underachieving at all levels of education we can assume that teachers bring preconceived notions of the students' abilities to their teaching practice. Nakhid (2003b) states that Pasifika students' "true" identities are not valued: they are not seen as they would want to be seen by their schools or teachers. Rather, how they are identified is pre-constructed by the school, not by themselves. They want to be viewed as a positive integral part of the school, and also 
as a success, not just as a failure, intrusion, or burden (Nakhid, 2003b). If the school views Pasifika students as underachievers this has a negative snowball effect with huge implications for how Pasifika are treated in class and their overall achievement levels (Murphy, Campbell, \& Garavan, 1999).

Bishop, Berryman, Tiakiwai, Richardson, Mitai, \& Savill (2002) discuss how teachers' low expectations of students create a self-fulfilling prophecy, leading to negative selfconcept and belief and ultimately failure for that student. Teachers empower their Pasifika students when they respect and affirm their identity and intellect (Airini, Anae, \& Mila-Schaaf, 2010; Fletcher et al., 2009). According to Benseman, Coxon, Anderson and Anae (2006) Pasifika students thrive when the teaching is student-centered, promotes strong relationships between teacher and student, and teachers have a commitment to high standards that they believe all students can achieve. How the school and the teachers perceive their students can have a huge impact of the actual success of the student (Bishop et al., 2002). According to Bishop et al. (2002) it becomes imperative that all students are seen as achievers, are given high expectations from their teachers and the role of the teacher is to make sure they work together with their students to ensure success.

The lack of family involvement in Pasifika education has been considered a barrier in academic achievement. This is because a lack of understanding by parents about their children's education and a significant disconnect between home and school life limits their efficacy to help their children (Fletcher, Parkhill, Fa'afoi \& Taleni 2006; Fletcher et al., 2009; Graham, Meyer, McKenzie, McClure \& Weir, 2010; Bourdieu \& Passeron, 1970). Due to the importance of family to Pasifika people this is an important topic for Pasifika (Pasikale \& George, 1995), particularly as familial support has been identified as crucial to academic results (Craven \& Marsh, 2004). While this is an important issue, it is not possible to guarantee that Pasifika students will ever get the amount of family involvement required; additionally and conversely, Pasifika students have been successful without a great amount of family support.

Furthermore, according to Hannant (2013) and Chu et al. (2013a) if there is a strong commitment at the institutional level to appreciating Pasifika, a strong emphasis on authentic relationship-building between staff and teachers and their Pasifika students, and a strong Pasifika presence in the institution - a space for them to go to that 
represents their identity in terms of culture; Pacific staff, support staff, and academic staff - then “obstacles” such as language and identity actually become strengths.

However, what is missing in the research is a focus on Pasifika personal power. Nakhid (2003b) concluded that much of the research on Pacific underachievement has reflected factors such as low socio economic status, literacy and numeracy deficiencies, language barriers and family parental engagement and support in education. Nakhid's arguments addresses the issue that much of the research is on the Pasifika in education is focused on improving the environments, institutional perceptions and assumptions rather than the Pacific student perspectives and how they can foster success and motivation (Benseman et al., 2006; Chu et al., 2013b; Fletcher et al., 2009). While it is true that Pasifika people come from collectivist societies, what often gets lost in research into Pasifika education is the individual, the internal factors that motivate and drive Pasifika students, this research will provide a platform to share that pacific voice.

This research explores the stories of Pasifika students who defied systemic issues, historical and recent education barriers to find success. It was anticipated that the barriers that impacted the participants and led them to underachieve during secondary school were also present when they became successful tertiary students. Therefore, this research asks what changed between the time of their failure and the time of their success, the context, or the individual?

\section{Rationale}

The rationale for this research comes from my own personal story in education. I am a second generation, Aotearoa New Zealand-born Samoan/Pasifika student that failed every year of secondary school. This is too often the lived reality of many young Pasifika people within the education system in New Zealand. In addition, too often, this is where the story ends in terms of research on this issue. If I was to stop here, my story could be broken down and sifted through with the use of a common problem-based inquiry. Problems would be identified within my social/community situation, my family, and school contexts and these would be associated or aligned with personal psychological, physical, and spiritual challenges. With problem-solving approaches solutions would be sought to "fix" me and/or my context. This is case in the prevailing deficit view on Pasifika in education (Chu et al., 2013a). It is reasonable to ask: if we think of Pasifika in education as an entity in itself, how does ending the story here 
empower Pasifika? From current education reports can we say this deficit/problembased enquiry is making actual progress for Pasifika in education?

Watkins, Mohr, and Kelly (2011) stated that Appreciative Inquiry (AI) is just as valid and contagious as the negative or deficit approach. The simultaneity principle of AI states that inquiry is change; therefore, the first question asked when inquiring contains the seeds of change. Whether positive or negative that first question will turn the organisation and its energy in that direction. Constantly asking "What is going wrong in education for Pasifika” will continue to lead to conversations about on how the future being constructed from this negative view.

It can be argued that this line of deficit thinking goes against common sense. Bushe and Coetzer (1995) stated that AI allows people to hold an ideal of what their future should look like, and then enquire into the stories of others living that reality to help transform their ideal into reality. When people want to lose weight they talk to personal trainers or people living that reality with a fit healthy body, and inquire "How can I look like you?" "What did you do to stay so fit and healthy?" They do not ask the overweight person “Hey can you tell me when and what went wrong in your life, so I don't do that ever do that again?” It makes no sense in those terms, but this is the predominant line of thinking of the questions that enquire into Pasifika in education.

I am asked to share my story and speak to young people around New Zealand. I have shared my story with hundreds of people, mainly Pasifika, not because my story ended with me as a failure, but because it ended with me being an education success. People want to hear my story because it gives them hope. It can change their own vision or dreams about what is possible for them in education. If someone who failed can come back and be a success in education then anyone can succeed. I want to explore stories of other Pasifika postgraduate students who, like me, turned failure in education into a driver of their success. My hope is that this will help to shift the collective ideal of Pasifika students in a positive direction. 


\section{Aim}

The aim of this study is to explore the experiences of PPGS who were deemed as failures in secondary school education. The research aims to explore the students' stories in order to understand how these young Pasifika students changed their “destiny”/future in education.

\section{Research Question}

What do the failure-to-success stories of Pasifika Postgraduate Students (PPGS) who are deemed to be academic failures at secondary school reveal about the internal and external factors that facilitated their academic progress and resilience?

\section{Sub-questions}

1. Given that tertiary study is seen as more difficult in terms of level of study, what facilitated participants' success in the more difficult education setting?

2. What changed for these students in terms of internal (psychological, physiological, spiritual) and external (social and cultural) factors that facilitated their success and resilience?

\section{Significance of the Study}

Fry and Barrett (2002) highlight that embedded in the stories of individuals are the riches of wisdom, hope, strength, and innovation. The Pasifika PPGS' stories of how they overcame secondary school failure can contain the wisdom, hope, strength, and innovation for future Pasifika students and educators of Pasifika students. PPGS' stories of courage and resiliency to overcome failure at secondary school and step back into a higher form of education and succeed should be celebrated, understood, and appreciated. Successive Pasifika Education Plans (PEP) (Ministry of Education, 2007, 2009, 2011, 2012) top priority has been to raise achievement levels of Pasifika students. PPGS' stories can enlighten this issue by revealing Pasifika students actually moving from underachievers in education to very successful postgraduate students. Embedded in these stories are wisdom, hope, strength and innovation that have the ability to transform ideals about what is possible for Pasifika in education and educators of Pasifika. It has been 13 years since Pasikale (2002) urged for exploration and research on Pasifika education failure and it is time for Pasifika solutions. 


\section{Summary}

This chapter looked at the background of the study. Understanding the context of both secondary and tertiary education as well as how Pasifika have been performing academically in these contexts. It identified how Pasifika are still underperforming in both contexts, as well as identifies some of the potential barriers that impact Pasifika education performance. In addition, this chapter looked at the researcher's rationale of the study as well as the research question, the aims of the research and the significance of the study. 


\section{CHAPTER 2: \\ Literature Review}

\section{Introduction}

This chapter will delve into some of the theories and literature relevant to this study. The structure of the literature review will start with the wider view of the topic in relation to the research question. This will cover an understanding of resilience, academic achievement, and academic failure.

- What do the failure-to-success stories of Pasifika Postgraduate Students (PPGS) who are deemed to be academic failures at secondary school reveal about the internal and external factors that facilitated their academic progress and resilience?

The lit review will then proceed to narrow its focus in relation to the sub questions identifying literature on academic resilience specifically, and the factors that facilitate and/or inhibit academic resilience. It will look to understand academic resilience, protective and risk factors, and finally the internal and external factors that act as protective and risk factors.

- Given that tertiary study is seen as more difficult in terms of level of study, what facilitated participants' success in the more difficult education setting?

- What changed for these students in terms of internal (psychological, physiological, spiritual) and external (social and cultural) factors that facilitated their success and resilience?

A summary will be provided at the end of this chapter.

\section{Academic Success and Failure}

Academic achievement can commonly be defined as obtaining a particular result in assignment, exam, subject, and degree and is conveyed in a numerical grade or level of distinction (Broadbent \& Poon, 2015; Richardson, Abreham, \& Bond, 2012). Therefore this research uses the criteria set by New Zealand's Qualification Authority (NZQA) to define academic success and failure. According to Hamachek (1995, p. 419) "academic achievement may not be simply an expression of students' abilities but of students' 
perceptions of their abilities”. The important factor might not only be whether students are deemed academically successful or failures by the system, but also how they perceive themselves after success or failure (Parajes, 1996).

The participants in this research have experienced both academic success and failure. Their stories will give insights into both sets of experiences and into what factors facilitate success and failure; moreover their experiences are true stories of resilience. Montero-Hernandez, Levin, and Diaz-Castillo (2014) commented that resiliency gives us insights into the factors involved in the growth of specific forms of self-perception and persistent action despite adverse environments. The participants' voices may give understanding about how resilience is enhanced both internally and externally in Pasifika.

\section{Resilience}

Resilience is the product of a dialectic relationship between the presence of risk factors and the "buffering" effect of protective factors to produce a positive outcome or change (Lessard, Fortin, Butler-Kisber, \& Marcotte, 2014; Luther, Ciccheti, \& Becker, 2000) Risk in people's lives is unavoidable; on the other hand, the presences of protective factors are not as easily discernible or present during tough times (Harms, 2005). The process of resiliency, then, is not about the removal of risk, but more about an individual's ability to increase or identify protective factors in their internal and external worlds that help them overcome the odds or do better than expected (Morales \& Trotman, 2004). This understanding is in line with a developmental view of resilience that describes the individual's inner and outer world resources used to resolve developmental significant issues (Capella \& Weinstein, 2001). Lessard et al. (2014) claimed that resiliency occurs when a positive outcome is achieved during a time when an individual is faced with risk and trauma. Luther et al. (2000) agreed that the state of being resilient is a "dynamic process encompassing positive adaption within the contexts of significant adversity” (p. 43). Finn and Rock (1997) maintained this idea that resiliency is the successful adaptations in the realm of social disadvantage. From these definitions resilience is a multifaceted process where an individual experiences success or a positive outcome due to certain internal and external protective factors that helps them overcome obstacles, severe risk, chronic adversity, and adverse conditions. 
More simply, resilience is a combination of three factors:

1. There is a level of risk or adversity involved that threatens development.

2. The presence of protective factors, both internal and external, facilitates growth despite the odds.

3. A positive, successful, or better than expected outcome is achieved (Capella \& Weinstein, 2001; Finn \& Rock, 1997; Lessard et al., 2014; Luther et al., 2000; Morales \& Trotman, 2004).

\section{Academic resilience}

Academic resilience has the same three factors as resilience it is just confined in the education setting. Morales and Trotman (2004) proposed that academic resiliency is when students succeed despite a history of low academic achievement. However, Bartelt's (1994) definition - students that overcome stress in their academic world to do better then what was expected of them - could potentially describe the experience of most students in an academic setting. These definitions, according Martin (2013), are both correct. He explained that there are two types of resilience in the academic setting. The less extreme form he coined academic "buoyancy", the ability to overcome challenges and obstacles that come with everyday academic life. He describes academic resilience as the capacity to overcome chronic adversity that threatens individual education development (Martin, 2013).

Martin and Marsh (2008) identified that academic resilience is characterised by the research as students that face "chronic" adversity. Typically, with a) group situated in adverse conditions (e.g., poverty, low socio economic status (LSES), gang violence), b) chronic underachievers, c) the interaction with ethnicity and underachievement, and d) students with learning disabilities (Martin \& Marsh, 2008). Using the constructs mentioned above a study on Pasifika students' academic resilience is both relevant and necessary. Many Pasifika students in New Zealand will come from families with LSES experiencing extreme financial hardship (Ministry of Pacific Island Affairs, 1999), Pasifika as a group has collectively underachieved for over twenty years. Pasifika are chronic underachievers and ethnically linked to underachievement. Hence, Pasifika students would be characterised by Martin and Marsh (2008) as students that face “chronic adversity”. With this understanding, stories and research of Pasifika students' 
academic achievement in New Zealand are inherently stories and research on academic resilience.

It is important to note that academic resilience is subjective in nature. What is a challenging experience, or risk factor, to one person may be only a slight "bump" in the road for someone else. It is important, then, for this study to be clear on the criteria that define academic resilience and successful academic outcomes. Lessard et al. (2014) noted also that the study of resiliency must come with clearly defined definitions of success or positive outcomes as well as risks. In chapter three, this study will outline the resilience criteria as well as a clear definition of what the positive outcomes will be.

Additionally, it is important to view Pasifika resiliency through a holistic approach. Pasifika peoples are generally collectivist in nature. Despite distinctions, they share the importance of relationships, family, and community and are interdependent on these factors (Thaman, 1993). Lessard et al. (2014) commented that academic resilience needs to be viewed through the lens of a holistic-ecological model so that it accounts for the individual factors that affect resilience, but also the external factors such parents and educators. Both the external and internal factors that facilitated the participants' success and resilience are taken into consideration in this study.

\section{Risk and Protective factors}

As mentioned above, resilience and academic resilience is the dynamic relationship between risk that threatens development, the presence of protective factors both internal, and external that facilitates growth that leads to a positive, successful, or better than expected outcome for the individual (Capella \& Weinstein, 2001; Finn \& Rock, 1997; Lessard et al., 2014; Luther et al., 2000; Morales \& Trotman, 2004). Therefore, risk factors and protective factors are important parts or the resilience puzzle.

Risk factors are defined as those factors that threaten development (Harms, 2005). Within an education context, risk factors are identified those that that interfere with academic achievement (Lessard et al., 2014). What the researcher also noted is the definition of being academically "at risk" is centralised around the external factors. "In education it usually refers to children and young people who are at risk of school failure by virtue of coming from as disadvantaged background such as a deprived socioeconomic background, region, ethnic status, family circumstances, and language” (Cefai, 2008, p. 20). Cherie et al.'s (2013b) literature review on Pasifika research in 
education had predominantly focused on the external influences affecting Pasifika achievement. What is missing from this body of research is the understanding of Pasifika student's internal risk factors, for example lack of drive or motivation for study, having negative views of themselves and their ability, do they care about building relationships with teachers, and why Pasifika students are not interested in school. These internal processes and what is happening in the hearts and minds of Pasifika students' needs to be further researched and understood. This study looks to be a platform to understand both the external and internal factors that affect education achievement and resilience.

Pasifika students by virtue of being ethnically Pasifika are deemed at risk in the New Zealand education system due to the historical nature of their underachievement. The notion of risk for Pasifika in education may be inevitable. However, the factors that help certain students overcome risk factors are not. In resilience research these factors are called protective factors. According to Harms (2005), protective factors help individual cope, be resilient, and thrive in adverse conditions. She also noted that resilience was not necessary the removal of risk factors as this impossible in some situations. This is especially true with students from LSES families'; It would be challenging to change a family's financial situation. Therefore, Harms (2005) suggested that because human service professionals could never fully eradicate risk they needed to increase an individual's protective factors to buffer the threat of risk. Werner and Smith (1992) study found that increasing young persons' protective factors was more beneficial to positive youth development than removing risk factors.

There has been some movement in increasing the protective factors for Pasifika in education. There has been a push to focus on education based mentoring (Chu, 2009; Farruggia, Bullen, Davidson, Dunphy, Solomon, Collins, 2011; Mara \& Masters, 2009). Pasifika sees mentoring as a relationship of influence that can counter the lack of relationships with teachers within schools and increase the likelihood of academic achievement (Chu, 2009). Also Chu et al. (2013a) identified three factors that were key to the success of Pasifika students' tertiary study, a) appreciative pedagogy, b) the teaching, and learning relationship, and c) institutional commitment. If institutions were able to incorporate these three elements then Pasifika students would flourish academically in tertiary education. 
However, a gap in the research on protective factors for Pasifika student is the internal protective factors that Pasifika students may develop despite of adversity. Currently, the cause and the cure for underachievement sits outside of the Pasifika students and rests within the contexts they develop in and the external support they may receive. According to Wildavsky and Dake (1990) risk is important but there will always be risk in peoples' lives the subjective nature of risk perception means that people can experience the same risk factors differently and people may have a higher tolerance to risk than others. This study will focus on the experiences of students that had two different education outcomes in their education journey. As mentioned in chapter two the education climate for Pasifika in both secondary and tertiary study is not ideal as they still underperform. This study intends to explore the internal protective factors that participants developed to overcome the contextual factors such as whether they perceived risk differently, what internally motivated them to persist, cope, and thrive in their second chance at education. In addition, did their beliefs about themselves and their ability change from secondary to tertiary. This study will now focus on some of the internal and external factors relevant to Pasifika in education and their function as either a risk or protective factors.

\section{External Factors Affecting Academic Resilience}

The predominant view on Pasifika in education has identified the external factors being a significant protective factor and barrier for Pasifika in education.

\section{Schooling experience}

In New Zealand, children can attend early childhood education from the ages of one to five years. From there students can go to a full primary school (Years 1-8), or a contributing primary school (Years 1-6) and then to an intermediate school for two years (Years 7-8), then most students go to secondary school (Years 9-13). Students then have a choice to go on to tertiary study or to join the workforce. The purpose of this explanation is show the number of transitions students in New Zealand have to go through. Hawk and Hill (2004) highlighted that if students go from primary school, to intermediate, to secondary they go through two transitions in three years during a critical time in their development. Schumacher (1998) stated that when students go from familiar settings to foreign ones it can be harmful and disruptive. Rice (1997) stated transitions are difficult for students, coining the term "institutional discontinuities" 
where students experience disconnect in two main areas, organisational and social. Simply the way the school is structured or organised in terms of class size, expectation, and rigour is different, as well as the need for students to form new relationships. The schooling experience in New Zealand continuously "pulls" students from familiar environments to foreign ones, often without real consideration of the impact this has on students.

One of the key areas of this research is the exploration of the transition from intermediate to secondary school, as secondary school is where the participants had failed. The Ministry of Education’s (2008) report “A Study of Students’ Transition from Primary to Secondary Schooling” discussed this transition period as being crucial for Pasifika students' academic success. The report identified the danger period for Pasifika being the second half of their first year (Year 9) at secondary school. This issue for Pasifika had previously been raised. Coxon, Anae, Maru, Wendt-Samu, and Finau's (2002) report for the Ministry of Education suggested that more research was required in the area of transition between school contexts for Pasifika. Unfortunately, Chu et al., (2013b) study indicated that minimal research had been done since Coxon et al.'s (2002) recommendation and this is still an area that needs to be explored.

Hawk and Hill (2001) gave insights to why Pasifika struggle in this transition from primary to secondary. They expressed that often there is a massive jump from intermediate to secondary school in terms of academic rigour, education processes, and expectations, and many students struggle to cope. Secondary school is seen as being fragmented, subject-based, and academically-orientated education, where the teacher, not the student, is in control of the learning (Kruse, 1996). This sterile form of education is in stark contrast to what New Zealand students have experienced at early childhood, primary, and even intermediate levels (Hawk \& Hill, 2001). Education in the early years is focused on collaborative learning, responsive teacher relationships, experiential learning, interest-based learning, and the students' participation in the learning process (Hawk \& Hill, 2001). The researcher believes the change from collaborative, relationship-based learning in early years to independent academicorientated learning at secondary suggest this transition may not resonate with Pasifika students. 


\section{Failing school}

According to Henry, Knight and Thornberry (2012, p. 156), “Academic underachievement has lasting negative consequences for the individual, his or her family, and society at large”. The impact of education outcomes on a person's wellbeing reflects the importance education has in society. When students do not do well in education, it can have adverse effects in their lives (Henry et al., 2012). However, Baumeister cited in Updegraff and Taylor (2000) stated that evidence suggests that negative life events can accumulate and lead to a positive outcome. The students in this study experienced academic failure and ended with a positive outcome. The study investigates how failure in school affected them and its importance to their motivation.

\section{Teacher influence}

As mentioned in the background chapter one, a key influence in Pasifika achievement is support from teachers. Pasifika tend to do better academically when they have strong reciprocal relationship with teachers. High teacher expectations and quality teacherstudent relationships have been shown to be a major protective factor in Pasifika education (Airini et al., 2010; Benseman et al., 2006; Bishop et al., 2002; Fletcher et al., 2009).

\section{Family influence}

The foundation of Pasifika cultures is the family (Pulotu-Endemann, 2009) and family influences, either directly or indirectly, will have a huge bearing on Pasifika achievement. Spiller (2012) found that school and teachers believe that Pasifika families do not adequately support their children in education. Many Pasifika come from homes with little education capital, the parents do not complete secondary school or go on to higher education and their idea of support is to work long hours in low-paying jobs to put their children through school (Krishnan, Schoeffel, \& Warren, 1994).

\section{Internal Factors Affecting Achievement and Resilience}

There has been a movement in education towards strength based and positive psychological approaches in education achievement (Dweck, 2010; Marsh \& Craven, 2006; Martin, 2009; Seligman \& Csikszentmihalyi, 2000). The focus of this movement is to understand how "students contribute significantly to their own educational outcomes through their personal attributes, abilities, attitudes, self-perception, 
motivation, behaviour, and family background” (Hannant, 2013, p. 8). This view has taken the "power" of change in students from the external factors that impact them in education and placed emphasis back on the student, by giving them self-determination over their own education outcomes.

\section{Self-concept}

Marsh and Craven (2006) stated that a positive self-concept has been closely linked to achievement and should be an education goal for students in education especially students from disadvantaged groups. As mentioned in chapter one Pasifika consistently underperform in education compared to other groups in New Zealand. Does this reflect that education in New Zealand is failing Pasifika students by not fostering strong academic self-concepts? Can the participants' failure and success in education in this study be linked to a positive or negative academic self-concept?

Skinner, Kindermann, Connell and Wellborn's (2009) notion of self-concept in their model of motivation development was an individual's own appraisal of their ability developed through the socialization within a context. Meaning students throughout their education journey will develop their self-concept through their education experiences. Chapter one identified two key barriers to Pasifika students are the schooling experience and the interaction with teachers. Therefore, the experiences with negative teachers' and harmful education experiences for Pasifika are not only detrimental because of the experiences alone, but also how these interactions shape Pasifika self-concepts and their beliefs about themselves after the experience. According to Hamachek (1995, p. 419) “academic achievement may not be simply an expression of students' abilities but of students' perceptions of their abilities”. The important factor might not only be whether students are deemed academically successful or failures by the system, but also how they perceive themselves after success or failure (Parajes, 1996).

Skinner et al.'s (2009) model showed that students with strong academic self-concepts made better decisions in regards to their education and had better eventual outcomes including achievement and skill acquisition. Brookover and Lezotte (1979) identified that effective schools accentuated the development of academic self-concept within the school and made it a permanent part of the schooling process. The lack of achievement in Pasifika education assumes that there is a lack of development of positive academic self-concepts in education contexts and more problematic is the proliferation of Pasifika 
learners holding harmful self-concepts in education. This study looks to understand what factors shaped the participants" self-concepts as both failures and achievers. In addition how did self-concept affect both their success and failure.

\section{Self-belief}

Rubie-Davies, Peterson, Garrett, Watson, Flint, O’Neill, and McDonald (2012) stated that self-belief is inextricably linked to academic outcomes. If students did not believe in themselves and their ability to perform in education than they would not achieve (Dweck et al., 2011). Dweck (2006) research has identified that ultimately students' beliefs about themselves, about learning and intelligence has a tremendous impact on how a student will perform academically. After twenty years of underachievement for Pasifika, Fletcher et al., (2006) and Fletcher et al. (2009) research suggest that, a majority of Pasifika students do not believe in themselves in education.

Self-belief is not only a major contributor to academic achievement it is also a major contributor to resilience (Bandura, 1997; Schunk \& Pajares, 2009). Bandura’s (1997) and Schunk and Pajares (2009) research identified that students that had self-belief and high-expectations were more likely to preserver in the face of a challenge. Fletcher et al. (2006) identified that Pasifika students 'lack confidence and do not take risk it school. This lack of confidence is a manifestation of lack of self-belief, a student will not be confident if they do not believe in themselves (Dweck et al., 2011). If students do not believe and are not confident, their ability according to Bandura (1997) and Schunk and Pajares (2009) hampered their ability to be resilient in challenges.

\section{Summary}

Numerous internal and external factors influence students' achievement and resilience. The literature review focused on the key internal and external factors that promote academic achievement and resilience in light of some of the challenges and barriers identified for Pasifika in education. Resilience and academic resilience are a culmination of three key factors the presences of risk factors the buffering effect of protective factors and ultimately a positive outcome. The literature highlighted many external factors as having both a risk function and protective function. For example interactions with teachers, if a teacher cares about the student and builds a good relationship is has shown to increase likelihood of academic achievement, conversely if 
teacher neglects a student and believes this student is "wasting" their time then this can pose as a massive risk and influence on the students achievement. The same is true with the internal factors they both serve as protective function and risk function. This chapter identified some of the theories and theories relevant to the study. 


\section{CHAPTER 3: \\ Methodology}

\section{Introduction}

This chapter examines the methodological inquiry used to navigate the factors Pasifika postgraduate students (PPGS) believed to be the most influential in overcoming early academic failure in secondary school. A description of the research positioning is presented, including definitions and explanations of the paradigms that guided the research, the theoretical framework, the research design, the process of connection and selecting participants, the data collection methods and tools, and the methods used in the data analysis. In addition, this chapter covers the ethical considerations related to the research and identifies limitations of the study. A summary is provided at the end of the chapter.

\section{Research Positioning}

The process of understanding these students' experiences came about through finding students who have had similar education journeys to the researcher. This notion of an intimate connection to the researched is often considered not flexible or not rigorous (Bishop, 2008). However, research of this nature challenges the hegemonic tendencies of traditional paradigms to favour an "objective” outsider view rather than a connected “subjective' insider view of the reality (Smith, 1999). The students and the researcher do not share the exact same stories, or even specific cultural and ethnic upbringing, but together they share a similar social dynamic of being Pasifika in Aotearoa and experiences of both struggle and success in academia (Bishop, 2008). It is in the hope that the participants' shared phenomena can help each other make sense of their stories, to sift through their Talanoa as members of the same "tribe" and to begin to create meaning, or understanding, in order to create a theory or a pattern of meaning (Strauss \& Corbin, 2015). This process is not only for the collective understanding of participants and researcher, but also, more importantly, how these success stories in education can contribute to the continued transformation of Pasifika people in the education system.

This research does not exist within one paradigmatic worldview. Guba and Lincoln (1994) state that paradigms are people's unique understanding of the world around 
them, or "worldview", which locates the individual within their world and helps to define their relationships within it. In this study, firstly, the researcher identifies with being of Samoan ethnicity, and broadly identifies as a Pasifika person, thus their worldview is shaped by their unique Pasifika heritage. Conversely, being a secondgeneration New Zealand born Samoan also contributes to shaping the researcher's worldview. According to Tupuola (2004), individuals form their identity "on the edge”, which means that some Pasifika people grow up in two worlds in New Zealand. They live and exist on the edge or "edgewalk" between their unique Pasifika worlds and their New Zealand upbringing, but can't necessarily lay claim to being specifically one or the other. I am both distinctively Pasifika and New Zealander and proud to edgewalk. Therefore, my paradigmatic view allows for conceptual looseness or slippages as it derives from a complex edge and comes from two worlds, as both insider, and outsider (Burnett, 2015).

Additionally, the participants and I share an affinity of being Pasifika and having similar schooling experiences, which is a motivating factor behind the research. The shared experiences unconsciously shapes the researcher's and participants' epistemological and ontological understanding (what people know, and what people think they know), their unique worldview on life and education (Gegeo, 2008). Thus, instead of trying to eliminate researcher bias which would have been near impossible (Maxwell, 2005), the researcher has let the bias enhance the Talanoa by going to an in-depth level that researchers without similar culture and experiences might not have been able to (Manueli, 2012).

\section{Research Paradigm}

Due to the researcher's intimate connection to the topic, this study was guided by a constructivist paradigm (Creswell, 2003). Constructivism suggests that each individual, through their subjective experiences, creates their own realities through interactions with different people and unique interactions with the world around them. This aligns well with most qualitative research as it assumes the subjective nature of lived realties is important and valid (Strauss \& Corbin, 1998; Creswell, 2008). Constructivist ideas also assume that there are multiple realities of the world people live in (Denscombe, 2010). According to Guba and Lincoln (1994) individuals live and learn by constructing meaning to what is happening around them and, though specific in nature, others can 
share similar elements of those social realities, across both culture and time. Through hearing the stories of the participants and sharing with them the researcher's own personal experiences, thereby acknowledging the subjective nature of their socially constructed realities, the researcher and participants' are able to create new knowledge (Helu-Thaman, 2001). Through interpretation of their shared experiences, the participants and researcher can began to generate new theory or a pattern of meaning (Creswell, 2003).

The Constructivist view aligns well with the cultural values and ideals of Pasifika. Pasifika populations are generally collective in nature. The segregation of Pasifika persons from their unique social environments may provide a snapshot of Pasifika peoples' true experience (Polutu-Endemann, Suaali'i-Sauni, McNicholas, Milne \& Gibbs, 2007) . Understanding Pasifika persons as being strongly connected as a member of their family and as a member of their wider community is equally important to understanding them individually (Seiuli, 2013). Pasifika people are socially constructing their identity all the time and are inseparable from their collective experiences as member of strong Pasifika families, villages, churches, and the community groups they associate with; for example; fa'a Samoa (the Samoan way). Therefore understanding them through the co-construction process of storytelling and finding the meaning within their narrative is appropriate for this study.

\section{Theoretical Framework}

Appreciative Inquiry (AI) is geared towards creating growth using strength based inquiry to identify what is working well, why is it working well, and how can we do more of what is working well. The basic premise for AI is that the growth will occur wherever the people and organisations focus their attention (Chu, 2009). Cooperrider and Srivastva (1987) developed AI as an alternative approach to understanding how organisations inquire about their systems, processes, and people. The authors believe that organisations can learn a lot about themselves by looking at what is working well within an organisation; by asking "what works" and "what is successful”, rather than the more common deficit or problem-based inquiry of "what went wrong”, "what's missing”, “what’s failing”, and “who’s to blame” (French \& Bell, 1984).

Chu et al. (2013a) have found that the predominant approach to research related to Pasifika education aligns with problem-based thinking. Hammond \& Royal (1998) 
suggest that if organisations continually use problem-solving inquiry there is the unconscious acknowledgment that something is broken and needs to be fixed. This deficit-based inquiry, then, suggests that Pasifika students are broken and need to be fixed. However, it can be argued that the potential of Pasifika students in education is no different to any other student group. Research should empower, enlarge, and appreciate the stories of what is working well for Pasifika in education (Chu et al., 2013a), as well as acknowledging things that need to change and what work still needs to be done (Cooperrider \& Whitney, 2005). Stories of Pasifika students' success in education have the potential to transform collective ideals of Pasifika students' performance in education and manifest it into reality. By removing the fear and the limitation of "blame" that comes with problem-solving inquiry, AI allows safe environments to uncover "truth" that might not be heard otherwise (Watkins \& Mohr, 2001). The collective truth in the stories of successful Pasifika students allows innovations to be made around evident challenges to meet a collective unlived reality or dream for future Pasifika (Chu, 2009). Bushe and Coetzer (1995) assert that the stories of those who have already experienced resilience, perseverance, and success as a lived reality can help transform these ideals into reality for others and organisations. For example, Bush and Coetzer (1995) advise that if enhanced leadership is the goal, then collect the stories of leadership at its best. In addition, if the goal for Pasifika communities, educators, and the government is to enhance educational success for Pasifika students, then unearthing the stories of Pasifika success in education should be the goal.

The students in this research have had academic success at undergraduate level, but they had all experienced academic failure at secondary school. Through appreciating their stories of success questions can be asked about what other insights their collective “truth” can provide. The participants have characteristics which signal resiliency through overcoming initial academic failure at secondary school. Their backgrounds also point to them as being courageous to re-enter education and then to begin to survive though sheer hard work for every bit of success they achieved in their University education.

The potential of appreciative inquiry, then, allows a glimpse into the collective truth of participants' academic success and what factors enabled their development. 
Furthermore, from the stories, the hardship, resilience, and the survival mechanisms can be appreciated and built upon for future Pasifika in education.

\section{Research Design}

Qualitative research is about making a difference through the understanding and insights attained through the research. Strauss and Corbin (2015) assert that qualitative research brings to reality the dreams of the researcher. Through actively going out, seeking answers, collecting, and interpreting the data the qualitative researcher is connected to the research as much as the participants are to the research. This dynamic and interactive style is often at opposite end of the spectrum compared to the rigour of quantitative design. However, that is the beauty of qualitative research; it is organic and authentic and it is driven by wanting to explore the human subjective experience of phenomenon. In addition, qualitative research seeks to know how meanings are formed and transformed, to unearth new areas of phenomena that have not been comprehensively researched. Qualitative designs give a holistic wide-ranging perspective of phenomena (Strauss \& Corbin, 2015). Qualitative research was chosen for this study because the research question seeks to explore the human experience and perceptions of participants. It is looking at an area of Pasifika education research that has yet to be unearthed thoroughly, and due to the multiple factors that influence education journeys this research needed to take a holistic overarching view.

The qualitative design of this research is enhanced by the use of Talanoa as both methodology and method. Talanoa is widely accepted as an appropriate methodology and method for researching Pasifika (Helu-Thaman, 2001), aligns well with qualitative research, is collaborative, and oral in nature. Talanoa is about the relationship between people as well at the conversation itself. It is acknowledged that this notion may be hard to grasp through a Western perspective. The conversation can only go as deep as the connection between people allows; conversely, the relationship is seen as just as important that what gets said. The Talanoa relationship between researcher and participants allows for deeper than normal conversations, the relationship allows for a richness that brings to fruition the co-constructed, inter-related, and authentic knowledge (Manueli, 2012).

Talanoa may also be described as a method of storytelling that brings out the experience without suppression of the emotional state of the individual (Halapua, 2008). "Valid 
Talanoa research is undertaken with the understanding that it is a culturally and emotionally embedded reciprocal exchange between researcher and participants. It requires a deep, interpersonal relationship and emotional sharing between all parties involved” (Morrison, Vaioleti, \& Vermeulen, 2002, cited in Otsuka, 2006, p. 3). Talanoa is about getting the truest sense of the lived reality of the participant; this idea of empathy gives a more intimate understanding of their hopes and struggles.

The use of Talanoa as the main methodology and method in the research was driven by the fact that the researcher is Pasifika, researching Pasifika participants, and therefore believed it was appropriate to use a Pasifika-based research methodology and method. The use of Talanoa also allows the researcher to stay connected to the participants through their shared feelings and emotions, due to their similar experiences. Farrelly and Nabobo-Baba (2012) comment that when the researcher is trying to be devoid of empathy and opts for the common sterile, impersonal approach they actually miss out on the true reality because it is the connection, the emotion, that carries the social cultural realities. Talanoa emphasises this idea of shared emotion and connection that one cannot exist without the other.

Johnson and Christensen (2008) point to pragmatism, the view that research should be designed with the intent of what will best answer the research question. Being Pasifika and exploring the realities of other students that share similar social, cultural, emotional, and educational realties, the researcher felt that using any other research method would not give the real richness of stories of the participants (Farrelly \& Nabobo-Baba, 2012; Halapua, 2008, Manueli 2012). The researcher understands that being emotionally connected can lead to non-reflexivity or bringing researcher bias into the research. However, interpretive validity requires the researcher to truly understand the "inner world" of the participants, to get inside their heads, to see the world through the participants' eyes, to see and feel what they do. Doing so allows an understanding of the participants' worlds and this can produce a more valid perspective (Johnson \& Christensen, 2008). In this case, as the researcher shares both ethnic background and educational experiences with the participants, the bias serves to bring to the research greater understanding from living a similar reality, thus, bringing empathy, and connection to the Talanoa relationship. 


\section{Participant Selection}

Six out of the eight participants the researcher had crossed paths with in different Pasifika education circles. It was only through conversation about the research with the six participants that it was found they fit the criteria and wanted to be a part of the research. The use of referral or snowball sampling was able to reveal two more participants. One participant not previously known to the researcher was the wife of an acquaintance; this created an immediate connection between researcher and participant. The second previously unknown participant was a fellow member of the researcher's leadership cluster. The leadership cluster is a community of Niu (young coconut, play on words meaning new) generation Pasifika leaders. Additionally, it was through strong cultural networks that the participants could be found.

Prior to the Talanoa process, every participant was sent the background information about the purpose and the aim of the research (see appendix 1) as well as the consent form approved by and in line with the guidelines set by Victoria University Research Ethics Committee (see appendix 2). Furthermore, due to the historical nature of the participants' experiences being sought the researcher sent each participant a Talanoa briefing document with questions and ideas about the research to get them to reflect on their education journey so they would not feel “put on the spot” during the Talanoa (see appendix 3).

\section{Sampling Method}

This section explains the sampling strategy used in the research. The sampling criteria were defined through the research question (Johnson \& Christensen, 2008). The question for this study had three main characteristics that determined who were eligible for this study. Firstly, the students needed to be of Pasifika ethnicity, to have experienced academic failure at secondary school, and also have either started or completed a form of postgraduate study.

The specific nature of these criteria also determined the sampling method that was used in the study. Six of the eight participants were already known to the researcher. However, it was only through asking the participants about their educational journey that it was determined that they met the criteria. The other two students were selected through snowball sampling (Johnson \& Christensen, 2008). 
Table 4: Participants' ages, ethnicity, and qualifications.

\begin{tabular}{|l|l|l|l|l|}
\hline Name * & Age range & Ethnicity & $\begin{array}{l}\text { Undergraduate } \\
\text { Qualification }\end{array}$ & $\begin{array}{l}\text { Currently } \\
\text { completing }\end{array}$ \\
\hline Alapati & $30-40$ & Samoan & PgDip & \\
\hline June & $30-40$ & Niuean & BA, MEd & \\
\hline Tanielu & $30-40$ & Samoan & BA, MBA & \\
\hline Sefina & $30-40$ & Fijian & BA, PgDip & \\
\hline Moana & $30-40$ & Cook Islander & PgDip & MA \\
\hline Maneta & $30-40$ & Samoan & BA, BA Hons & BA Hons \\
\hline Fetu & $50-60$ & Samoan & BA & BA Hons \\
\hline Penina & $20-30$ & Tongan & BA, PgDip & \\
\hline
\end{tabular}

*names have been changed for confidentiality

Snowball sampling (Goodman, 1961) is the process of using the researcher's social networks and the participants to lead them to other people that fit the research criteria. Another name for this type of sampling method is chain-referral sampling (Erikson, 1979) where the researcher starts with a small number people and through the process of referrals from the small set of participants is able to grow the sample set. The researcher believes that was an appropriate way to sample for this study.

The use of referrals has a duel effect. First, the researcher can be introduced to people they might have never have met without the key connection. Secondly, having a participant refer new participants can instantly build relationship and rapport between the researcher and the new participant through the mutual association of the person that referred them. The researcher can ride on the "coattails" of a pre-existing trust, rapport, and relationship that serves as a bridge that is easier to cross than if the researcher had they tried to meet the new participants by themselves. This is particularly relevant when using Talanoa which, to be effective, first requires a deep understanding of and strong connection to the participants (Vaioleti, 2006). Trust and relationship are key components of Pasifika culture and, without these, Talanoa will not go the depths it can. Vaioleti (2006) asserts that, within Talanoa, the deep affinity between participant and researcher allows for more mo'oni (pure, real, authentic) information. Hence, 
particularly in Pasifika research, snowball sampling and chain-referral sampling are excellent sampling methods to create both deep relationships and community between researcher and participants.

\section{Sample Size}

Sample size for this research was determined by multiple factors. Firstly, the use of a qualitative design means that research should follow the principal of saturation (Glaser \& Strauss, 1967). Saturation describes the point in the data collection process where new data no longer shed any new light on the issue or phenomenon being researched. Ritchie, Lewis, and Elam (2003) comment that the law of diminishing returns impacts on qualitative research and that there comes a point in the research where the sample is generating more data but not necessarily any more information. This is the point at which Glaser and Strauss (1967) would say the data has reached saturation. Unlike quantitative analysis, qualitative research seeks to understand individuals' stories in depth, seeing the world from the participants' eyes. Thus, simply adding more participants does not add any more depth or richness of information than a smaller sample set would. However, this does not mean to say that the number of participants involved is not important in qualitative research. The concept of saturation is a frustrating point for many researchers as there is not a set definition about what sample size would guarantee saturation; it depends on the study and who is doing the study (Charmaz, 2006). The point of saturation can come sooner or later depending on research design, research questions, and methodology. Additionally, an experienced researcher may be able to yield more deep and rich data from a sample set of three compared to an inexperienced researcher who may have a sample size of twenty (Jette, Grover, \& Keck, 2003).

Guided by his supervisor and the feasibility of using the information for the completion of a master's thesis, the researcher decided on six participants. This number of participants was deemed appropriate for the specific nature of the research question, which meant the population size to choose from was minimised. At the beginning of the research, however, the snowball process revealed two more participants that are eligible. The researcher, with guidance from his supervisor, then chose to limit the study to eight within the parameters of the Master's thesis requirements. 
The method of data collection also limited the number of participants. Talanoa are unstructured with no set time limits or set questions involved; one interview could possibly take anything from 30 minutes to a few hours. Therefore, for a master's thesis to have any more participants could verge on being counterproductive and not feasible within the time frame and the resources available (Strauss \& Corbin, 1998). Fortunately, for the researcher, none of the Talanoa sessions went beyond an hour and a half. Nevertheless, the number of participants in this research is in line with proposed phenomenology sample size guidelines recommended by Creswell (1998), who asserted that 5-25 participants was efficient for qualitative design, by Morse (1994) who believed that qualitative researcher should have at least six participants. Moreover, the number of participants in qualitative research is of secondary importance to the depth and quality of information that is collected.

\section{Data Collection}

Data collection refers the methods by which the researcher gathers information from the participants. The methods used for this study are described below. Above in the research design I described Talanoa as methodology in this section Talanoa will be described as the data collection method.

The key method of data collection was Talanoa. Talanoa can "loosely" be described as a conversation; it can be both informal and formal as well as the exchanging of ideas and thinking between people (Vaioleti, 2006). "Tala means to inform, tell relate and command, as well as to ask or apply. Noa means of any kind, ordinary, nothing in particular, purely imaginary or Void” (Vaioleti, 2006, p. 23). Talanoa by definition means to talk about nothing specific and to converse without any rigidity or structure. This does not mean that Talanoa is limited to only general conversations. Talanoa is used in multiple places in the Pacific, particularly in Samoa, Tonga, and Fiji where Talanoa is a formal way to discuss important matters between family, community, and Government (Vaioleti, 2006). The researcher also believes the importance of Talanoa is not so much about what is said but, more importantly, the relationship that evolves. Talanoa has been compared to semi-structured interviews and unstructured interviews (Manueli, 2012). In essence, they share similar features, the main difference being that traditional research methods are usually used only for research purposes, whereas Talanoa is used within everyday practices of Pasifika people. Moreover, through the 
deep connection that Talanoa can produce between people, it is hoped that lifelong relationships are formed (Manueli, 2012). For example, the researcher could have a conversation with a participant and have no real connection to them, and they may share lots information but the shared experience is not as deep and therefore may limit the understanding of the knowledge produced. However, if the relationship between researcher and participant is deep, the knowledge shared might not be as extensive yet, due to their deep affinity to each other, they are able to fathom what is being said at a greater level of understanding.

Talanoa is an appropriate research method when working with Pasifika. Research has to recognise that Pasifika peoples' epistemological and ontological understanding of the world have survived for thousands of years (Vaioleti, 2006). Thaman (1998) argued that to say knowledge produced by Pasifika is not credible unless it follows a Western framework is both ethnocentric and arrogant. This perception holds to the false idea that the origin of knowledge is all the same when clearly it is not the case (Vaioleti, 2006).

Embedded in Talanoa is the ancient epistemological and ontological understanding of Pasifika people. Talanoa is part of the cultural fiber of the people; it is not just a method created by Pasifika academics to serve their needs, it is a cultural practice first that has been adapted into a research lens (Vaioleti, 2006). As qualitative research becomes more understanding of indigenous methodology, Talanoa aligns well with some Western views on research such as pragmatism (Johnson \& Christenson, 2008). The methods and methodology used in research should be the most effective way to do the research for the people being researched. Talanoa is appropriate because it is the Pasifika way to understand Pasifika people.

There are some disadvantages to using Talanoa, as it does not have the rigidity of more traditional methods of data collection. Talanoa does not have a set timeframe and therefore the researcher must be prepared for this. One of the strengths of Talanoa is that it is very flexible; however, this can also be one of its drawbacks as a research method (Manueli, 2012). The researcher must think about the feasibility of transcribing interviews that have gone on for many hours. Does the researcher have the timeframe and the resources to transcribe six to eight interviews of that length? Talanoa has no set agenda so participants that are more dominant may lead the Talanoa down a direction that steers the researcher away from their research question (Manueli, 2012). It requires 
great skill on the part of the researcher to get the conversation back to the original line of thinking. The researcher in this study sent the participants a briefing document with some probing question for them to ponder over and reflect on. The briefing document served the purpose of having a borderless agenda, meaning there was no set agenda but everyone seemed to be clear about the focus and direction of the Talanoa.

In this research, every effort was made to ensure that the Talanoa in this research was conducted in comfortable environments for the participants. The researcher wanted the participants to feel as comfortable as possible so the researcher asked each participant to choose the location of the Talanoa; also drink and food were shared during the Talanoa sessions. Using Talanoa the researcher was able to feel the true emotion of the participants. They shared laughter, tears, hopes, aspirations, fears, and leadership. Every part of the Talanoa engagement felt connected and authentic. To the researcher, it felt like he was having a conversation with his brother, sister, aunty, or uncle. This deep connection is the true essence of Talanoa and these people will always be good friends.

\section{Data Analysis}

Data analysis in qualitative research design according to Creswell (1994) is eclectic; there is no clear right way to go about it. Good analysis comes down to the researcher being comfortable about developing codes, categories, and themes out of the information that is given (Creswell, 1994). The researcher must also acknowledge their position in relation to the data and must be open to new or alternative findings being transparent as possible. The analysis really comes down to how the researcher interprets the data, and due the wide variance of the human experience there can never be a right way to interpret the information.

The amount of data collected in qualitative designs can be sizeable and overwhelming (Creswell, 1994). Qualitative design is not measured in numbers but in words and expression. One skill needed by the researcher is the ability to separate material into what is and what is not important. However, good qualitative research understands that frequency does not necessarily mean something is more or less important, something said once could be just as significant in qualitative research as something that appears many times (Strauss \& Corbin, 2015). The importance allocated to data should be guided by the research question, the research design, and by the researcher themselves. If the researcher has collected the information, they are much a part of the research as 
the participants and this intimate connection is invaluable (Strauss \& Corbin, 2015). Nevertheless, there are measures or steps that qualitative researchers can follow in their analysis to help them (Tesch, 1990; Bryman, 2008).

The data analysis of this research was guided by the four stages of Bryman's (2008) qualitative analysis. Bryman's stages are systematic processes that can be followed post transcription. The researcher in this study fused some of stage one into the transcription process as key ideas kept cropping up in the researcher's thinking as he transcribed the data.

Stage one: Read the text. In this process Bryman (2008) encourages the researcher to read the text with minimal notations and to write most of the notes about the researcher's key thinking, what the data is about, key themes, categories, and concepts at the end. This researcher integrated some of this stage during the transcription phase; however, this was minimal. Stage one was repeated by the researcher.

Stage two: Read again. This stage recommends reading the text over again, this time marking the text. The researcher is encouraged to underline, highlight, and circle to start giving codes of segments of information. What the researcher is trying to do in this stage is highlight anything that stands out to the researcher. This could be words, a sentence, or even a whole paragraph of data. In this research, this process was conducted twice for each Talanoa: first the researcher went over the data with a highlighter, and then went back over the data writing brief notes on the data that was highlighted.

Stage three: Code the text. This stage recommends going over the text and systematically coding the data according to the notes on the text into a word or an idea about what that bit of highlighted information means. Reviewing the codes may show two different words used for the same code, or that codes naturally come together. For example, "negative belief" and "positive belief" could both come under the code of Belief. Bryman (2008) suggests that the researcher start grouping codes together that fit under a certain category that will fit within an overarching theme.

Stage four: Relate the text to theoretical ideas. This stage is about making sense of the data, about the interpretation of the codes, categories, and themes and about relationships between codes. The purpose is to identify what is significant, what codes 
seem more important than others, and how they relate to the research literature and the research question.

In this study, this process was aided by the use of Excel. The researcher put every highlighted note/information and code into an excel spreadsheet. The researcher gave every coded bit of information a number on the written text. This bit of data was transferred to an excel spreadsheet with a source number (e.g., interview 1-8) and a note number (the number given to that code information on the written text). This was useful in finding direct quotes for each code later. This process was repeated for every interview. This allowed the researcher to filter through excel by codes, showing every source that listed that code that helped in analysing key themes across the research and also the differences across the research.

\section{Validity}

Qualitative research has always been at odds with quantitative design about how to ensure the research has validity and reliability. There is a sense that qualitative research originally tried to defend the rigour of quantitative design by using words such validity, replication, and reliability (Creswell, 1994). However, over time other labels have been created to describe what validity means to qualitative research, words such as “trustworthiness” and “authenticity” (Earlandson, Harris, Skipper, \& Allan, 1993).

Qualitative research can be claimed to be trustworthy and authentic when it has strong internal validity. Internal validity is acquired in qualitative research when the research findings match reality, and depends on how authentic or trustworthy are the findings. There are few ways to create robust internal validity in qualitative research; one is interpretative validity. Johnson and Christenson (2008) describe interpretive validity as the researcher making sure the research findings reflect as accurately as possible the meaning given by the participants, that they are not misinterpreted by the researcher. In this study the researcher returned some of the transcripts to the participants to make sure the interpretation of the findings was as accurate as possible.

To ensure trustworthiness the researcher used Inter-rater reliability (Johnson \& Christensen, 2008). During the analysis process, the researcher attached codes to bits of data, attached those codes to certain categories, and grouped categories under major themes with an operational definition. Inter-rater reliability looks to identify whether 
people outside of the research would match up the codes, categories, and themes in a similar way to the researcher. This can give the researcher an indication on the accuracy of coding and categorisation. If there is any major disconnect between what the researcher finds and what others find the researcher can inquire into whether he has the accurate codes, categories, and themes. Due to ethical considerations, in this research the researcher was only able to use this process with his supervisor. When categories, codes and data were placed on a table in random order the supervisor was able to accurately match them in a way that corresponded with what the researcher found.

\section{Ethical Considerations}

This research involving human subjects required informed consents such as, but not limited to, the voluntary involvement of the subjects and voice recording. During the research this process was managed through completing the required ethical consent processes. The research gained approval from Victoria University of Wellington Human Ethics Committee on the 9th June 2015 (Ethics Approval: 21541- see appendix 4). The researcher gained informed consent from all participants and also gave them enough time to reflect on the research topic through a briefing document so they could make informed choices and ask the researcher for any clarification if need be.

The researcher ensured the protection of the participants' wellbeing was a top priority. In accordance with the human ethics guidelines the researcher and his supervisor only accessed the data collected. All written material was kept in a locked file cabinet and only accessed by the researcher. All electronic information was secured on a passwordprotected file and only accessed by the researcher and his supervisor. In addition, pseudonyms were allocated for confidentiality as well as the names of schools mentioned. 


\section{Summary}

The aim of this chapter was to describe the research methodology used in this study. This study began as a tiny dream in the researcher's heart and mind, a wish to understand his own story better through finding others like him. This chapter acknowledges that, due to the intimate nature of the researcher to the topic, it was impossible to eliminate researcher bias. However, this deep affinity to the research project served to deepen the understanding of the participants' stories and to give a richness of data that would not have been possible otherwise. Additionally, the research was underpinned by a constructivist paradigm. The research sought to understand how the participants constructed their own realties from the world around them. Through Talanoa, the shared experiences of the participants and researcher can begin to generate theory or a pattern of meaning. The stories of the participants were interpreted using the lens of appreciative inquiry that looks at what factors the participants believed made a positive difference to their social realities. This follows a trend of Pasifika research to move away from deficit "what's going wrong” problem-based inquiry. The design of the research was qualitative and was based around the use of Talanoa to address the research question. The participants were selected mainly through having an existing connection to the researcher and by snowball sampling. Data was gathered through indepth Talanoa and analysed using Bryman's (2008) four stages of qualitative analysis. Interpretive validity and inter-rater reliability were used to maintain strong internal validity and trustworthiness. The study is intended to identify and explore the key factors enabled Pasifika students to overcome their initial secondary school academic failure and become successful postgraduate students. 


\section{CHAPTER 4: \\ The Findings}

\section{Introduction}

This chapter discusses the findings of the study. There were a number of significant factors that facilitated the success of Pasifika postgraduate students who had failed academically at secondary school. The findings section explains the themes generated from the Talanoa sessions. The main themes are defined, segmented into categories or sub-themes drawn from the data. These categories are supported by passages from the data. This process is replicated throughout this chapter in accordance with Saldana's (2009) coding manual for qualitative researchers and Bryman (2008) qualitative analysis phases. Additionally, the themes selected were interpreted by the researcher as being significant across all of the lived experiences of the participants.

The overarching theme of the research is resilience. The stories in this study are about Pasifika students who have overcome great odds and adversity in their academic lives to become successful in education. Resilience is discussed briefly, before exploring "academic resiliency" in more depth. Under academic resilience each participant's story is briefly summarised to give context to the remaining themes which look to understand and explore how was resilience built, maintained, and developed in these Pasifika postgraduate students who failed academically at secondary school.

The researcher acknowledges that human experience is multidimensional and therefore the interplay of internal and external factors is hard to segregate, meaning what happens on the outside of individuals will lead to an internalisation of that event where and an individual will give meaning to the experience (Harms, 2005). Nonetheless, the researcher has tentatively put the remaining themes into external (social) and internal factors (emotional, psychological, and spiritual) to apply more structure to better understand resilience in this context. The five themes that the researcher has labelled external factors are a) schooling experiences, b) life events, c) transferable extracurricular activities, d) support, and e) leadership. The six themes labelled as internal factors are a) emotional influences, b) motivational influences, c) self-concept, d) selfbelief, e) confidence, and f) perseverance. A summary is provided at the end of the chapter. 


\section{Resilience}

Resilience has been described as an individual's ability to "bounce back” to generate a successful positive outcome despite going through adversity, misfortune, setbacks, and experiencing adverse conditions. Resilience, then, is a combination of three factors.

1. There is a level of risk or adversity involved that threatens development.

2. The presence of protective factors both internal and external facilitates growth despite the odds.

3. A positive, successful, or better than expected outcome is achieved.

\section{Academic resilience}

Morales and Trotman (2004) stated that academic resiliency is when students succeed despite many obstacles and a history of low academic achievement. In essence, academic resiliency has the same combination of factors as resilience - risk factors, protective factors, and a positive outcome - the only difference being it is confined to the parameters of an education setting

\section{Resilience criteria of the participants}

In this study, each student had to have largely failed academically at secondary school in New Zealand. Seven of the eight students did not get any formal qualification, meaning they had failed completely. One student struggled at school and for the most part was seen as an academic failure, but was able to scrape through and get university entrance in her last year. This student confirmed that by today's standards this would only allow provisional entrance into university, meaning that she would have meet certain requirements to be able to attend. The stories of the students in this study reflect Morales and Trotmans' (2004) definition of academic resiliency as most of the participants have a chronic, historical history of academic failure.

In terms of Morales and Trotmans' (2004) definition, above, the evidence of the academic resilience of the participants in this study that they were all postgraduate university students. This reflects that, not only had they overcome historical academic failure, but that they then achieved and thrived at undergraduate level and kept going to the next level of study. Research on Pasifika students reflects that they constantly underachieve in education, despite (positive) findings that when they do succeed in undergraduate study they are more than likely to go on and do postgraduate studies and 
be successful there as well. Six of the eight participants in this study completed undergraduate qualifications and went on to do postgraduate study. Two participants had had lengthy careers in their industry and community work and were able to use this as a measure of their ability and go straight to postgraduate study. Six of the eight participants have actually completed their postgraduate studies and the other two have almost completed.

\section{Story Summaries}

The following sections are the summaries of the journeys of the Pasifika postgraduate students. As a Pasifika researcher, the researcher believes it is important that the stories of these Pasifika students be briefly summarised and seen first as a collective whole, before being compartmentalised under traditional research methods. Morales and Trotman (2004), writing on academic resilience in America, believed the stories of resilience should be understood first for their individual uniqueness, before finding the shared factors and themes. From a Pasifika perspective, the researcher felt it was important to give mana to each individual and acknowledge the uniqueness of their individual journeys, to give each participant a voice. The researcher also believed that it was beneficial for the research, the participants, and the readers to see academic resilient stories in their entirety - to show what academic resiliency looked like for each individual. Conversely, these are only summaries, a snap shot of the amazing journeys of each student, not a detailed reflection of the richness, the greatness, the highs, the lows. The names have been changed for confidentiality.

\section{Participant 1: Alapati}

Alapati is a male of Samoan decent. Alapati attended several colleges in secondary school for two reasons. One was social acceptance - to try and fit in among the "cool kids" of the school. Second, it was a way to avoid being seen as a failure academically as he had failed at the previous schools he attended. Growing up, Alapati's parents' level of education support was acknowledging that school was important, however not going much deeper than this. Often family commitments got prioritised over school. Over time Alapati felt that school was not for him and, therefore, was not engaged and became disinterested. He also knew that only a couple of teachers in his secondary school actually were interested and invested in him. This lack of support pushed him to solely focus on the social side of school or simply not turn up (truant). Alapati had some 
success in academic work but only in the classes of the teachers he knew validated him. He finished secondary school as an academic failure with no formal qualifications. He always knew that he had strengths in other areas but was just not academically strong. Alapati hustled his way into university through some back doors, but again soon realised that education was not for him. He dropped out of university and found a successful career in computers. Alapati was able to work hard and climb his way up the corporate ladder. It was during this time he also fell in love with his community work with young people. It was through community work that led him to some life-changing experiences. He was chosen above graduates and postgraduates to present a speech to the U.N. Additionally Alapati was voted one of NZ's upcoming leaders among highly esteemed New Zealanders such as politicians and sports stars. It was after these experiences that He wanted to come back to education. Through his work experience with computers and community work, and his recognised leadership Alapati was able to enrol straight into a postgraduate diploma in Pacific studies. Alapati, with the support of influential academic staff and peers and his determination, worked hard to navigate his way to academic success. What helped him stay on course was his desire to contribute. Alapati realised the learning he was doing was very relevant and enabled him to contribute in more effective and powerful ways. This student is now a successful pastor of his church and continues to lead people, especially Pasifika people in his community.

\section{Participant 2: June}

June is a female of Niuean decent. June's described her experience at secondary school as being a "dark time”. She grew up in a predominantly Pasifika community and did the majority of her schooling in this community. She started secondary schooling at the local co-ed college and had previously been seen as a successful student in local primary schools. This level of success continued at secondary school as she was chosen in speech and writing competitions. After a holiday she and her family decided that there had to be better schooling than the one she was attending. June decided to go to an all-girls school in the city that was $30 \mathrm{~km}$ away from home. It was here that June experienced the darkest times of her education journey. She was very confident and made friends quickly at her new school; however, she felt that sometimes people interpreted her confidence as her having everything together, but she was struggling academically at her new school. A teacher saw her character as the "class clown" as disruptive and told June that she would never make anything of herself. She felt really 
isolated at prize-giving as people were recognised for their academic achievements but not her. She always wanted to bring her parents to prize-giving but was ashamed because she was failing and they were spending money to get her into the city every day. The parents' academic support was limited to making sure she got to school as they did not really understand what she was learning and couldn't help her. June soon started hanging out with the wrong crowd and disengaged from school and began to truant regularly. June finished her secondary schooling as an academic failure and followed friends to do a certificate at a Private Training Institute. June failed this course and then, again following friends, enrolled at university. June got into university through being over 20 years of age. She enjoyed the party life and was able to pass some papers without even trying which gave her a false sense of reality. It was not until the second year that she completely "bombed”. She was placed on academic report and bounced from paper to paper with no clear academic pathway. Pasifika tutors urged June and her friends to not be another statistic, but the message fell on deaf ears. After years of “mucking” around at university, tragedy struck and June’s father passed away. It was this moment that drove June to seek academic success, believing that had she not wasted time her dad would have been able to see her graduate. She remembers one moment of massive support when a lecturer acknowledged her father's passing, showing true empathy; June realised that this lecturer actually cared. She struggled her way to passing papers soon realising and believing that she could do this. She was asked to tutor a paper and, though doubtful, took on the task. It was the first time she felt intelligent. June would eventually graduate in public policy and go on to battle again for her master's in education. June is currently leading an academic support team at a community tertiary education institution, hoping to contribute and lead other students to the same success that she has found.

\section{Participant 3: Tanielu}

Tanielu is a Samoan male. Tanielu started his secondary schooling at a co-educational school outside out of the small city that he lived in. He knew early on that his passion was music and sports: the small community he lived in was really competitive around these areas and to be good you had to be the best. He was awarded a sports scholarship for rugby at a prestigious Catholic boys school in the city. During this time Tanielu excelled in sport and represented New Zealand in age grade rugby. However, Tanielu was not doing well academically and just could not "get” some subjects, believing they 
were not for him. Coming to the end of his schooling knowing he was not doing well academically Tanielu sought the teacher/careers advisor about possible options for his future. He inquired about university but the careers advisor told him that he should try and work or go to a private training organisation as, based on his academic performance, university was out of his league going. At this time there was no doubt in Tanielu's mind that he wanted to go to university and, determined to prove her wrong, he promised himself that he would send the careers advisor a copy of his degree. Tanielu's determination was learned through sport. He understood that the more you trained the better you would become. Tanielu took his determination into university and failed just one paper. Another key driver for Tanielu was that rugby was not going as planned and he wanted to make a profile through rugby to get his music going. He decided that he definitely needed some qualifications if rugby was not going to pay off. He was also motivated to finish his degree when he could see other Pasifika students being happy just to be at university. Tanielu got around with an older crowd and was able to get some good support from them with his assignments. He was also able to build some connections with his tutors and lecturers. Tanielu graduated with Bachelor of Art (BA) in Education and Pacific studies and was able to send his careers advisor a copy of his degree. Tanielu was then able to follow a similar strategy and complete his Master's in Business and Administration (MBA). He now has a successful music career and uses his education and music to help young people follow their dreams.

\section{Participant 4: Sefina}

Sefina is a female of Fijian decent. She started her secondary schooling at an all-girls Catholic school in the city outside of small town she lived in. Sefina, from day one, felt like a minority as it was predominantly a European school. Naturally, Sefina gravitated towards her Pasifika peers. However, she felt that being part of the group came with rules of socially acceptable behaviour that it was not cool to achieve; thus she did not want to overachieve because she felt she would be separated from the group. Sefina, like most of her peers, was in the middle of the class overall, not achieving academically. Sefina's passion was netball and she had a dream of playing for New Zealand. One time she had a big tournament and forgot to do her homework and a teacher told her "it does not matter that you play netball you still have to do your homework", but Sefina held true to her dream that she was going to make it at netball. Approaching her last year and not doing well academically, Sefina was in line to be the 
netball captain but was overlooked for a Palangi student that she believed "greased" the coach and was a decision based on race. Her way of protesting was to transfer with a close friend to another all-girls school across the city and play for them instead. This secondary school had more Pasifika students and she could see them not really trying at school. Sefina avoided them and was really focused on netball and, with her only one real strong friend, also became focused on school. She found the teachers more interactive than at her old school and was really invested in her learning. She passed three subjects, enough to get into university. After leaving school, Sefina moved with her family to another part of New Zealand. Her parents believed school was to get a job so she worked to help out the family. After a netball coach wanted her to come back and play for a rep team, Sefina returned and decided to try university as well. She found the level too hard, reporting that she did not even know what they were saying. While studying she picked up some work and as her university got harder she took more hours and quit university. Following this, she moved to London and built a good career in management and realised that, as with netball, if she worked hard she could be successful. She was forced to come back to NZ when she fell pregnant. Sefina realised she needed to make something of herself and her baby and had built confidence and belief in her experience in London, so she attempted university the second time. Despite constant challenges, turmoil, the tensions between being a mum and studying, her previous failure and lack of academic success, and family expectations of her, Sefina graduated with a BA in social policy and education before completing her Postgraduate Diploma in Teaching. Sefina now works for a Māori and Pasifika support team that is part of the university she attended.

\section{Participant 5: Moana}

Moana is a female of Cook Islands decent. Moana was an average student at primary school obtaining grade Bs during intermediate. Moana went to an all-girls Catholic school in the city. Her family, especially her dad, believed success in school was everything over personal ambition. Moana was a very good tennis player and wanted a career in that as well as wanting to become a forensic scientist. However, both ambitions were squashed early when Moana started failing school, especially maths and science, and a teacher told her to forget a career in forensic science and to focus on something else because she was not good at these subjects. When she showed her dad the $\mathrm{D}$ she got for an assignment he was so disappointed in her that he took away her 
tennis and he "looked down" on her. However, one teacher wanted Moana to play for the school team also offered help her out academically. Moana felt that this teacher believed in her academically; however the disappointment she felt from her father as well as her continued failure at school made her feel like she was worthless and “dumb”, so she forged her mother's signature and signed herself out of school at sixth form (Year 12). Trying to escape the disappointment, Moana moved $800 \mathrm{~km}$ away to another major city and worked at McDonalds. Here she found herself hanging out with the wrong crowd, getting into trouble at nights doing small crimes, while being an “angel” at work so no one even knew. It was around her new peer group that she witnessed her friend being held up at gun point that Moana decided that she needed to get out. She connected back to her family and her mum told her to come home; even though things with her father were still not good she decided to go back home. Her goal was to get an office job as she did not want to be serving fries all her life. She attended a local PTO, studied at the certificate level, completed this, and was able to get a good job at Work and Income New Zealand. She built her way up the business ladder as well as doing more study in finance part time, but wanted to push herself. Moana gained the confidence to send a letter to the finance team requesting a secondment in the finance department. She was accepted and slowly moved up in that department. Her study was really slow and she knew that she needed more qualifications to supplement her experience so decided to go to university. Based on her experience the university was able to enrol her in the Graduate Diploma in Commerce. Through her own hard work, support from the tutors and lecturers, and with the love of her husband and children, Moana at the time of her interview for this study only had a few weeks left to complete her Diploma. She is also confident about completing a Master's Degree. Moana is now employed at head office at Work and Income doing finance and accounting.

\section{Participant 6: Maneta}

Maneta is a Samoan male. As a child, growing up in Porirua, Maneta loved one thing above all else - rugby. He started playing at age four and says his obsession with New Zealand's national game had been instilled by his dad. Maneta was quite the academic and sporting star at his primary schools, at intermediate received a report of all A's and one B grade. He decided that he would leave the community he grew up in and most of his school friends and go to an all-boys secondary school in the city. It was a new world for Maneta, a school enriched with tradition from the uniform to the daily 
practices of the school. He was tested and streamed in his first year of college: from those tests he knew he was not in the top stream and felt unease at this. Maneta went on to fail every year at college. There were more than 1,200 hundred boys at his school and he fell through the cracks in their system. Not once did a teacher reach out to him and this usually followed with reports saying that he needed to apply himself but he did not know what that meant and believed they should have applied themselves to him. In his last year, a few months before school finished, Maneta was asked to leave school by his seventh form dean and to go find a job. Despite carving out a successful path with the school's first XV, the second generation New Zealand-born Samoan says he gave up rugby when he left college because he had not made any rep teams. He described being unemployed, having no qualifications, and getting into trouble every day with his friends as being some of his hardest days. It took an intervention from his father, and a stint overseas coaching rugby, to set him on the right path. He returned home six months later, determined to channel his renewed enthusiasm into a rugby career. He trained hard and eventually got into his city representative team, then made a New Zealand age grade team and later, the city's top team. During this time he was also able to complete a certificate in sports coaching. After accomplishing his rugby goals, he realised he could be the first person in his family to get a degree. Even if, initially, tertiary study was simply the lesser of two evils, it would get him out of labouring or work on the roads while he made it in rugby. The first essay he got back was a D with some harsh feedback. Maneta thought he was okay but he couldn't write academically. He was advised to do a writing course which reaffirmed his belief he learnt in overseas coaching at an elite academic primary school that education could be learned, that it's something you can actually get better at. Success in rugby helped him realise that if he could set goals in other areas, like education, he could do it. This realisation was a turning point that prompted him to talk to every lecturer and student support service he could find. He asked his fellow students to check his essays and gratefully used their advice. Maneta knew that he would probably never be the smartest student but he could be the hardest working, often spending late nights studying, working around his rugby commitments. This drive was also supported by the many "amazing” lecturers who invested in him and encouraged him on his journey. Maneta became a mentor to others as he wanted to help students who struggled like him, and in his last few years at university was asked to tutor a few papers. Maneta graduated with BA in Pacific studies and Education and then went on to graduate with a first class honours degree in 
Education. From his honours study, Maneta was awarded the Medal of Academic Excellence in 2013 and admits it was a hard slog to get where he is today - helping others achieve their goals, as a lecturer in Youth Development, and completing his MA (Master of Arts) in Education.

\section{Participant 7: Fetu}

Fetu is a Samoan male. Fetu was born in Samoa and came to New Zealand at an early age. He moved to the small community of Porirua that had a strong Pasifika community. He described his secondary schooling as tough. Fetu went to secondary school in the 80's and he described the focus for Pasifika back then was to get a job after school. The scars of his academic failure are still evident as he can remember his exact scores in the fifth and sixth forms, when although he did pass some subjects, this was not enough to pass the year. Fetu repeated sixth form again and came back to repeat seventh form, failing again. His big driver to repeat was his rugby coach who wanted to him to come back to rugby. Fetu was good at maths, which he also believed was helped by that one good maths teacher. Fetu, at that time, did not get into trouble, he just did not do well in school; this has a lot to do with his strong Mormon faith. At the time, he was not very disappointed that he failed as he was following a family and community tradition of working for a car manufacturer labelled the "Samoan University". The belief was you went to school until you could get a job like his brothers did as there were a lot of jobs back then. His grandfather persisted in always telling Fetu that education was important. Then Fetu decided to complete a two year mission for his faith. After coming back, the message rang clear that he needed to make something of himself so he enrolled in some basic papers in all sorts of areas and trades. Through one of his courses he found a job in the tourism industry and during this time raised a family. He applied for another job in the tourism industry and got it; university was not on the forefront of his mind as he had a family to think about. Fetu's bosses told him to apply for this manager's job in the same area but he did not get the job. It was not until another three attempts that he saw it as a sign from his creator. Fetu believes God knew he was loyal person and had he got the job would have still been there today. One of the reasons Fetu chose university was that he felt he probably needed more qualification to get him the jobs he wanted. He entered blindly not knowing what uni was about, only that at school he had thought it was only for the "white kids". He found some of his friends that were going there and also made good connections with tutors and staff and 
through hard work, and balancing his family commitments, he graduated with BA in Pacific Studies and Education. Fetu went on to do his BA honours in Education and is only one paper from completing this postgraduate degree. As well as his role as senior coordinator of Māori and Pasifika outreach programme at the university he attended, Fetu's love of rugby sees his spare time spent coaching the sport.

\section{Participant 8: Penina}

Penina is a female of Tongan and Māori decent. Penina grew up in a small community with a strong Māori and Pasifika presence. Penina does not have a strong connection to her Tongan ancestry as her father left when she was really young. However, her Māori and Te Reo (language) is really strong. Penina was able to move to a different town to do her secondary schooling, about three hours' drive from where she was brought up. However, she got into trouble and her mum shifted her back to attend the secondary school that most of her friends from intermediate attended. Penina started in what she called the "cabbage” classes and built her way out. In Year 11 she passed with flying colours and her work was used as template for other students from one amazing teacher. She described this teacher as going the extra mile and being just really invested in her. The principal described Penina as the next dux and also the soon-to-be head girl. However, Penina did not really study in that year and things went downhill. In stark contrast to her Year 12, a lot of her friends had given up or dropped out so she felt socially isolated. Also a lot of her teachers changed. Penina's academic results went from really good to horrible. She felt teachers no longer cared for her that they still got paid whether she turned up or not. Penina's response was to disengage - she would only turn up to school for art or to smoke, or not turn up at all as she would rather be at home than feeling alone at school with because she had no friends. She eventually dropped out of school and followed a similar path to her sisters, who just worked for their mother. Penina believed that school was just to get a job and because she could just work with her family she saw no reason to stay. However, Penina still wanted more for herself so she completed multiple certificates, realising she could pass things. She tried her hand at fashion as she was good at art. However, in her first week at fashion design she felt out of her depth and dropped out and did a bartending course instead. Penina got work in hospitality and this spiralled to heavy alcohol abuse. During this time Penina fell pregnant and, in consultation with family, decided to have the baby. She knew she had to make something of herself and wanted to become a teacher for her and baby. She 
gained entry into university and studied for a Bachelor of Arts in Education and Māori. Penina realised she wanted to help students like her. After a rough start in education she pushed herself to be the best she could be leaving the social life at the door, creating a routine where she could do her mother duties, work commitments, training and study full time - her friends and family call her Superwoman. Through hard work, balance, and determination she was able to complete her BA in Education and then a postgraduate Diploma in Primary School Teaching. Realising that front line teaching was not the area where she could contribute the most to Pasifika and Māori young people in education, Penina is now doing her BA honours in Education and is a tutor at the undergraduate level. Penina is adamant that this is only the beginning and that a Master's or $\mathrm{PhD}$ is just over the horizon.

\section{Themes}

The major themes that emerged from Talanoa discussions are those that were most common across the participants' stories. These are categorised into two major categories - external and internal factors - each of which has a number of subthemes. Also in the participants' quotes, the college names have been taken out and people they mentioned have been given pseudonyms for confidentiality.

\section{External factors}

The external factors are the "outer worlds" and the contexts that people live in that influence their development (Harms, 2005). For example, a student in the education system in Aotearoa New Zealand will be influenced by many different environments. They will be indirectly influenced by the Government education strategies and their school's philosophy, and directly influenced by their relationships with teachers and staff. In this study the participants identified five key outer world influences that affected their academic resilience and achievement: schooling experience, transferable extra-curricular activities, life events, support, and leadership.

\section{Schooling experiences}

The experiences in the schooling system in Aotearoa New Zealand can have a significant adverse or helpful impacts on students' overall relationship with school and the notion of education. This section looks at how experiences of transition from intermediate to secondary school affected participants' academic achievement, 
wellbeing, and resiliency, how failure in the education system influenced them; and also identifies experiences of the schooling process were helpful in tertiary study.

Adverse experiences in the schooling system

These are the experiences the participants identified in the schooling system that impacted their academic achievement in a negative way

\section{$\underline{\text { School transition }}$}

Carr (2001) stated that school transitions can be either successful leading to overall wellbeing, or troublesome leading to academic failure. In this study one of the key themes to emerge was that students did not have successful academic transitions from intermediate (primary for some) school; additionally, some participants in this study mentioned that transitioning from one secondary school to another affected their development.

Many of the participants were very successful academically at intermediate.

Maneta: $\quad$ The biggest difference for me going from intermediate where I was actually quite successful, I can remember from my grades I was mostly an A student, I think I got one B for Māori... but I think one of the biggest difference was, kind of the knowledge that was privileged.

June: $\quad$ Prior to secondary school I was always in the top maths group at primary school but when I got to intermediate, oh yeah, I was still top and then I got to college then it all changed. I don't know what happened.

Moana: $\quad$ So I remember going home at the end of my form 2 year and I had all straight B's and then to go to college and come out with a D.

After transitioning to secondary school this is how the same participants identified their experience:

Maneta: $\quad$ I failed every year and I got kicked out on the final hurdle and so I didn't get to finish. 
June:

I didn't pass anything, yeah no school cert, yup I got a few subjects, but a few subjects isn't anything in the world of what the system is, yeah awesome you got top marks in English or history but sorry about it but you didn't get the rest, aye, you know.

Moana: $\quad$ End of sixth form I left, with nothing, fifth form, second year fifth form I did like English and math, failed, sixth form came along. Back then it was you had to get under 21 or something ridiculous, I think I got 22.

The participants reported that, despite being successful academic students in intermediate their struggle to transition to secondary school impacted their academic achievement.

Some participants talked about a different inter-school transition that impacted their academic achievement. Tanielu transferred from his local school to a single sex school in the city for his rugby talents. He succeeded in his rugby but failed to find academic success:

Tanielu: $\quad$ I was educated at... College right up until my sixth from year. Then got a scholarship to play rugby at Black College in town...for my seventh form year, but then repeated seventh form.

June was very successful in her local community secondary school and was recognised as such. When she transitioned to a supposedly "better" single sex school in central Wellington she struggled academically and was not recognised by the school.

June: [At] college I was in speech competitions, stuff like that. This was at ...College and then I thought, "nah this isn't for me let's move, let's go to town”. When I went to town, that was a whole new world. So, I went to ...College and I guess I just got lost in a system - and I mean lost because there is heaps of students so, you know, so if you didn't stand out academically, you know you were never gonna be in the prize giving and things like that. 
In contrast, Sefina's experience of changing secondary school impacted her academically in a positive way. She transferred to a supposedly academically inferior school, but was able to find some academic success:

I wefina:
reflect ('cos that's what you do now in education), when I
went to ... college was really good because the majority
there were islanders and majority where you could see the
ones that would just hang out in the common room that
didn't go to class, I was actually, I don't know, but my mind
just changed. I just came from ... college and that's a good
school and everyone's gonna think I failed because I left ...
college and because it was mostly P.I. I was like "no way,
I'm not gonna”, so actually kind of went against the grain.

Collectively for most of the participants, transitioning from one education context to another was a major barrier to their academic achievement.

\section{Academic Failure}

The majority of the participants talked about their experience of being an academic failure in school. Their concept of failure was broad, not just referring to failing an individual subject or an assessment, but whether they succeeded or failed academically over the whole year. Most of the participants talked about how they had actually passed one, two, or even three subject for that year but this did not meet the criteria for passing set out by the New Zealand Qualifications Authority (NZQA) and, therefore, they believed they were failures.

Maneta: $\quad$ I actually put in a really good effort but, and I got three subjects, but according to the NZQA that's not enough - it was four and so they didn't appreciate the three and I didn't feel like I got appreciated for getting three subjects. And the funny thing was the subjects were English, Math and Science, so I got the three core ones but I failed economics and geography and...even though I got that three, it was “how many subjects did you get?” I didn't want to say I got three because I was ashamed because that's still a failure 
and I was like "oh nah you know”. I think, I think, I don't know if I lied, I said maybe "I got four".

June: $\quad$ I got a few subject but a few subjects isn't anything in the world of what the system is. Yeah awesome you got top marks in English or History but sorry about it but you didn't get the rest, aye? You know and I, that was my biggest thing.

June: $\quad$ I was good at English and I could write and I could do a sentence but, you know, English is not what you get judged on - it's your whole academic year, it's all the subjects so it was like...no one saw that.

Fetu: $\quad$ At school, I'd probably say I didn't do that well, you know I - back in those days it was school certificate, so I passed two subjects Maths and Biology. The rest I got 39 for Geo, I think 40 for Science, and I got 24 for English.

Moana: $\quad$ So Math's obviously I was failing. I ended up getting ah think I got a like a C - maybe a D even in math's. English I got a B, History I got a B, Religion, pfft, you know, I was getting good marks in all those subjects that weren't important, yeah.

The students' perceptions of failure is driven by how the school and how NZQA defined failure. Students identified that they had had some success at secondary school but that this was seen as insignificant by the school and NZQA.

\section{Helpful schooling experiences}

The participants also identified schooling experiences that were helpful to their tertiary study.

Tanielu: When I got to university, you know you obviously have your three four papers for that term. They were quite isolated in the sense that you could focus on each one, give it more attention, whereas, you know, at I think at secondary school you have five or six papers that you just... not really 
interested in, you know, you actually pick the papers that fit your schedule and the ones that you really wanna do, so I just think you probably more likely to do something that you're passionate about.

Fetu: $\quad \quad \quad \quad$ You know uni is a bit different from college, college you got no time during the day to do any study whereas at uni I did, you had time and I think that was the difference between college and uni you actually had the time.

Most of the participants reported that the tertiary study environment was not an easy system to navigate and that it was just as hard as secondary school.

Sefina: $\quad$ Lectures didn't suit me, the person up there talking and then me and I'm supposed to know everything from that one-off sitting, didn't work.

The way tertiary experience is structured benefitted some of the participants; however, the context was identified by most of the participants as academically difficult. This struggle is explored further under the section perseverance.

\section{Transferable extra-curricular activities}

Transferable extra-curricular activities (TECA) are those activities outside of the main curriculum that students participate in that have transferable skills that benefit individuals in other areas of their lives. Many of the participants recognised that TECA were instrumental to their success in education. Participants were able to use skills learned from their experiences outside of the education to assist them in their academic endeavours at tertiary. In this research the key TECA identified were sport and work experiences.

Sport

The participants were able to use some of the skills they learned from sport in their tertiary experiences.

Tanielu: $\quad$ When you get to a certain threshold of training you become used to it and then you just keep pushing and so, you know, once you just get to that point and I found with the MBA it 
was hard in the sense of that once you understand the workload and what needs to be done, then you just condition your body and your timing to get through it.

Sefina: I think a lot of it comes from sports, like it was, it's something that's mirrored, it's not the same, but there is that confidence if you can do sports and its training so lots of analogies along like that. So I kinda knew I wasn't giving it my all in the academic sense, so I kinda knew that, well, if you're not gonna give it your all, then you're not gonna do well. So I think that had that parallel with sports and, yeah, just not giving, like you know, you gotta go to class and I wasn't. And you need to do these things that would set you up and I wasn't, so clearly didn't give myself a chance, but I was confident that if the day [came] that I would give myself the chance, I would do it.

Maneta: $\quad$ I kind of just realised when I kinda failed up here, actually... I wasn't giving the effort that I needed to, and so by transferring that kind of skill from sport - that effort, the idea, that mind-set about effort, that mind-set about pushing yourself, persistence, and discipline - to school, it really made the big difference.

Fetu: $\quad$ I did martial arts...before I went to college, 81 till about 1983-4, so instilled the discipline in me so all these little things, I couldn't say I was the most disciplined... I started playing rugby when I was at college...that kind of helped me get through because at college I started kinda, like, being recognised for this and for that and I think I started getting like some, started achieving certain things.

The students acknowledged, then, that skills attained through sport were able to be transferred to their academic lives. 
Work

After failing school, many of the students built strong careers in the workforce and were able to transfer some of the skills acquired at work into their education experience.
Alapati:
I dropped out after the first semester, and then I got a really good job at IBM, and then I had a really good career there.
Sefina:
So left NZ when I was 24 so a lot of experience overseas, so going into London and just working my way up - you kind of got talking and kind of realised and like in London it's easy to climb the ladder as it were - as long as you work hard because there are people that are not so hard working but there are lots of jobs so that was cool.
Sefina:
I was on a secondment for three years, then we had a restructure. I went back into the Hutt into fraud, for six. I gave myself six weeks and then from six weeks I got a job in risk and assurance which is basically internal auditing, and then from there I just thought, I need to do something other than one paper a year, cos I want something behind my name.

The participants' experiences suggest that this ability to work their way up corporate ladders and make progress or gain success in another field enabled them to carry over some of those skills. For the participants many of those skills - such as commitment, hard work ethic, drive, and determination - enabled them to gain a level of success in education.

Alapati's experience in the work force also helped changed his impression of himself.

Alapati: $\quad H u m a n$ resources, yeah, sort of just built my way up there, and again I think it confirmed for me that even though I didn't have the actual quals, that I could make, you know, that I wasn't totally dumb, and I did really climb the career ladder there. 
As these examples show, the benefit from finding success in areas other than education was a major protective factor for the participants in their tertiary success.

\section{Life events that influence education pathway}

The participants identified both positive and negative life events after their secondary school experience that affected their education choices.

Positive life events

Many of the students discussed positive life events after they failed school that had an impact on their academic pathway. Alapati's experiences persuaded him he could be a successful student in education because he was able to compare his skill set in a safe environment to others that had graduated or were studying.

Alapati: $\quad$ I think a motivation for me to go back to study was that I went on this thing called a ship for world youth and you're with all these young people from all around the world and I think at that time I was 26 or 27, and then with all these young people from about 30 different countries, a lot of them were lawyers, doctors, doing their masters, finished their degrees and I had nothing. Anyway, you know, I went there and I did really well. I [was chosen over] a lot of them to like, you know, do a speech and a report for the U.N. even though they were all qualified and I wasn't at all.

Maneta's experiences in the sport he loved, rugby, indirectly influenced him back to education:

Maneta: $\quad$ I was talking to a 9 year that old I was coaching - one of the schools I was coaching at was an elite school so...they feed a lot of students into the Ivy League. They are one of the top primary colleges that feed into Ivy League in America and so they're amazing students - and I was just talking to one of the young boys and...what really changed for me was the amount of effort that he gave despite him being intelligent, so 'cos I thought the top 0.1 school, so this gave me an indication of my mind set cos I thought top 0.1 naturally 
talented, naturally gifted at academic - and then...he said "man I study a couple of hours before school and I have private tutoring after school. If I don't have rugby and sometimes after my private tutoring I would study until about 11 ”, and I was just thinking, “wow and I thought this guy was naturally bright”, but I realised, he did, he worked, he was training himself the way he was and he needed to be better so that changed my mind-set.

Sefina and Penina's positive experience was about being mothers. They realised that they needed to make something of themselves, as they would now be looking after two people. They wanted their lives to mean something more than what they were living. They wanted to be positive role models for their children.

Sefina: I figured the unfinished business of starting uni and not finishing, I had to finish it and I was - that I realised I wasted what, five years? It was great years in London, but I had my own time line which was her growing up and so I think, my thinking was start now and so I started when she was nine months because by the time she reaches three or five, I would have finished.

Penina: $\quad$ I got a wakeup call and found out I was gonna be pregnant well I was pregnant and I was gonna have a kid and I didn't wanna have a kid at all because I was too selfish and my life wasn't sorted and then my mum had the talk and was like “you know, I raised four of you kids by myself”. I was like "oh gosh" and then I kind of got suckered in and then I kept him - but then I was like sweet but now I need to, you know, I can't just think for myself and each day at a time anymore. I have to think of the future.

As these examples show positive life events gave the participants confidence in themselves, as well as giving them a new found purpose to want a better future. 
Negative life events

Many of the participants discussed negative life events after their secondary school experience as being the turning point which brought about positive changes in their thinking.

June: $\quad$ I was partying and, um well, when I got home he had already gone to the hospital, yeah, and so that was the, yeah, and then, cut a long story short, like he had cancer and he passed away - but that was the biggest trigger because I was like “man, you've mucked around but your dad would have been around when you were, he would have still been alive and seen you graduate had you have not mucked around”, so he would have been there to see me to walk across the stage within the three years it would have taken me, but I was too busy partying.

Tanielu: $\quad$ I went to see my guidance counsellor or my careers advisor and asked her "oh I'd like to get a look at some of my options for you know whether it be polytech"...I wasn't doing well in school and she basically said oh I didn't have the work ethic to go on to higher learning, yeah, and that was the trigger.

Moana: $\quad$ I saw my mate, and...what triggered me really to get out of where I was and to go back to school and to look at my life thorough-clearly was when she had a gun pointed to her head and then I was in a situation where I was on a break at work and I saw a guy get shot in front of me.

Fetu: $\quad I$ applied for a few jobs there, a manager's job and it was training manager's job. My bosses said to go for it and I should get it. Well, I didn't get it, and I thought "oh yeah". The same one came up again and I applied for it again and my manager said “man you should get it”. Well, I didn't get it; again the third time didn't get it, the fourth time I didn't 
get it and that's when I resigned. I resigned and I came to uni, blind as bat.

These harmful life events, then, actually spurred on positive long-term effects. Success in education did not come directly after such an event however; this was a catalyst of incremental steps towards success in university. These events triggered a process of self-evaluation, examination, and reflection.

\section{Reflective skills after events}

Reflection, according to Mezirow (1998), is the awareness of our thoughts, actions, habits, feelings, and experiences as well letting our mind amble over decisions or possible outcomes. The transitional period after a life event enabled the participants to reflect critically on their lives. They were able to see that their current way of living was no longer good enough, tolerable, or beneficial for them and others. This process of critical reflection allowed individuals to step back and think about why they were living a certain way and possibilities for themselves in the future.

Alapati: $\quad$ Then I realised, man, I think had an early mid-life crisis. And I was thinking to myself, "you're smart but you've actually got nothing behind you, you know, you've got no quals”, and I knew I was smart but I actually hadn't but I knew could be smarter, you know.

June: $\quad$ I was like, "Oh man I gotta get my A into G because I have spent so much time at uni just mucking around" and, um, you know, he was my biggest support and, yeah, that was the turning point really for me.

Tanielu: $\quad$ I actually was offended but I was also, I'm one of those guys if people sort of doubt me, you know, I always try to prove them wrong and so I just thought, "well sweet, I'll finish my degree and then I'll fax you my degree, a copy of my degree - which I did.

Sefina: I had baby, yeah, so actually coming back was the whole, like, clean slate, like reassessment, you know. 
Maneta: $\quad$ I started to look at my life, when I started making it in rugby. I started reading, like, human development stuff, selfdevelopment books, and they were all about working on yourself, making yourself that if you change your mind-set, you can change, you know, your world around you and all that kind of stuff and I started really reading into that and because I wanted to make it in sport. I needed to get that edge so I started to read all the stuff about self-help and personal development and that really blew up in terms of "man, what they say is that you can do anything right", so I was thinking, "man could I do it in education" and I think, I think when you read that kind of stuff and they get you to reflect on your life.

June: I was just, like, this pretend life that I am living is gonna catch up with me sooner or later and I'm either gonna be shot dead or I'm gonna be going home in a coffin to my parents and I need to - you know there's only so much that you can do as a person and as an individual when you wanna blame others, and for many years I blamed my father and my mother for not supporting me and [then] I thought, “this is actually my life and I can't be this 30-40 year old saying 'oh yeah I work at McDonalds', I've gotta own it”, so I went home. I came home. I knew that I wanted to get into an office, I knew that there was gonna be no shortcuts, that I needed to get back into education so I took that risk, I took that risk and I thought, you know, what I have to do and I can do it.

Penina: $\quad$ I started thinking wider, what I needed to do, and then I thought, "okay cool, what do I wanna change if I really wanna settle down with one thing and not jump from the others? What can I be good at? "And I thought, "well I've always been someone that taught stuff well and explained things pretty well, so I could teach" and then I looked 
around but I didn't know how you go about going to teaching. All I knew was that there's teaching colleges.

In Fetu's situation his reflection was related to his purpose to God, he reflected on his experience as being a sign of his faith:

Fetu: $\quad$ For me it was like, you know, Heavenly Father had said to me, I know cos he knows what I'm like, I'm a loyal person, when I'm, at a place I will stick to it until I've had enough even having had enough for me I still stayed, I'll still stay at a place regardless and I think Heavenly Father knew if I stayed at Te Papa ('cos I quite enjoyed working at Te Papa), had I stayed there, had I had got the job I wouldn't have left. So it was almost like Heavenly Father said, “Mate you're not meant to get this job on purpose”, cause my managers even said to me I should have got the job, you know, so I kind of started putting two and two together thinking to myself, "mate, this is probably the sign".

Reflection appeared to be an important ingredient in transformation and learning. All of the participants were able to reflect and question themselves about the way they had been living and their decisions thus far. Through self-assessment, the participants could put into place the actions that would enhance or turn around their life's trajectory.

\section{Support}

In this research, support is defined as the people and networks the participants could draw from in their outer worlds to assist them in their academic lives.

\section{Support related to teaching and learning}

Support related to teaching and learning includes the impacts and relationships students had with teachers and lecturers.

Harmful experiences with teachers

According to Rockoff (2004), teacher quality is vital to student achievement. Many of the participants talked about having a harmful experience with teachers at secondary school. If academic success is closely linked to teacher quality then it is assumed that 
the academic failure of the participants at secondary could relate to their experience with teachers. These experiences are as shown:

Alapati: $\quad$ So even at primary school I knew when teachers hated me or didn't ever care about me or weren't invested in me. So I had that, I knew that, like, intrinsically so that by the time I got to third form I sort of just knew if a teacher was interested in me or not.

June: $\quad$ But I don't think the teachers around me could see the academic ability that I had, yeah, so I wasn't the best student straight out. I had one teacher tell me that I would amount to nothing.

Moana: $\quad$ I didn't understand a lot of it and when I wanted to pursue going into forensic science etcetera, Math's and Science weren't my strong subjects so basically my teachers said, "Don't bother”, so I looked at accounting and, again, 'cos Math's wasn't strong my teachers said, “Don't bother”.

Penina: I I had no connection to any of the teachers. They pretty much used that deficit theorising, "Well if you're not here to learn I still get paid, you can stay here at school but it doesn't matter to me", and they were like, "I'm gonna use my energy on people who actually wanna learn”, so I was just like, "whatever", so thought I was wasting their time, they were wasting my time. I thought get out now because there's no point.

These interactions show not only neglect of the participants' abilities but also a lack of sincerity in forming reciprocal relationships. Alapati's experience shows that students actually know when a teacher is interested or not.

Affirmative experiences with teachers

The bulk of the participant's experience with teachers at secondary school was not helpful. However, not all teachers had a negative impact on the students at secondary school. Though there were few positive secondary school teachers, the students still 
could remember their impact in their lives during this hard time. Not only are the participants' perceptions of these teachers different, their attitude and their achievement in those teachers' classes were also positive:

Alapati: I chose those two subjects intentionally and English was one of those, and I think my teacher just really affirmed my stuff, you know, and she was just really cool and I think she was just kind of interested in me. I was kind of like a bit of an out there student and, like, I would never just wear the right uniform - I would always add a different tie and different blazer, and she was really cool; she was like, "Oh you look cool as today”, you know. Ha ha. It sounds really stupid. Anyway she just took a real interest in me, so that was one teacher and I ended up doing really well in English that year.

Moana: I started to just fall down, but my English teacher was the only one - she was same as my English and my history - so I got really good grades with her, but I really tried because I felt certain teachers believed in me. I gave them my all. I gave them more than what I would normally give other teachers.

Penina: $\quad$ I learned how to write in English because there was this one teacher who was really committed. She would come in on Saturdays, she would buy us McDonalds, and she actually believed we could do something, and I didn't think I could write, and then she was using all my work as like templates for everyone else, so I was like "cool”. You know, that was my first excellence I ever got in any of the classes.

The impact of the quality teachers on student achievement is evident in the excerpts above. Significantly, the qualities that the participants identified had nothing to do with the teacher's competency in their subjects. The quality that was expressed was relational in nature. The "good" teachers were identified by the participants as caring, hard- 
working for them, generous (sharing food with the participants), affirming of their identity as Pasifika, and believing in them.

The shift from secondary education to tertiary education

The participants identified that the support received from their lecturers was mainly positive. Many believed that their success at tertiary level study directly related to the support they got from influential lecturers and tutors at the time. Again, the qualities espoused as helpful for the participants were relationship-based and had little to do with the subject knowledge of the lecturer. This was evident in Alapati's experience; lecturers went beyond support.

Alapati: $\quad$ I mean, looking back now they were invested me and, you know, yeah, I think they had an allowance of grace and concessions for me when I wouldn't get my assignments in on time, especially, I can't necessarily remember, I mean I don't know if I ever got any assignment in on time. I definitely remember my last assignment for the masters I think, I got an A+ but, literally bro', I handed it in months late and I can't believe they accepted it, you know, but they did, and they were just real supportive. But I just know, had it not been for that relationship that I had with them that I should have definitely failed, but I really think they gave me a lot of support,

Moana's experience reflects persistent support that required her to get the information she needed but also the lecturers made sure she achieved.

Moana: $\quad$ The lecturers are obviously really, really open and we all know it's because they need you to pass, but the information that they give you is just invaluable because they physically want you to pass - and then, with certain lecturers, for me, personally, they wouldn't let me go until they saw that it clicked. 
June reported that she had a strong relationship with her lecturers and this meant that they were able to tell her the truth and be honest without June feeling like they did not care about her.

June: $\quad$ It was hard and, you know, even though I got my ass kicked in terms of not, you know, with my Master's and things like that, you know, they were still there, and it was all real talk, I was still getting real talk, still getting the hard words and things like that, but it was never, you know, you're gonna fail.

Overall teacher and lecturer support made a big difference to the academic achievement and resilience of the participants. When teachers/lecturers made an effort to form strong relationships with the participants, the participants were willing to work hard for those teachers/lecturers and this led to success. When teachers/lecturers were not interested in the participants this often influenced the participant to disengage from those classes. In addition, when teachers/lecturers viewed the participants as successful people first, this set the precedent of strong reciprocal relationships which clearly benefitted the students.

\section{Support related to family}

The foundation of Pasifika cultures is the family (Pulotu-Endemann, 2009). The family importance to Pasifika people means that their influence will have a huge bearing on Pasifika students' academic lives. The participants identified the family as being both affirmative and non-helpful in their schooling success.

\section{Affirmative support from Family}

In this study, many of the participants identified that their parents were very supportive in making them understand the importance of school. However, this was viewed by many of the participants as the full extent of their support:

June: $\quad$ My story didn't turn around for a very long time. You know, it didn't turn around even though my parents were supporting me, like, they knew education was important... they were there, but I guess they didn't really understand in terms of what I was doing. 
In Maneta's experience his dad was willing to support his dream. Due to that extra support from his father investing in his dream he was able to take the next step in that career. However his dad made sure he went back to back for education as well as playing rugby.

Maneta: $\quad$ I really wanted to get back into rugby, "Dad, can you make a call? I wanna go back to play rugby". I didn't wanna go back to Norths because so many of the talented rugby players were there, so my dad called my brother-in-law and he just said, "Would there be a spot for Maneta at this club, you know, he wants to go, he wants to join up”. They said, "Yes, he just needs to come over and play".

Maneta: $\quad$ My dad said I needed to do a course so I got into Whitireia and did a certificate in sports coaching.

Sefina spent many years working in London after dropping out of university. During this time, Sefina's mum went to university and graduated. Her mum's success at university encouraged Sefina to believe that she could be successful too:

Sefina: $\quad$ Once they realised that this was my own strategic decision, my mum, actually, because...when I was overseas, and without no help whatsoever, she came through and graduated in...early childhood, so that was kind of, "Okay, Mum can do it and I can do it”, you know.

Fetu's grandfather was an educated man but not schooled in the academic sense. The support Fetu described getting from his granddad was that he was wise. A conversation they had had continued to play back in Fetu's mind, manifesting itself many years later.

Fetu: Wouldn't say educated man in terms of university, not academia, but he was an educated man, a wise man - that's a better word - my grandfather was a wise man, you know, and my grandfather said to me ..."go and get an education first and things will come right"...and that kind of played in my mind, you know, it was one of those things like kinda "oh yeah, yeah, yeah". 
The participants' stories reflect that the support from the family remained fairly constant throughout their education journeys. Families believed school was important and also ensured their children went to school. However, many families, particularly the parents, did not have the education experience to help their children with more "hands on" support in terms of study.

\section{Non-helpful experiences with family}

Participants also identified non-helpful family experiences as being harmful to their academic aspirations. Alapati's family opened up a business that took a lot of his spare time and overshadowed his schooling, despite the parents promoting the importance of education.

Alapati: $\quad$ So although my parents really expressed, like, said education was a priority - looking back now they didn't, there was a lot of other things competing for the time.

Penina's experience of family support was impacted by inter-generational academic failure. Penina's family was the only one of all the participants' families that did not believe school was important. Her mother and sisters did not do well in college and promoted getting a job over academic achievement, so when Penina started failing school she followed what her family had done.

Penina: $\quad$ They talked about getting a job, so in my mind I was, like, I would just go work with my mum when I finished - like, that's what my sisters are doing and just get out now, go work with her and make money, and then I don't need school.

The examples above reflect the impact family obligations and commitment to family can hinder academic progress and achievement.

\section{Support related to peer group}

The participants' identified a major support and barrier to academic achieving was the influence of their peer group. The support and the need of that support was very different for many of the participants from secondary to their tertiary study. 
Peer group support at Secondary school

Some participants stated that "fitting in", or the need for social acceptance amongst their peers, was a key influence in their academic achievement. Some participants' need for social acceptance and to fit in was more important than academic achievement during secondary school. Alapati's driver was to find some cool friends and belong.

Alapati: $\quad$ Education definitely was not the key for me; it was more like trying to fit in and find some cool friends and to be perceived as cool, which is embarrassing now to admit - so that was the journey for me.

Penina would rather not go to school than to have no friends and this really impacted her attendance and in turn her academic results.

Penina: $\quad$ My friends changed then too, so I was kind of lonely and all my other friends didn't want to turn up, so I didn't wanna go to school because I'd rather stay home or be a loner on the courts or something. So that social acceptance, I think, was a huge thing and that...contributed to my attendance and ability.

Sefina tried hard not to achieve so that she would not be left out of her peer group. The school she attended was predominantly made up of Pakeha students and Pasifika students were a minority. This increased her need to belong and be accepted.

Sefina: $\quad$ I was always in the middle of the class, but I never really tried, like middle was okay for me, like, it was almost like I didn't want to excel because there were other islanders there as well and you kinda knew where they hung out and you may have thought that...you could do better, but you didn't want to. There was that kind of, I don't know, something there, so I was still tryna...not that it wasn't cool but didn't wanna overachieve in case that put me out and made me more Pakeha. 
Many of the students did well socially, meaning they were very popular and made a lot of friends. However, they were not doing well academically. June talked about have lots of friends as if this was equally as important as her studies.

June: $\quad$ I was popular, had lots of friends but I wasn't doing really well academically.

The importance of peer relationships across the participant's experiences at secondary indicates that social acceptance is an important component of schooling. For many of the participants, success in forming friendships overshadowed or took priority over their academic success.

\section{Tertiary Education}

In tertiary education, the need for social acceptance diminished and the need for making something out of their lives became participants' priority. Participants wanted to do something with their lives and this meant being successful in their academic pursuits. In addition, this meant the participants needed to find new groups of people with the same vision and goals. June's initial experience at university at first was similar to that of her experience at secondary school; she was popular but was not achieving academically. After June's dad passed away, she chose to focus on study and this meant finding a new group of people.

June: $\quad$ I didn't really start seeing that crowd anymore. A lot of them had dropped out of uni.

June: $\quad$ Yeah, and so hanging out with a different crew...it became about that, just became about that journey, like, you know, you can do this, you can graduate.

Tanielu acknowledged that he became really close with class mates at university and they became his peer group. However he also recognised that building strong social groups required getting to know one another outside of the classroom.

Tanielu: $\quad$ We had to have those times outside of the academia to kind of bond, so that we knew that, "oh man you got my back I got your back", and, you know, when times, when some of us 
couldn't sort of pull our weight, the others would pull it, you know, and so forth.

Penina's experience clearly shows a reverse in her need for social acceptance from secondary through to tertiary - she focused on her studies, and was not phased about loneliness or friendships.

Penina: I go to uni to study and then I leave. I don't care about making friends but the people I meet I'm, like, nice to, and then I make friends with them but I need them to succeed like I did at Uni. I don't care what they think of me.

It was evident that the role of the peer group could be either helpful or unhelpful. The students became acculturated in the ways of their peers. If their peer group disliked school and did not succeed then participants were highly likely to follow. However, when a group of peers shared the same vision, were focused on working together to achieve academic success, then results were more positive for everyone.

\section{Support related to academic services}

One difference between participants' experiences in secondary school and at tertiary level was the availability and use of academic services. Most of the participants did not mention any academic services that the students could utilise to help them achieve academically at secondary school, where as the participants talked about building strong relationships with academic mentors or learning support tutors in their tertiary education.

At first Sefina was hesitant to use the support services because of her fear that she was not good enough if she needed this type of support. However when Sefina finally used the support the impact on her academic grades was instantaneous.

Sefina: $\quad$ I used Erica Smith yeah. I didn't in the first slash second or maybe around the middle years, and got over the fear factor and being nervous that she would think I was really dumb then reading my stuff. So I actually used her and I wrote a bit of my assignment and just what she advised and handed it in and got an A- and I was like" wow". 
Penina and Maneta used the support service as a learning tool to improve academically.

Penina: $\quad$ He liked looked over my writing and it would take him more than that fifty-minute session to, like, work on it. He's like, like, really frustrated because he had to move stuff around and I was, like, okay. So then I would have to get there twice, so I'd have to do my work a week in advance. He would do it and then I had to book again to get it checked again and then enough of those sessions. I was, like, "Sweet, I got this down pat”.

Maneta: $\quad$ He was like, "Bro you gotta break up your study days like this man. You've got these, all these hours between your classes you gotta study”. So I was learning a lot.

Moana built a strong relationship with her academic mentor at student support.

Moana: $\quad$ So student services, so right on, so I had really, really good relationship with Julie Smith. She was a major support.

This increase in one-to-one academic support benefitted the participants' academic progress because they were willing to use it. Fetu explained that despite the availability of support services, it still requires the student to be motivated to use the support.

Fetu: $\quad$ Even though we might have the tool, like the support services here, if internally you cannot get yourself motivated to go and use it then it's pointless.

That support shown by the academic services also reflects a strong reciprocal relationship. The participant identified strong working relationships with their learning advisors and this connection helped their academic achievement and resilience. Fetu also identified that support is only effective if students are motivated to take advantage of the service. It is clear from their responses that many of the participants were highly motivated to do well in their academic work. 


\section{Leadership}

In this research the participants identified moments in their life where they were given responsibility to lead other people. They described this leadership experience as beneficial to their academic achievement.

\section{Situational leadership experiences}

Leadership in this context relates to the participants showing personal leadership attributes and being involved in situational leadership experiences. Kouzes and Pozner (2007) state that leadership can happen at any time and at any place, sometimes when you least expect it, but leaders rise up to the challenge. Many or the participants stated that during their lives they were put into leadership situations. At times, this was unexpected and not necessarily what the participants may have wanted. One of the key influences that many of the participants identified in their education journeys was being called into a leadership role in their family or education institution. Tanielu's experience identified that, being the oldest, he always felt responsible to lead his younger siblings, that this leadership inspired him to graduate.

Tanielu: $\quad$ But being the oldest, the eldest of my family, I'd always kind of a tendency...to just get that hustle, you know, like, I don't know whether that's being a first-born, you know, just a little bit more responsible, little bit more hungry to get that ...goal. But, yeah, we always try to find ways around, oh man I wanna get to that place, you know. I would've liked to have finished with a, you know, better mark but, you know, man C's get degrees, you know.

Moana was motivated to go back to education to secure her children's future. She wanted to make sure that she could give them the best and to put them in a position in life where they could be successful in the pursuit of their dreams. To ensure her children's success she needed to be successful herself.

Moana: $\quad$ My children are also part of my drive because they model what they see their parents do. Not gonna lie to you, the system out there in education and the environment, the social economies are getting harder every year and I dread to see 
my children, you know, kind of financially suffer the way that a lot of our Pacific Island people are.

Sefina also identified that she needed to be successful so that one day her daughter would look up to her and be proud.

Sefina: $\quad$ So I always had this thought that if there was a bring-yourparents-to-school day, Baby could take me and I could tell them what I did and it would be something that she would be proud of, you know.

Maneta's experience of situational leadership was when a lecturer asked him to become a tutor in his final year of undergraduate study. Throughout the whole process Maneta was nervous as he would be tutoring some class mates from other papers but this leadership experience drove him forward academically.

Maneta: Don't think, like, you have to know everything because the collective intelligence of the room will know more than you anyway, and some of those students will know different things a little bit better than you, so it's about facilitating their learning. And that just really grew me. I started to see myself as an academic. When I felt like a tutor, I felt like, “Wow, I'm a teacher".

At the same time Alapati was contemplating going to university for his second attempt he was chosen as one of New Zealand top 100 leaders for his community work. His life experience thus far and this national recognition of his leadership solidified his decision to come back to tertiary study.

Alapati: $\quad$ I just realised that you could actually go into a postgraduate qualification if there was $R P L$, you know. And anyway at that stage, at that same time ,I'd been chosen as one of, top 100...emerging leaders in New Zealand [with] Michael Jones, Bernice Mene, and others. 
Being a leader was not necessarily something these participants naturally gravitated to; however, the leadership experiences affected their decisions to come back to education and also drove them to be successful.

\section{Internal factors}

The internal factors are an individual's unique inner world such as biological, psychological, and spiritual that is influenced and influences their outer worlds (Harms, 2005). When the participant experiences something in their outer world there is an internalisation of that event in the inner world. The participants identified five internal factors that influenced their academic success and achievements. These are emotional and motivational aspects influencing learning, self-concept, self-belief, confidence, and perseverance.

\section{Emotional and motivational aspects influencing learning}

Many of the participants identified how the emotional and motivational aspects of their learning influenced their academic success and failure. The researcher has chosen to put motivation under emotion, as he sees motivation as an emotional response.

\section{Relevance and passion}

Studies have shown that as students move from junior/intermediate school to high/ secondary school, motivations and academic interest wanes as they go through adolescence (William \& Stockdale, 2004). Many of the participants talked about relevance and interest as being big motivators for learning. Alapati talked about not being interested in secondary school.

Alapati: $\quad$ I actually realise I wasn't that interested in high school.

Fetu also talked about his disinterest in secondary school.

Fetu: I probably wasn't that interested, you know, to be honest, other than I was at school to be at school but I probably enjoyed school social life more than I did the academic life.

Tanielu talked about his subjects at secondary school not being stimulating enough. His lack of interest meant he did not do well and gave up on those subjects as soon as he could. 
Tanielu: $\quad$ I struggled with math's man, yeah, and I'm not too sure, I think it might have been a combination of me just not enjoying math's but also the teacher at the time wasn't, maybe he was an old-school guy and really didn't stimulate, you know, my interest for math's so I took it right up until fifth form. Then I stopped.

Maneta got one of his best marks at secondary school when he invented a text about rugby.

Maneta: $\quad$ The funny thing was I actually for my English exam I got my best mark, I got, think I got B, but I forged the book that I read. I made it about rugby, yeah, and I wrote about that and I got a better mark.

However, at university Alapati and Tanielu had a real interest in what they were learning as they felt it was relevant to their work.

Alapati: $\quad$ For the first time in my life I'm actually reading about stuff that appeals to me, relevant to me, and I was, like, oh there is a word for that, you know what I mean? So there's, like, people, other people have written about this and I started see myself in the writing and I started to just develop a more critical mind and just to expand that, and that was really cool.

Tanielu: $\quad$ After working for five years I was also seeing how some management people manage really badly and some managers are good. There are some boards that manage really well and others not so well, governance wise. I just thought, "man, I could do a better job”, and so everything that we did study in the MBA was all applicable to life whether it be church, schools, or whether it be whatever. I just found, oh man, whether it's marketing, or accounting, or negotiating, or human resource management - all of those things. 
Maneta during university still did not have a positive experience with the word education. When asked by his friend to study "education" he did not want to do it, however she showed him the range of different assessments they used in some papers and this sparked his interest to change his major and be successful.

Maneta: $\quad$ I was like, "oh, Pftt, whatever. I hate education.” But then she was talking to me when I was in $14 \mathrm{KP}$, she was showing us that actually we make education better. She showed me the models that they do and think about, thinking about education like that, and I thought, “fuck, that's actually really cool, you get to create, you get to draw”.

During their secondary school experiences the participants failed to see the relevance or be passionate about what they were learning causing them to lose interest in study and fall away from learning. At tertiary level, they were able to focus on subjects that were relevant and they were passionate about. The students were interested and invested in the subjects they were learning, and therefore were able to finish those courses and thus their degrees

\section{Contributing motivational factors}

What drives students to take advantage of their education opportunities? The researcher believes that motivation is the symbiotic relationship between what happens to us and what happens on the inside of us that stimulates energy and desire to either to do something or not do something. However, motivation is a complex phenomenon and therefore lacks any real overarching definition. According to Wigfield and Eccles (2002), academic motivation is more easily defined by what an academically motivated student looks like rather than what academic motivation actually is.

June, already motivated by the loss of her father, was also motivated by not wanting to conform to the statistical representation of Pasifika in education as being underachievers.

June: It wasn't instilling that fear in you, but it was like, “man get your A into $G$, like if you really want this, and don't become a statistic”. 
Academic motivation was very high straight out of secondary school for Tanielu. He had already told himself he was going to send his degree to the careers advisor who doubted him, but also he wanted to go against the grain from what many Pasifika were doing at university.

Tanielu: $\quad$ A lot of the guys that I was going school with they just, you know, loved the fact they were at university, and you could be cool, you know. I just went, "oh man I'm here to focus and try to keep forward".

Sefina talked about her child being the big driver for her coming back to university, but also realised she could no longer play her chosen sport.

Sefina: In my head I was thinking, "Well sports is finished now"...this became my priority. I think, you know, there was no sports now, you know, time has run out. I've got a kid now, what is your next thing so the priority and application was $100 \%$.

Academic motivation for Moana was already high from her wanting a better future for her children. Additionally she had her own personal drive to not settle for less than she could be and keep going and growing in her academic studies.

Moana: I I think to be honest with you though, there was, there is, there was a personal drive in me to be, to not settle for where I am. So even though I've got my postgraduate I can honestly say that in a couple of years' time I'm moving to go into my master's.

This personal drive was also mimicked by Maneta and Penina. Maneta was motivated to work as hard as he could, while Penina did not want to settle for average marks.

Maneta: $\quad I$ was learning a lot and then I was so into it that I ...started recording all of my lectures, especially the hard ones, and I would just stay up. I would be, after training I would be just staying up here just working and, yeah, I really got into it. 
Penina: $\quad$ My friend was like, “don't be freaked out if you get a really bad grade for your first one because C's get degrees." I was like "okay, that's very, you know, empowering”, and then I got a B- and I got really, really upset.

Fetu's motivation or drive came from his commitment to his faith.

Fetu: $\quad$ I think there was a drive in me which I probably can't explain other than I know it's probably for divine drive, you know, that actually kept me going.

The examples above identify that what motivated the participants varied, however what all examples reflected when the motivation level of the participants was high they were only willing to accept academic success and would do whatever it took to attain it.

\section{Self-concept}

Hamachek (1995) describes the self-concept as an individual's feelings about themselves. The self-concept is constantly being reinforced by the results individuals get in life as well as the external worlds they are part of. Many of the participants at different times of their schooling experiences had different feelings about themselves. At secondary school the participants mostly had negative self-concepts, and at tertiary they started to see themselves more in a positive light. These differences in self-concept correspond with the difference in academic success and achievement.

\section{Negative self-concept}

The participants developed negative self-concepts in education due to not doing well in school and other external factors. Many of the participants identified secondary school as the time these negative self-concepts formed.

\section{Negative labels for self}

Negative self-concept often led to negative labels/identities of themselves that did not align with being an academic achiever. Alapati saw himself as a lazy person and this influenced his attendance and his achievement 
Alapati: $\quad$ I was always aware of my limitations, and I knew I was a lazy guy too, so I was really lazy, like I wagged school heaps, had the worst attendance at every school.

June was always popular with her friends because she was the funny girl. However, this obviously did not mean academic achiever as well.

June: $\quad$ I was portraying the funny girl, not the one that was, "Yeah I'm gonna sit down with my school books because me and my school books are best friends".

Maneta's failure to pick up the learning in college led him to self-conceptualise that he was not intelligent.

Maneta: $\quad$ I was behind in terms of some of the academic rigour which led me to kind of self-conceptualise that I was actually not intelligent, and I think that's the biggest thing.

Seeing himself as unintelligent Maneta adopted other self-concepts as a way to cope in school.

Maneta: $\quad$ So, if I was the man, if I was cool, that was just as important as school.

Fetu labelled himself as “dumb”, believing that his grades at secondary school reflected his intelligence and his ability to go to university.

Fetu: $\quad$ I always had that kind of thinking that I was too dumb to go to university.

Many of the labels the participants gave themselves reflect their lack of academic success and the way they saw themselves as students.

\section{False Identity}

In this research, some of the participants identified times when they would present to the world a false identity. This meant the way the participants were portraying themselves did not reflect how they felt on the inside. Maneta and June portrayed being very confident as a way of avoiding or overshadowing other issues. 
June:

My biggest thing, like, yeah, I was happy, I was still confident, but definitely, deep down inside there was a disconnect.

Maneta: $\quad I$ was trying to be confident in other things that would overshadow that lack of academic skill.

Moana knew deep down that she was pretending, living a life that she didn't want and was getting her into trouble.

Moana: $\quad$ I was just like, "This pretend life that I am living is gonna catch up with me sooner or later and I'm either gonna be shot dead or I'm gonna be going home in a coffin to my parents”.

Alapati, did not want to reveal that, in his first attempt at university, he snuck in the back door by taking Māori papers.

Alapati: $\quad$ I was flipping imposter to the days, like, I didn't want to tell anyone that I was doing the Māori courses.

The examples reflect how important it was to stay congruent with their self-concepts. That despite how they were feeling if it was part of their self-concept they did everything to maintain that negative self-concept of themselves.

\section{Effective self-concept}

Effective self-concepts were formed from gaining success academically at school, and other factors affecting the participants. During their tertiary education experience many of them formed strong self-concepts. These effective self-concepts were not all developed at tertiary, however; some participants felt they had implicit competence in their ability at secondary school.

\section{Competence}

While the participants mostly developed strong negative self-concepts at secondary school, many also had believed that, despite their academic results reflecting otherwise, they had an implicit competence, not just in schoolwork but also in other areas. This tiny bit of hope remained in some of the participants. 
Alapati: $\quad$ When I did go to high school, I was always a bit of a reader and I always knew...that I was a bit of a go-getter and so I always knew I was smart.

June: $\quad$ I knew I was clever but I didn't know if my teachers knew I was clever, so I don't know if you get that, but it's just, you know, I was quite happy to go through school.

Sefina: $\quad$ I always knew that I could have done better if I tried.

Moana: I knew at a very young age there was ambition and drive, everything. I wanted to pursue my passions. What I believed I was very good at got squashed because everything was about being educated.

When Tanielu started at university straight after failing secondary school he still felt that he had the ability to do it.

Tanielu: $\quad Y o u$ know mine was always wasn't like arrogant belief. I always just felt there's a little hope that I can try and get through, but there was always times when I doubt, oh shucks I can't get through this.

Despite failing in education the students still felt as though they had strengths in other areas.

Positive labels of self

Some of the participants used positive labels to describe themselves. As these participants gained momentum in their education their self-concepts and the labels they gave themselves evolved as well. Alapati saw himself as a keen learner and his actions reflected his feelings about himself at university.

Alapati: $\quad$ [I]bummed all the way through school but then just became a real ardent learner, and I just thought I am going to read and read and read. 
During Penina's undergraduate study, she was balancing a part-time job, study, sports training, and being a mum. Penina and her family now label her as someone that can take on any challenge.

Penina: $\quad$ They call me superwomen.

After working really hard for his undergraduate degree, when Maneta was told that he would only have to do four papers to get his honours degree he felt unstoppable.

Maneta: $\quad$ They said, "You only have to four papers". I was like, "This is easy". I was just so academically now just a different monster, a beast like that this is easy.

The findings above reflect that as the participants experienced change and success the labels they give themselves reflected their achievement.

\section{Self-belief}

Self-efficacy is often used interchangeably with self-belief. Bandura (1994) defines selfefficacy as "people's beliefs about their capabilities to produce designated levels of performance that exercise influence over events that affect their lives’' (p. 71). In this study self-belief was identified by the researcher in three categories: harmful beliefs about self, and fixed ability beliefs, and affirmative beliefs about self.

\section{Harmful beliefs of self}

Harmful self-belief refers to the participant's beliefs that impacted negatively on their education journeys and pathways. In her secondary schooling June did not believe she was any good academically. After failing consistently in some of her papers she believed her presence at school was wasting the teacher's time and her time, never believing she could pass.

June: $\quad$ I think I'm just wasting their time, like why do I ask questions and I'm not gonna do my homework and, you know, 'cos it's a waste of time 'cos I probably won't pass it anyway. 
June, even in her undergrad studies, still held some harmful beliefs about herself and her ability. Even though she eventually tutored papers, she was apprehensive because she did not think she was the right person for the job.

June: $\quad$ And then I got the tutoring stuff and I cracked up 'cos, like, man, why am I tutoring for? Like I'm the worst choice.

Sefina mentioned that when she tried university for the first time she had a lot of selfdoubt about her ability. This led to her eventually dropping university and going to work.

Sefina: $\quad$ I went as far as, like, writing a plan for an assignment. I'm gonna do this, but I didn't take it further, because a lot of doubt.

When Moana struggled to succeed academically at secondary school her beliefs about herself became negative. These beliefs broke her spirit and she believed that she was destined to be nothing and just another "negative Pasifika statistic".

Moana: I started to believe the inner voices that were like, you know, you're gonna be nothing but a retailer; your gonna be another statistic, or Māori and Pacific Islanders are gonna be good at cleaning - all that stuff. And I think I just allowed myself to be degraded and then... a lot of negativity just was confirmed really.

Moana: $\quad$ I started going to, self-hatred, you know, started feeling like "you're worthless and you know there's nothing that can pick you up”.

Maneta felt held back by his belief about himself at secondary school. He believed that he could not learn and his actions reflected this.

Maneta: When you start to feel like you can't learn, no matter how hard you try, when you have that belief, that will hold you back no matter what. 
Maneta: Unconsciously I was thinking, "Yeah I'm no good at this", but...I don't think I was consciously thinking. My actions were showing that I didn't believe in myself.

Fetu believed that ethnicity had an impact on his beliefs going to university.

Fetu: $\quad$ I always thought that university...was a level above me and there was no way that I could...go to uni 'cos I thought it was just going to be for brainy white kids you know.

After doing well in her fifth form (Year 11) Penina did not do so well in her sixth form year, leading her to believe she was not good enough for school and that she would follow her family's example.

Penina: $\quad$ Maybe I'm not cut for it, like I'm not as good as I thought and this sixth form was just a whole different level so I just went from being "YAY!" to "I suck and I'm not gonna make it. I'm just gonna be like my sisters", so no one in my family...passed sixth form.

The findings above reflect that negative belief and failure are closely connected. When they experienced failure, it shaped their whole belief system and this led to more academic underachievement. In addition, when the participants that were successful failed they had very limited resilience.

\section{Fixed ability belief}

This term represents the beliefs the participants had about themselves as been fixed, meaning there is no room for growth in that area. After experiencing failure a lot of the students believed that being successful in school was something you either "had"/were born with or not. The participants believed their abilities were fixed and could not improve.

Maneta: $\quad$ Because it doesn't matter how much effort you give, if you think you can't learn, if you think you're not intelligent, I think that belief will always block you from doing, taking the right actions. 
After failing school June jumped into a private training organisation course. Her belief about her ability to learn new or hard subjects was fixed meaning she would never grasp it. This caused her to question whether she should stay on the programme.

June: I'm always a trier, it's like, "nah got to stay gotta stay", but then it's like, "Well you're no good at these subjects but you're still gonna waste time and money".

Moana felt at secondary school that learning was a "natural” part of successful students and would never be a part of her.

Moana: $\quad$ The peer pressure you're up against - these A students you're up against these people who it just comes naturally to them.

Fetu believed that certain subjects were beyond his comprehension and that he would never grasp them.

Fetu: $\quad$ English...was kinda...above my comprehension, you know, so I found it quite difficult, you know, to understand that kind of stuff.

The examples above show that many of participants' believed the education ability was fixed. Once they experienced failure and identified themselves as a failure there was no way they could ever be successful.

\section{Affirmative beliefs of self}

Affirmative self-belief refers to the participant's beliefs that lead to positive outcomes in their academic lives.

Maneta's experience reflects his inner growth as a person and as a student after graduating with first class honours and finishing his master’s degree.

Maneta: I I think about me now, and what I know [is]...there isn't anything I can't do academically. 
Even though Tanielu was failing in secondary school he believed in himself and that none of this failure would matter once he got to university.

Tanielu:
I just knew, I could get a handle of it if I really apply myself.
or I'm gonna work” you know.
I always remember me and my friend were in the same
situation and, you know, the last few weeks of our seventh
form year, we were talking about university 'cos I don't
think he had bursary either, but he kinda just said "Man, it's
not how you get there, you know it's...getting there that
counts”.

After losing her father June felt that she had to redeem herself. After focusing on her schoolwork she started to succeed and this influenced her belief about her ability.

June: $\quad$ I had to redeem myself because my dad gone. I had to kind of redeem myself and, yeah, so my thinking was, "Shucks I can do this", so, you know, the momentum was starting to build.

When Sefina came back to university the second time she believed she could do it and constantly had to remind herself.

Sefina: $\quad$ I would just, I don't know, in the back of my head was like, "You can do it you can do it, just keep reading".

Moana believed she took a risk coming back to education after leaving school following the sixth form, but believed she had to make something of herself and that she could do it.

Sefina: I took that risk and I thought, you know, what I have to do and I can do it....So I enrolled at Whitireia back in 2000. My good friend took me and I started to do my business and administration and computing certificate.

Growth ability belief represents the affirmative belief the participants have about being able to grow or progress academically. Tanielu realised that his belief in natural talent 
affected his rugby and music. He now believed that natural talent is only a small piece of the puzzle to success in anything.

Tanielu: $\quad$ The same as my rugby, I just wanted to let my natural talent try and take it all the way, realised now that natural talent even in music is only ten percent, you know.

The findings above show when the participants started believing in themselves they were more resilient. The participants' new found belief in themselves helped them to stay positive in pursuit of their objective.

\section{Confidence}

Confidence in this context is an "action" orientated attitude. In this study, confidence is perceived as a contingency of self-belief. Participants identified that when they believed in their ability academically this affected their self-confidence to take the right actions. Many of the participants illustrated that their academic success in tertiary education influenced their individual confidence. It provided them with an energy towards their academic work; some got their best ever grades, and many were able to overcome some previous fears about education. In his first few weeks at university, Alapati really battled with his study but he kept persisting until he got it. When he got his first A grade it really increased his confidence and excitement about his learning and influenced him to earn top marks.

Alapati: $\quad$ When Wally handed me my assignment I was just smiling from ear to ear. I was like man if we had Facebook back then, I'd be like "Everybody gotta know this". I remember walking up the hill in Stokes Valley beaming from ear to ear. I remember coming into the kitchen. My sister was there and I told her and she just started laughing 'cos, you know, I think at the time I was age 27...and she was like, "You've never had an A in your life"....I was really excited and I think that just really built up a lot of confidence and then that year I think I was like A's, A's, A's, the whole year and I had never had that before and I was just really excited, you know. 
When Fetu got his first B grade ever, it was in his first paper at university. This really "boosted" his excitement and energy for study.

Fetu: $\quad$ My first assignment I got a B - you know, I never got past a C...at college cos I don't know whether, I don't even remember my grades back in school other than I know got 52, 53. But later on...when you look back, in those days in the school certificate when it says 52, 53 it then kind of has the grade beside it and it's a $C$, so I only knew of C's, so when I got a B, mate I was like buzzing. Mate I was going, "Whoa, B at university!" So, you know, those little seeds again...gave me a bit of boost.

With her confidence up, June was able to overcome her fear of talking to lecturers to seek their support and this confidence adapted her thinking about giving her best effort towards her study.

June: $\quad$ I guess not being scared of my lecturers anymore, like starting to ask for help. Or I guess it's a shift when I was like, "Man I gotta participate as opposed to just surviving and being in class”.

Moana came back to education through polytechnic. She was able to build her confidence at certificate level study. Her success in this course showed her she could be successful in academia giving her momentum to do more study. She also felt confident about her future in the job market from the security of having qualifications.

Moana: $\quad$ I'm very confident now, yeah. So I've never passed anything you see...so going from a certificate at Whitireia to, you know, when you start passing a little bit...you know it's going to get recognised and, you know, that it's kind of like a weight behind you, and you can actually go to an employer [and say] "Actually, I've got this and that". When you start passing it builds your confidence even more to think, "Well, actually, I can go further and keep going and keep going”, so yeah, my confidence is way up there. 
Maneta remembers receiving some feedback about one of his assignments that really increased his confidence.

$$
\begin{aligned}
& \text { Maneta: } \quad \text { I remember getting an assignment back from Joanna and I } \\
& \text { did it on gangs, and she was like, "Your ideas and thoughts } \\
& \text { were at the postgraduate level...but your writing still needs } \\
& \text { work. You know, if your writing was better, man, this essay } \\
& \text { would be awesome”, but I remember thinking that, "Far out! } \\
& \text { Postgraduate level! ” }
\end{aligned}
$$

Penina is so confident in herself and ability that plans to attempt a doctorate after she completes her honours degree in Education.

Penina: $\quad$ I reckon I can do a PHD for sure. Yeah, I'm getting a scholarship for next year without even having, I just know it!

The students acknowledged, then, that when they are confident their self-belief about their potential and ability is also strong. In addition, when the students experienced academic success this also increased their confidence.

\section{Perseverance}

Perseverance is an action-orientated attitude. It is an individual's ability to take positive actions despite obstacles, difficulties, delays in achieving a desired outcome. Johnson and Sessions (2014) argued that many students miss out on academic success because they do not endure the difficulties long enough to be rewarded. When things get hard in pursuit of individuals goals or dreams students give up or avoid it. Perseverance requires a good work ethic and maintaining that despite hardship. The participants' stories reflect a lot of perseverance and determination towards a new direction in their lives. Perseverance has been defined as persistence towards goals, time management towards goals, and goal setting.

\section{Persistence towards goals}

Persistence towards a goal is a key factor in a students' overall perseverance. Persistence parallels perseverance as it describes a person's ability to stay on course despite factors impacting their goals. However, the researcher views persistence more as an individual's ability to overcome the daily challenges needed to attain the main goal at 
the end. This would be a student's ability to persist with an assignment, a paper, or a course. Alapati talked about his persistence to making sure he was successful. In addition, he made a decision that he was not going to turn back and he was willing to do whatever it takes to succeed.

Alapati: $\quad$ I'm here and I'm not going to flippen turn back now.

Alapati: $\quad$ Honestly one thing, I just really worked hard. Like there would be nights where I would be in the postgrad student lab and I would work from after work like 5 o clock the night before and I wouldn't go home until the 6 o clock bus the next morning, you know, I was just committed and I would do that several times and then I would sleep on the bus on the way out to Stokes Valley, go home, have a little bit of a moe, and wake up for my next class. So I was, I'd never worked harder in my life, you know.

Alapati: $\quad$ I always knew there was going to be a bit of effort but I didn't realise how much effort, you know, and actually realised then $I$ just need to, there is so much to learn here and I remember just nights I'd be like, "I've got give up. You're so useless, you don't understand." I remember literally just wrestling with the stuff, remember doing the readings, I'm like, I don't know. I'd read again and again and again and again anyway.

June identified that it was hard work and being persistent through the hard times that made the difference for her. She was also able to reframe what failure meant to her in this process.

June: $\quad$ I didn't do really well, you know, I wasn't good at this, but, yeah, this is where I'm at today and, you know, it's hard work. It's hard work you know, and I guess that's what I would tell them - that it's a lot of hard work but, you know, the failures really help with life. It's just sometime you can't see past the failures 
Maneta explains that persistence also made a difference to him.

Maneta: $\quad$ That mind-set about pushing yourself, persistence and discipline to school, it really made the big difference. It was hard; there were times where I was falling asleep in the library. There were times where I didn't wanna do it, but I knew that it was worth it.

Sefina and Penina identified that challenges - obstacles, difficulties, and hard times are part of the journey in academic life and should be expected.

Sefina: $\quad \quad \quad \quad Y o u$ know, when you come to uni you might have something that will knock you off or that challenges you, but you get up and do it again, or you communicate with the lecturer to give you another chance...I think that's why extensions are there, so you're still in...it's not that gonna be on a high....there will be ups and downs and just recognising that is it. But it's not like a down that you're out, it's just a lull, but you'll carry through.

Penina: $\quad$ When you feel the world is throwing everything at you to say you can't do this, like whenever any big hurdle comes your way, instead of crumbling and thinking that you can't do it, think. Remember what your purpose is, why you're doing it.....That talk gives you that wakeup call "I can do this, this is why I'm doing"...like every hurdle, 'cos there are heaps, a lot, and they all come at the wrong time and you think it's almost unfair that you could be given that.

The learning did not come easy for Moana but she persisted and developed new strategies to ensure success.

Moana: $\quad$ I am not a natural academic. My hours that I had to put in, was just trying to understand what it was all about so, you know, sitting in a class I would record the lecture, then I would come home and listen to what it was about. 
Fetu's drive kept him going and a lot of this drive came through a build-up of multiple factors from his secondary school experience.

Fetu: $\quad$ Kind of persevered. I had setbacks. I failed a couple of papers, late nights, all that kind of stuff. But I think that drove me and I think that drive didn't just come just then; it's been a build-up of from when, you know, I left college.

Collectively for the participants their tertiary experience was challenging however, they did not let this be a barrier to their academic success. They persisted in the face of many obstacles and challenges.

\section{Time management towards goals}

Some of the participants stated that managing their time and priorities was an underlying factor in their perseverance towards goal achievement. Many of them came from no structure to their study or no planning around their academic work at secondary school. Once at tertiary the participants realised that time management was crucial and they had to make study a priority in their lives. Tanielu talked about how prioritising his time into what is important and what is not important was key to his academic success.

Tanielu: $\quad$ It's another thing to know that three years is a long run, eh? It's not a sprint and so I think one of the key things for young people to understand is the whole principal around prioritising, and, you know, they need to know that there are things that are important and there are things that are more important than those things - like your assignments due on time.

Alapati talked about making the most of his time at university for longer-term better outcomes.

Alapati: $\quad$ Don't waste your time here. You know what I mean? Don't just go through the motions, man. Don't be another statistic, you know, don't just build up those student loans and nothing else...make good use of your time. 
Moana and Sefina talked about maximising every hour despite heavy family commitments, every hour that was spare had to be prioritised and used for school work

Moana:
half an hour with my husband every night. I did this for a
whole year, so from 7.30 to 9.30 or 10 I would study. If there
was an assignment due or an exam I would be up at 4
o'clock in the morning and I'd be studying to memorise
everything. Weekends my husband would take the kids out
and give me four hours during the day, then we would do
family stuff, and then again 7.30 till 9.30 or 10 at night.
Once my exam was finished he would send me to bed,
because I'd be falling asleep on the couch.
Like I would do 9-3 despite the fact that I didn't have a
class, and the crèche were really awesome as well so, and I
think everything tied in, like, I had to pass for her to go to
crèche... I would use up the time because I knew I wanted to
be available to Baby when I got home, so every hour was
spent.

In secondary school, June never understood the importance of time management. They gave her a diary but that was it. She explained how at university they explained exactly how many hours you had to study for each paper. This gave her a target to try to meet.

$$
\begin{aligned}
& \text { June: } \quad \text { Time management is a big thing, like, we don't get. I mean } \\
& \text { they give you a diary and they're like "put in your classes" } \\
& \text { but, you know, like, at uni you get hand out and it's like this } \\
& \text { is how much time you should study, but you don't get that in } \\
& \text { college. Like I never got, you know, one hour of English } \\
& \text { class equates to three hours of study. I didn't get you know } \\
& \text { that - it's not, I guess, not broken down to the point. }
\end{aligned}
$$

Penina commented that students do not know the true meaning of hard work. She explained that she must balance multiple commitments every day without sulking about 
it. Through good time management, Penina is able to do everything she wants to do as well as being a successful student.

$$
\begin{aligned}
& \text { Penina: } \\
& \text { when they hear what I have to do, they're like "oKAY!' cos I } \\
& \text { train as well at night and I'm, like, shattered. So I've got my } \\
& \text { boy full-time and so in the morning... I'd drop him off at } \\
& \text { school, I'd go to work, I go to uni, then I either do my other } \\
& \text { job or then I'll come back home, pick him up by three every } \\
& \text { single day - it sucks because he got kicked out of childcare - } \\
& \text { and then do mummy duties and what not, homework, cook, } \\
& \text { clean, and then go to training and then go for my run, come } \\
& \text { back and put him to bed and study - every day! }
\end{aligned}
$$

Time management and getting structure in their study enabled the participants to withstand the eventual difficulties and obstacles that come with study. The participants had to be better prepared and make study a priority in their lives to ensure their academic success.

\section{Goal setting}

A major impact on some participants' perseverance was goal setting. Goals enabled the participants to "future think" and set themselves targets to aim for. For example, Tanielu felt that getting through a semester was tough, but once he set little goals for himself that he could visually tick off, this propelled him to keep going. Sefina was so driven by her desire to make her daughter proud that she wrote that on her desk and looked at it every day. Moana knew what she wanted to once she came back to education and she set it as her goal and made a plan to make it happen, without knowing she would succeed or without any previous success. Alapati stated that having a vision and a goal is one of the most important steps you can't take to ensure your academic success.

Tanielu: [I] just can't really stress enough about goal setting as well. You know just, man, I wanna get through this semester, how many more papers have I got left? You know, ticking them off. 
Sefina: $\quad \quad Y e a h$, I had that written right on my desk, there, so I can always read it and I'm like "oh, okay".

Moana: $\quad$ So I had my goal in sight of what I wanted to do or be - a case manager - and I just mapped out a plan of how to get there.

Alapati: $\quad$ Honestly, have a vision and a goal, eh!

It is clear from the participants' comments the importance of goal setting in their academic achievement. Clearly, their goals were a source of motivation for them to keep going in their academic pursuit. The eventual hardship they faced, was overcome by having a clear vision or expectation of goal achievement, this helped them to persevere.

\section{Summary}

The aim of this chapter is to illustrate the key findings from the research. The overarching theme that emerges is resilience, particularly academic resilience. Research suggests that resilience is the presence of protective factors, risk factors, and an eventual positive outcome. Though the theoretical framework is strengths-based and the focus is on what works rather than what does not, the researchers understand the importance of acknowledging some of the risk factors as well. The stories of resilience are to be understood under two key categories, the external factors and the internal factors. The external factors are those factors influencing resilience from the outside: the impact of the schooling experience, transferable extracurricular activities, life events, support networks, and leadership experiences. The internal factors influencing resilience are emotional and motivational aspects of learning, self-concept, self-belief, confidence, and perseverance. This deconstructed view of the research is to assist with understanding the phenomena in more depth. However, in reality our inner and outer worlds are interrelated and interconnected and one cannot change without influencing the other. 


\section{CHAPTER 5:}

\section{Discussion}

\section{Introduction}

The focus of the research was to explore and appreciate that the factors that facilitated postgraduate students' academic success after experiencing academic failure in their secondary school education. In addition, it is anticipated that the process of appreciative inquiry into these stories will enable the key findings to progress educational growth for Pasifika people. The overarching theme identified in the research is resiliency. These participants were found to be resilient insofar as they did not let their academic failure at secondary school hold them back in their pursuit of further education goals.

Several factors related to the development of academic resilience and what this means for future students and educators of Pasifika were identified. These factors fell into two general categories: external factors and internal factors. The external factors were further categorised into five dimensions - schooling experiences, transferable extracurricular activities, life events, support, and leadership. The internal factors were also categorised into five dimensions, identified as emotional and motivational influences, self-concept, self-belief, confidence, and perseverance. The factors were categorised this way in order to help to understand the phenomena in depth as a whole; however in reality the factors are highly interconnected and interrelated (Harms, 2005). Below, these factors are discussed in depth and incorporated into a Pasifika resiliency framework.

\section{External factors}

The external factors are related to the different environments and the relationships within those contexts that influence individuals' experience and development. Resiliency, as discussed in the literature review, refers to an individual in the presence risk factors being shielded by protective factors to enable a positive, successful, or better than expected outcome to be achieved. The participants in this study identified both risk and protective factors within their schooling experience: these included transferable extracurricular activities, life events that influence education pathways, support, and leadership. 


\section{Schooling experience}

The participants identified both adverse and helpful education experiences during their involvement in the schooling system. One of the key barriers they identified was the making the transition between schools. Three students in this study were successful at intermediate school; however, they struggled academically once they got to secondary school. This negative adaption to the new environment suggests that the students never really settled in, did not feel comfortable with their new environment, or were not prepared well enough for it.

The Ministry of Education's (2008) report “A Study of Students' Transition from Primary to Secondary Schooling” discussed this transition as crucial for Pasifika students' academic success. This was in line with Coxon et al's. (2002) earlier report for the Ministry of Education suggesting that more research was required on Pasifika students' transitions from intermediate to secondary school. Nonetheless, Chu et al. (2013b) indicated that minimal research had taken place on the issue since Coxon et al.’s (2002) initial recommendations.

In addition, the transition to tertiary education was also difficult for the participants. Their failure at secondary school ensured the students entered tertiary education with a lot of negative "baggage" about themselves and about education in general. The participants identified the experience of university as being equally as challenging as their secondary schooling experience. Many found the lectures did not suit them and the associated course readings difficult. However, some participants identified that being able to target one or two subjects (majors) at university suited them and tutorials made them feel comfortable to discuss complex content. Tutorials are designed for students to clarify their learning from lectures in smaller classes that allow for more interactions between students and tutors/lecturers. Even then, many of the participants felt incompetent to participate in discussions in tutorials as well. The unsettling experience of tertiary education resulted in a couple of the participants quitting university in their first attempt.

The transition into any new education environment seems to throw up certain challenges for Pasifika. However, the fact that they were able to successfully navigate tertiary study but not at secondary school suggests that academic success is more than just contextual. The schooling environment will be a factor in terms of influencing 
academic achievement and resilience; however, what the participants' experiences highlight is that a challenging schooling environment is not a definitive factor as to whether a student will be successful or unsuccessful.

This finding concurs with resilience research that states that resiliency is enhanced through the increase of protective factors and not removal or avoidance of risk factors (Irby, Ferber, \& Pittman, 2001). In any environment, risk, obstacles, and difficulties are inevitable. Morales and Trotman (2004) highlights that risks in education are those factors seen as detrimental to a student's academic achievement. The participants' stories identify that their success at tertiary was not due to the environment being risk free, but the culmination of protective factors in their inner and outer worlds shielded them from the challenging environment. The predominant view in Pasifika education research, evidenced by Chu et al.’s (2013b) literature review on Pasifika education research found five key findings across the research all pertain to creating a "risk free" or better education environments for Pasifika students: these include governance and leadership, family and community engagement, literacy and numeracy, effective teaching, and transitions. Despite these five findings being important issues that need to be researched, there needs to be space for research on resilient Pasifika students that generate success despite systemic and environmental challenges.

\section{Transferable extracurricular activities (TECA)}

TECA are the non-academic related activities, such as sport and work experiences, that the participants identified as influencing their academic resiliency and success. These activities acted as protective factors in the participants' tertiary education insofar as students were able to transfer skills from sport and work and apply these to their academic study. For example, some of the participants realised the work ethic required for success in sport paralleled the work ethic needed to be a successful in education. The participants knew that to be successful in their chosen sport and/or career they had to work very hard and, in addition, they had to push themselves past uncomfortable places in trainings and in competition.

The participants also understood that being successful in these areas came with an acceptance that the journey is never easy. Once the students could make this parallel connection in their minds, they were able to re-evaluate how they viewed learning in general and in study (Mayocchi \& Hanrahan, 1997). Through this new frame of 
understanding, participants approached study as they would their sport or career and this was a major influence on their education success. Likewise, the participants knew if they were not studying or giving their best effort then they were responsible for their own academic misfortune (Wiant, 1977).

Mcknight, Bernes, Gunn, Chorney, Orr, and Bardick (2009) identified that success in sport teaches people they are responsible for their own success or failure. The participants were able transfer this mindset of responsibility to their academic study. This notion made them accountable for their own success and failure, and at the same time, liberated them by showing them their success no longer comes from "elsewhere", outside of themselves or from someone else.

While the predominant research findings (Chu et al., 2013b) in relation to increasing Pasifika academic achievement focus around external factors, the researcher believes this focus unintentionally removes the power to achieve from Pasifika students and places it on factors they have no control over. Schools cannot guarantee quality governance and leadership, positive school transitions, effective numeracy and literacy programmes, effective teaching, and successful family engagement for Pasifika, even though this should be the norm. Pasifika achievement does not have to be at the product of "wishful thinking"; the participants in this study are evidence that a resilient student can find a way to achieve, no matter the circumstances.

Furthermore, identifying how TECA affected some of the participants' also gives evidence to a predominant belief system that Pasifika students hold that intelligence and learning is fixed. TECA showed them that if they worked hard like in their studies, as they did in sport or their career, then academically they would get better and reap similar success. However, prior to seeing the parallels from TECA to their education it is presumed the participants believed the opposite that education and in the broader sense intelligence is "fixed" or "permanent" and not malleable and they could not improve. This notion of fixed ability is discussed in more depth in the section Internal Factors, below. 


\section{Life events that influence education pathway}

A majority of the participants talked about life events that influenced them to return to education. Participants talked about the one moment in their life they considered to be the turning point for them. It was at this point that they decided that they needed to change their life for the better. Significantly, for many of the participants it was a negative life experience that influenced this positive life change. Updegraff \& Taylor (2000) state that for some individuals a traumatic experience can serve as a risk factor in the development of anxiety and depression; for others, however, these experiences can bring about positive change and be a catalyst for a positive self-examination and reflection.

Both positive and negative life events served as a chance for the participants to take a balcony view of their lives; to reflect deeply on their lives to examine their worlds and take ownership of their life trajectory. They were able to step back from the situation and critically analyse their life, encompassing their actions, their thinking, their decisions, and ultimately their future. This reflective process can be described as a transitional period where individuals view their usual way of living as no longer adequate or good enough (Basseches, 1984). Individuals question and challenge their own expectations during transitional periods such as life events. This interchange between stability and instability remains constant as individuals experience different life events and it is within these anticipated or unexpected life events that new structures will form to become the new standard (Levinson \& Levinson, 1996). In this study, the participants' life events influenced them to reflect, re-evaluate, and challenge their current way of living to form their new standard.

In the overall analysis of life events identified by the participants, there are no clear commonalities between the actual events themselves. Two participants had children, one was told they were not good enough to be at university, one had an overseas experience talking to a young child, one was denied a promotion in their job four times, one of the participant's fathers passed away, and one witnessed a gun pointed at her friend. However, what was common was the response to such life events. Each participant went through a reflective process whereby they re-evaluated their life and decisions and began to think about possible outcomes in the future. Therefore, this indicates that self-reflection plays a crucial part in the both the development of life change and resilience. 
Perry and Jamison (1997) stated that "experience plus reflection equals wisdom" (p. 178). Life events affect individuals in different ways; the learning and transformation happens when individuals can self-reflect on their experiences to go forward or be better, either from negative or positive experiences.

Wood (2012) commented that visualisation is a critical part of self-reflection; when individuals reflect about their life they are visualising their current situation as well as future possibilities. Through imagining new possibilities, the participants begin the process of developing new self-concepts and beliefs. "Possible selves are elements of the self-concept that represent what individuals could become, would like to become, and are afraid of becoming. These representations of the self in the future are...an important component of effective performance” (Ruvolo \& Markus, 1992, p. 95). Ruvolo and Markus' (1992) study identified that individuals that imagined future success outperformed those that imagined themselves as unsuccessful. The participants in this study life events changed their self-concept by changing how they visualised or imagined themselves in the future, effectively creating a result in their mind before it eventuated in reality.

\section{Support}

The notion of support was identified by the participants as being very influential in both their academic achievement and failure.

\section{Support related to teaching and learning}

The support related to teaching and learning was based on the students' experiences with teachers. Many of the participants could only identify one or two good teachers in their secondary experience. The standout features of these teachers had nothing to do with the teachers' content knowledge or expertise in the subjects. It came down to the teacher simply expressing care for the student. The participants described these teachers as people that believed in them, went the extra mile, had high expectations, and were invested in building a relationship. With this level of support from a few good teachers the participants succeeded in their classes.

The nature of teachers' expectation is usually reflected in the students' results. According Rosenthal \& Jacobson (1968) this is the Pygmalion effect or the selffulfilling prophecy (Merton, 1949) where students usually live up to the expectations 
teachers have of them. If teachers expect students to do well academically then usually the students' performance reflects that expectation and vice versa. In this research the teachers' expectations were evident in their actions and their investment in the student. The teachers' positive expectation towards some of the participants enhanced their relationship and the student behaviour and actions reciprocated that of the teacher, enabling them to be successful for those specific teachers.

Ringold (2005) argued that many teachers hold negative stereotypes of Pasifika students. These stereotypes automatically come with preconceived expectations and assumptions about these students that will govern the teacher interactions with them. The participants identified that they knew pretty quickly when teachers were invested in them and their behaviour was congruent with the stereotype held of them. When Pasifika students enter schools teachers already have assumptions about them often limiting the progress of the student (Steele, 1997). Many of the participants identified that they only had a couple of "good" teachers and the rest they intuitively knew were not invested or interested in them and this had to do with a majority of their teachers having negative stereotypes of Pasifika students. These negative stereotypes dissolve any real reciprocal relationship forming between the teacher and students (Steele, 1997).

Having positive relationships with teachers, then, was important to both the students' resilience and achievement. Strong reciprocal relationships acted as protective factors for Pasifika in both secondary school and tertiary education contexts.

It is disturbing that Pasifika research still has to discuss pedagogical deficiencies like “teachers negative expectations on students" these issues were evident in the Hawk, Hill \& Seabourne's (1996) AIMHI project in the 90's. This seems to be a consistent issue around Pasifika underachievement without a definitive successful solution (Chu et al., 2013b). The researcher believes that this will only change when the education system ensures that all teachers are adequately trained to understand Pasifika students. However, the participants' stories reflect that although teacher expectation is significant, Pasifika students do not have to wait for drastic changes within the system in order for them to be successful in education. Like the participants, future Pasifika need to form strong academic resilience to negate, persist, and endure in the face of encountering "bad” teachers. 


\section{Support related to family}

Podmore and Savao (2003) explained that Pasifika families find it hard to be actively involved in their children's academic learning when it does not reflect their Pasifika culture. The focus of the learning in New Zealand still represents the mainstream culture and this serves to acculturate smaller minority groups like Pasifika (Gorinski \& Fraser, 2006). The participants described their parents as being very supportive and said that they promoted the value and importance of education. However, the level of actual academic support from their parents was very limited due to parents and families not understanding the learning and content delivered in secondary school.

This aligns with Bourdieu and Passeron's (1970) ideas that the resources that students bring with them in the classroom serve as a way to keep the dominant culture in power. This process is done through the education system privileging the dominant culture more than the other. For example, in New Zealand schools English is a compulsory subject for students, while Māori, another official language of New Zealand, is not compulsory. Furthermore, English privileges studying Shakespeare, not Pasifika poets or playwrites; in Art students study the European classics, not Pasifika art. Bourdieu and Passeron (1970) argued that minority students come into education underequipped to be successful due to having less financial, cultural and social capital compared to dominant group families. They also commented that in such a privileging environment families from minority groups will feel marginalised and that this is meant to happen. The education system wants these students to not do as well through the misalignment in cultures; the learning is geared predominantly towards the dominant culture as a way to marginalise students so they find it hard and either drop out or give up. The participants' in this study indicated that family support did not improve during their tertiary study but that their resilience and protective factors increased. The learning at tertiary level is still geared towards the dominant culture; however, the participants were not the same - despite the misalignment of culture, they knew if they worked hard and stayed in the "fight" they would eventually get there.

Research in this area highlighted the importance of family involvement in Pasifika students' education (Chu et al., 2013b). However, in this study family involvement remained constant, specific academic support was limited, and did not affect the participants' academic resiliency and achievement in university. The results of this study reflect that parental involvement maybe more crucial during secondary school 
while Pasifika are still maturing and transitioning through adolescence, as family involvement was not identified as a major protective factor for students coming back to education and being successful.

\section{Support related to the peer group}

For the participants, the influence of the peer group changed dramatically between secondary school and tertiary. Participants highlighted the importance of social acceptance during secondary school, whereas during their tertiary study social acceptance was less of a priority. According to Wentzel, Baker, and Russell (2012) empirical evidence suggests the extent to which the young person believes their peer group and teachers have high expectations of them in terms of academic achievement and behaviour, appears to have a positive effect on the young person's academic engagement: "Students also communicate to each other their values and expectations concerning academic achievement which, in turn, predict motivation and performance outcomes over time” (Wentzel et al., 2012, p. 608). For example, one student talked about purposely under-achieving, or not giving her best, because she wanted to be accepted by her Pasifika peers in a Pakeha dominated school. The majority of her Pasifika peers were not academically successful. Accordingly, social acceptance for this student meant accepting the socially communicated rules of the peers that were not pro academic achievement, leading to her underperforming.

According to Chu et al. (2013b) reported that little is known concerning the impact of peer influence, peer expectation, and peer pressure on Pasifika on academic achievement. Benseman et al. (2006), however, stated that peer group pressures were a major influence hindering Pasifika academic performance. Benseman et al. (2006) noted that hanging out with friends was fun and part of growing up. However, when friends became a priority over deadlines and academic requirements was when it really impacted their education. In their study of factors impacting Pasifika first year students in tertiary study in Australia, Kearney \& Donaghy (2010) identified peer group expectation as a major factor. Pasifika students whose peers underperformed at secondary school often had low aspirations for tertiary study and this caused other students to question their ability. Pasifika students "felt forced to choose between peergroup acceptance and university aspirations” (Kearney \& Donaghy, 2010, p. 6). 
The participants identified that the influence of peer group changed dramatically. Firstly; some participants described their experience as being very individual, saying that they were there for a purpose - to study and succeed - and that friendship, if it came, was a bonus. Many of these students built good relationships with tutors, support staff, and lecturers, steering clear of anything that might distract them. Secondly, some participants talked about associating with people with the same aspirations to form more positive peer groups. In these groups they were able to support each other in their education journeys

\section{Support related to academic services}

Support related to academic services included tutor mentoring, Pasifika support services, and learning support. Some students identified that having a good relationship with a learning support services in tertiary acted a major support. One participant who is now a Pasifika outreach support person for university commented that academic support is only as good as the people that use it; a student can have all the support available but if they do not use them, or see them as beneficial then they are of no use. Benseman, et al. (2006) identified the lack of knowledge of support as a barrier, hinting that Pasifika students need support to use support. This was reflected in one student identifying being tentative about taking their work to support services because of the fear that they would look "dumb”. Even when a fellow Pasifika student became an academic support person she was hesitant. But once she got over the fear and her grades developed positively, then she kept using the support. The key hurdle for Pasifika to use support is not the support service, or the support person, but more about what the use of support means to Pasifika students. For a Pasifika person to use support would be an acknowledgement that, first, they need help, and second, this acknowledgment questions their competence, intelligence, and presence in education; that is, if they need help then maybe they should not be there. This tension between knowing they need support and the fear of what support means can often cripple Pasifika students to access support. Most of the students talked about the relationship being long term rather than just sporadic use of support services. Pasifika use of support is not something they find easy to do unless they have a trusting and reciprocal relationship. This relationship obviously helps them overcome the fear and changed their perceptions of what support means. Furthermore, most of the student chose the Pasifika or Māori support person so this may also have been a factor in easing the transition into using support. 


\section{Leadership}

The final significant external factor in the study was how situational leadership experiences impact on students' academic success and resilience. Leadership is contextual and according to the different experiences identified by the participants was a factor that impacted their studies. Participants' leadership experiences varied, with some seeing themselves as role models for their young children, some being asked to be tutors at university to help other students study, and some being the eldest children in their families who felt duty-bound to lead their younger siblings.

Although each experience was different, their leadership roles compelled participants to feel that their success now meant more than just individual aspirations; they felt obligated to succeed for others. One of the key foundations of leadership is integrity and trust (Kouzes \& Pozner, 2007). Kouzes and Pozner (2007) explain that the plausible explanation for this is that a leader is judged not only on his words, but by what he does. Leaders must "walk the talk" or people will not trust and therefore not follow them. This leadership experience served as a protective factor because the participants felt they needed to walk their talk. As leaders of their young children, students, and siblings there was an expectation that they needed to succeed academically in order to not face the fear of failing the people.

\section{Internal Factors}

\section{Emotional and motivational aspects that influence learning}

Relevance of learning and the passion for learning was a major factor that affected participants' academic success and resilience. During secondary school, the participants could not connect to the learning. They found the learning at secondary school to be irrelevant to their lives, not interesting, and the delivery of the content ineffective. At tertiary study the students felt they had the freedom and control to focus on what they wanted to study, rather than someone choosing courses for them. Some participants intentionally chose papers related to their work outside of university but still struggled to grasp it. Hulleman and Harackiewicz (2009) found that when students could see the relevance of the content to their lives, even if they were underperforming students their academic performance increased. As mentioned above when looking at the support of family, Bourdieu and Passeron (1970) argued that low social economic and minority students are intended to not see the relevance of the learning to their lived experiences 
so that the dominant students stay dominant and everyone else stays in their place in society. The difference at tertiary for the participants in this study was that they were determined enough to overcome learning information not relevant to their lives, they just created ways around it. Also in tertiary study the participants had more choice of course selection and could purposefully select courses that were more relevant to their lives and future goals.

In addition, for the first time students were able to choose Pasifika content to study in university. Relevance to the learning directly relates to the students level of engagement and motivation (Martin \& Dowson, 2009). This increased their passion to learn because for the first time they were learning about people like them, their histories, and their knowledge. Participants can relate to the content because it feels familiar, makes sense to them, or they have lived it.

Motivation can be both extrinsic and intrinsic, meaning there are many components that can make us feel compelled to take some kind of action. Martin (2002) conceptualised academic motivation as the student's energy and drive to learn in school. The participants in this study were highly motivated already by the impact of their life events to change and come back to education. However, the participants described other motivating factors that helped them to maintain momentum towards their goal. They identified that they were driven to attain education through their faith, to avoid being a failure in their life, to not settle for less, to avoid being another Pasifika education statistic. The life events motivated students to return to education, but it was other motivating factors that enabled them to persevere long term.

\section{Self-concept}

One of the major contributing factors the participants recognised as critical to their academic achieving and resilience was self-concept.

According to Pajares (2001, p. 29) "academic self-concept represents a composite view of him or herself as a student, a view formed through experience and feedback from others”. For the participants in this study the accumulation of negative interaction with teachers, the lack of reciprocal relationships, limited support, and negative academic results helped shape and mould the participant's academic self-concept at the time. This negative self-concept became a "label" or and identity that students held of themselves 
in education and ultimately self-concept shapes self-beliefs, self-efficacy, and behaviour. The participants in this study identified that their attitude and behaviour in secondary school was congruent with the negative self-concepts they had formed. The participants labelled themselves as lazy, funny girl, not intelligent, cool, “dumb”, and failures at secondary. These self-concepts often hindered academic achievement. According Pajares (2001) self-concept aligns itself with the students' self-belief and efficacy in education. If students hold, ineffective self-concepts of themselves that do not promote being successful in education their beliefs about their ability, efficacy and potential will be congruent. If students see themselves as lazy, their beliefs about education also reflect this self-concept.

Purkey (1985) stated that self-concept is learned and serves as a barometer for behaviour: "People behave in accordance with the ways they have learned to see themselves and others in their perceived worlds” (p. 256). For example, Fetu in this study had a self-concept at secondary school as “dumb”, his beliefs about himself were congruent with this self-concept. He believed that certain subjects were above his comprehension level and university was only for Pakeha students. Purkey (1985) stated negative self-concepts will lead to negative actions and behaviours in school and ultimately a negative result. This negative result often serves the purpose of reinforcing the negative self-concept, giving the individual confirmation of the self-concept e.g., "I told you, you were dumb” and ingraining it permanently in a person’s identity

Seaton, Parker, Marsh, Craven, and Yeung (2014) explain that self-concept is multidimensional, that students can have self-concepts about themselves in the different worlds that they develop in. For example, a rugby player may have a very high selfconcept with rugby but a very low self-concept in education. Many of the participants recognised this when they talked about having an implicit competence in themselves despite a negative academic self-concept. They always felt in the back of their minds that, despite negative results and negative teachers at school, they had an underlying competence in themselves in other areas. Their experiences in sport, community, family, gave them an understanding that they were competent at something's and not completely inadequate.

One of the most consistent debates in the research around self-concept it its link to performance and achievement (Hattie, 2014). Many studies find significant correlations 
while others have found the correlation negligible and the data inconclusive (Wylie, 1979). Marsh and Craven $(2004,2006)$ now argue that there is a reciprocal relationship between academic achievement and academic self-concept. When the students' selfconcept is high, then the students will show improvements in academic achievement, and when students' academic achievements increase then students show improvement in academic self-concept. It was clear in this study, that as participants started gaining success in their degree level study, their self-concept also improved. Participants changed from using ineffective to effective labels such as ardent learner, superwomen, and an academic monster. These strong positive labels were in line with being academically resilient and successful. This also shaped the participants' beliefs about their ability and potential, and their behaviour and actions reflected this change.

\section{Self-belief}

The study found that a key influence on the students' academic achievement and resilience was self-belief. There is interconnectedness with all of the internal factors of an individual; however self-belief has a close association or is in a reciprocal relationship with self-concept. Bandura's (1997) social cognitive theory explained academic self-efficacy as the personal assessment of an individual's ability and potential to succeed in academic pursuits. How participants viewed themselves and their ability (self-concept) shaped their beliefs about their capability and potential. Overall, when the participants started failing secondary school this failure ingrained itself into their academic self-concept. The beliefs the participants formed about themselves both academically and personally were impacted on. The participants believed they were worthless, they were wasting time going to school, they doubted themselves and their ability, they could now only go on to low paying jobs, and some descended into selfhatred. Most of the negative beliefs the participants held went beyond just academic failure; participants believed they were not only inept in education but that, holistically, they were simply inept. Failing academically impacts Pasifika students' belief about their employment quality, their ability to continue to in education, and their overall selfworth. Despite the multidimensionality of self-concept, beliefs around the connection between school performance and life outcomes is so entrenched in New Zealand and Western society that failure impacts more than just a student's academic self-belief and self-concept. 
One of the key beliefs that impacted the student academic success and achievement was about the relationship between education and intelligence. This belief was stronger at secondary school and was almost non-existent in their tertiary experience. During secondary school the participants believed that school was a measure of intelligence, potential, or ability, and - as mentioned above - this impacted their self-concept, beliefs towards school, attitudes and actions.

Dweck et al. (2011) stated that this belief or mind-set about school and intelligence is reinforced by their failure but learned and transmitted through the praising of individuals talents. Dweck (2006) has looked extensively at this issue. When children are praised for being talented in academic work - for example, Penina does really well at math test and the teacher praises her talent, "Penina you are really smart at math" this kind of praise seems beneficial and appropriate. However, according to Dweck the underlying belief this praise transmits to Penina is that academic success is related to being “smart” or intelligent. After this experience Penina feels and believes she is smart, but what happens when she does not do well in the next test? Penina now views herself as unintelligent and not smart and may question her purpose for being there. Dweck also highlighted that students may try to cheat or avoid experiences like tests to maintain this perception that they are smart, avoiding failure. This belief automatically transmits a self-concept of intelligence to students and a belief that intelligence is fixed which shapes their beliefs about their academic ability, behaviours, and results of their actions.

Dweck (2006) argued that if a student believes that their intelligence and learning is fixed this would inhibit their ability to be resilient in education. When a student believes their success in education is determined by being smart or intelligent when they hit challenging times and do not do well, failure must also mean the student is not smart or not intelligent. Students who believe they are not intelligent are less likely to endure difficult times. As mentioned in the findings, some of the participants who were successful at intermediate school struggled with transitioning to secondary school and failed academically. It is not determined whether the participants were praised for talent at intermediate. However, their belief about fixed ability could explain why they quickly gave up at secondary school. When the participants struggled with increased academic rigour at secondary, they found the learning difficult and gave up trying. Without constant reassurance about their ability the students are more likely to disengage or disconnect from subjects, classes, and school. This impact of fixed belief is reflected in 
the participant's actions towards school. They truanted, dropped out, used school only to socialise, or got kicked out. As Dweck (2006) pointed out, students will not try if they believe their intelligence is fixed, or that they can never improve. Students are more likely to give up than fight a lost cause.

Dweck et al. (2011) commented that belief about fixed intelligence can be countered by the promotion of "growth mind-sets". When students are praised for effort, hard work, and persistence, rather than for talent they realise that success and intelligence in education is attributed to their effort, hard work, and persistence. The findings did not reveal whether the participants were praised for effort in their tertiary study; however, their experiences from TECA, their behaviour and actions at tertiary reflected that they believed success in education was related effort, hard work, and perseverance.

\section{Confidence}

The participants identified confidence as a contingency of self-belief. They talked about being more confident in their academic studies when they experienced a combination of positive self-concept, positive self-belief, and academic achievement. The results revealed that when the participants believed in their ability their academic grades increased and this amplified confidence towards their academic work. For example, one participant talked about working hard and getting his first A grade at university. His confidence amplified, felt good about himself, and from that point on his confidence kept building and he continued to get A's throughout his university work.

Other students talked about confidence enabling them to use learning support and to approach lecturers and tutors for help. A consistent theme of research is the negative stereotype that Pasifika students are shy and do not ask questions (Chu et al., 2013b). Again, this could refer to the belief about fixed ability, that asking for help means that students are out of their depth or unintelligent. For many of the participants in this study, seeking help from support services, tutors, and lecturers showed there was a shift in their self-concept and self-belief. Seeking out help meant making an extra effort to ensure the work was at a high standard, thus showing the participants wanted to improved and believed they could improve, reflecting a belief in growth.

In addition, some of the participants talked about how experiencing accumulative success in lower level tertiary studies built up their confidence to enrol in degree level 
qualifications. Before enrolling at university, many of the participants had enrolled in certificate and other lower level courses delivered in polytechnics and private training organisations. Their success in these courses gave them self-belief and, therefore, confidence that they could be successful in future study. The participants' positive academic self-concept and self-belief increased academic achievement in lower level study and ultimately built confidence through reinforcing and strengthening their positive self-concept and belief system.

\section{Perseverance}

The participants identified perseverance as being a significant protective factor in their academic achievement and resilience. Although, the participants were successful in their tertiary study, it did not come easy for them, as they had to overcome and withstand a lot of external and internal pressures. Perseverance was identified through three categories: students’ persistence towards goal, time management towards goal, and goal setting.

Many of the participants expressed that their persistence towards their goal was a key contributor to their academic resilience and success. They identified that their determination, relentlessness, and never-quit attitude helped them overcome challenges at university. Participants identified having to do lots of complex readings, attend massive lectures, and other barriers, but that through working hard and often "wrestling" with the content and sacrificing personal comfort such as by studying late and sometimes all night, they were able to attain success. This definition of perseverance concurs with Dweck et al. (2011, p. 5) who say, "Difficulty, be it intellectual or social, does not derail them. They see a setback as an opportunity for learning or a problem to be solved rather than as a humiliation, a condemnation of their ability or worth, a symbol of future failures, or a confirmation that they do not belong”. It becomes clear that perseverance has a relationship with self-belief. Senko and Hulleman (2013) also agree that self-belief and competence are antecedents of goal pursuit, that if students know they will or can do well this is a precursor for them pursuing achievement goals.

Dweck et al. (2011) state that "tenacious students know how to remain engaged over the long haul and how to deploy new strategies for moving forward effectively” (p. 6). As 
identified by the participants in this study, their ability to persevere long term was through a culmination of two strategies time management/priorities and setting goals.

The participants explained how a protective factor in university was ensuring their study was a priority in their life and they managed their time well. For example, four participants had young children during their tertiary study; however, they did not use this as an excuse but saw it as an opportunity to improve their time management, to maximise every spare hour. This ability to manage their time enabled them to persevere despite the obvious barrier of having young children. This relationship between time management and academic success is constantly identified in the research (Hettich, 1992; Locke, 1975; Meredeen, 1988; Race, 1992).

Race (1992) also identifies that time management helps with academic readiness. When students use their time better they are more ready to deal with the obstacles that come their way. Participants noted that by maximising every hour of study they were prepared and ready if issues with children, partners, and family popped up. Pasifika students are generally the students with external expectation placed upon them from family and community (Chu et al., 2013b) and, therefore, cannot afford to be underprepared or waste time so when issues arise they get left behind. Most of the participants identified they were not taught time-management or shown how to manage their time better; they developed this skill at tertiary out of their own necessity.

Finally, the participants identified the importance of setting goals and having something to aim for. Participants identified that by actually setting out what they wanted to achieve encouraged them to persevere when study got hard and the eventual obstacles and problems came up. They always had their end goal in their mind to keep them on track. Morisano, Hirsh, Peterson, Phil, and Shore (2010) conducted a study of a single goal setting session as an intervention and its impact on underperforming undergrad students compared to a control group. They found the students who set goals experienced increased grade scores, improved ability to manage course load, and reduced impact of negative effects. The results from their study mirror the participants in this research. The Participants in this study showed that setting goals influenced the increase in grades and an increase in overall academic achievement. This finding corresponds with other research on goal setting in education and its relationship with improved academic performance (Pintrich, 2000; Wigfield \& Eccles, 2000). 


\section{Framework}

\section{The Fa'amalosi framework}

Fa' amalosi comes from Samoan language and the word loosely means "to be strong". The idea to use this term for the framework came about through the researcher's experiences in sport. During a rugby game, one of the children's mother shouted out "fa'amalosi, fa'amalosi", urging her son to be strong, to go hard, do his best, and fight for victory. This word really captures the essence of what the researcher was trying to unearth with this research. The researcher wants Pasifika to be strong, to "go hard", to do their best, and to fight for success in education despite the overwhelming odds stacked against them. To do that, the researcher needed to identify other Pasifika students who, despite such odds, fought for their own academic success. The Fa'amalosi framework is a dedication to those eight students as well as a gift to future Pasifika students and educators. The framework details how Pasifika can fa'amalosi - be strong in any education environment and do well.

This framework is based on the stories of Pasifika students in combination with the literature to highlight the key external and internal factors that shape and foster academic resiliency. The symbiotic relationship between much of the findings enabled this visual representation. The purpose of the framework to describe the close relationship between significant factors, and to enable these relationships to be viewed visually in order to aid understanding and implementation of the framework. The framework is intended to be a starting point for other researchers, students, and educators to test, critique, and develop the framework over time in practice. As an emerging researcher I have developed this framework to inspire a shift and transform Pasifika students' experiences in education.

The common deficit view of Pasifika as "problems to be fixed" needs to be replaced with more strength-based approaches and for Pasifika to be viewed as "greatness not yet unleashed". Whether this framework can be transferred and used as a vehicle to enhance resiliency in future Pasifika students is still unknown, but is something the researcher wants to "get his hands dirty with" and find out in research and practice. 


\section{Pasifika Resiliency Framework}

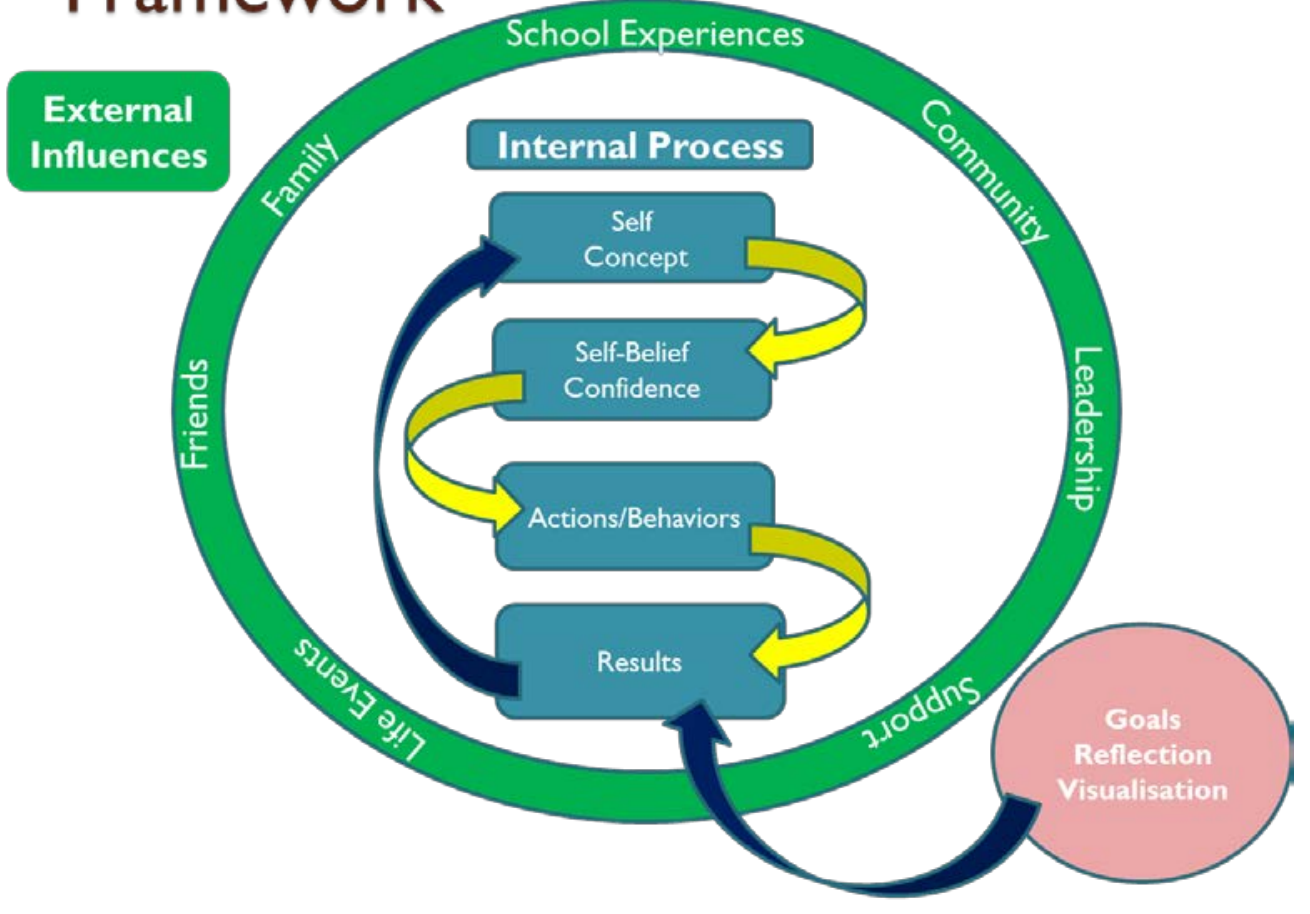

It is important to understand the Pasifika Resilience Framework holistically. The external factors influence the internal process and the internal process will shape perception of events. The synergy between the external and internal factors influenced the participant's academic resilience both positively and negatively.

The green circle on the outside represents external factors that affects academic resiliency. This list is not exhaustive as there many other external influences; however, these are the key external factors identified by the participants. The use of a circle was influenced by Bronfenbrenner's (1979) social ecology model. The external factors the participants identified were defined using social ecological theory and shows they are constantly influencing us and multi-layered.

Inside the circle are the internal factors and processes that affected the participant's academic resilience.

The pink circle represents the factors the participants identified as important strategies and processes that caused a "shift" in their internal process, which was a catalyst to their education transformation. 
The arrows represent a systematic ordering of the process. These arrows represent an interconnection and explain how the process works. The dynamic relationship between all factors is in actuality very complex and interconnected and, in real time, everything is happening at the same time. However, across the participants' stories this sequential ordering of the process and the close relationship between internal factors became clear as they talked about their experience

\section{How the Pasifika Resiliency Framework operates}

\section{Secondary school}

- External factors and self-concept: The combination of external experiences shaped participants' self-concept. For example, when a teacher told them they were "nothing" in education as a young person, this impacted on how they saw themselves. Furthermore, if they failed a paper or their parents did not have education experience this shaped their self-concept.

- $\quad$ Self-belief and confidence: Self-concept shaped the students' belief about their capability and potential. When they saw themselves as "dumb" or a "failure" this identity shaped their beliefs they had about their potential, ability, and intelligence. This often followed with negative self-talk such as "I can’t do it”, “This is too hard,” and "I’m not brainy".

- Action and behaviours: The participants' actions reflected what they believed about themselves. When they did not believe they could do something they disengaged with school by giving up trying, truanting, and focusing on the social side of school.

- The result and outcome: The participants' actions lead to results of academic underperformance and failure.

- The result reinforces self-concept: the underperformance and failure reinforced the negative self-concept students had about themselves in education. This internal cycle was repeated until, eventually, after enough experiences of failure, the students disengaged fully from education and had ingrained self-concepts not congruent with being academically successful. 


\section{Tertiary}

- External factors and self-concept: Through experiences of sport and work students developed self-concepts that were more positive. Life events caused them to step back and reflect on their lives, asking themselves where their life was leading them currently, where they wanted to go, and what they wanted to become.

- $\quad$ Reflection: Being able to reflect deeply on their lives positively influenced selfconcept by getting the students to see themselves for the first time as more than what they were currently living. They could see themselves as having a different future. Some set goals about where they wanted to go and what they wanted to achieve.

- Self-belief and confidence: These shifts in terms of positive self-concepts shaped the participants beliefs about their future, their ability, and potential. This belief propelled them just enough to take small actions towards a new direction, such as signing up to a course or university and being brave enough give education a second chance.

- Action and behaviours: The students' new beliefs shaped new actions and decisions. The participants were more driven to do well, to commit. This is reflected in their confidence and belief to access the support networks that were available to give them their best chance. In addition, their study habits improved now education was a major priority in their lives. In addition, some set small goals for themselves.

- The result and outcome: The participants' positive actions were rewarded with attaining small victories in education. Some passed certificate level courses before going to university. In addition, for the first time in their lives they were rewarded and could see the direct impact of their effort with good grades.

- The result reinforces self-concept: These results boosted the participants' confidence and reinforced their new positive self-concept in education. This internal process from self-concept to result was repeated, and students were unstoppable in their postgraduate studies. Education is now just another part of who these participants are and is reflected in their consistent academic success. 


\section{Recommendations}

\section{Academic resiliency}

This research along with the literature suggests that developing academic resiliency should be part of future Pasifika education plans. According to Dweck et al. (2011) increasing academic resiliency has been shown to increase academic performance and achievement, which has primarily been the focus point of Ministry of Education strategies for Pasifika. Therefore, the goal for Pasifika should be to increase students' academic resiliency and tenacity. Using the Fa'amalosi Pasifika Resiliency Framework developed from the research, there are three key strategies for enhancing academic resiliency in Pasifika students. These strategies are 1) educators as positive self-concept and self-belief builders, 2) Pasifika engaging consistently in reflection and to reflect forward to a better and brighter future, and 3) the importance of goal setting and visualisation.

\section{Educators as positive self-concept and self-belief builders}

Educators from Early Childhood Education ECE through to tertiary should concern themselves with fostering and building positive academic self-concepts in students. Educators, especially teachers are very influential in the development of academic selfconcepts within education. Pasifika students need to develop learner orientated selfconcepts that promote lifelong learning and that nurture a belief system that reflects growth mind-sets. Growth mind-set beliefs reinforce the idea anything can be learned and that intelligence is ever-evolving in every student, more so when attempting difficult tasks (Dweck, 2006).

Educators of Pasifika need to believe in the unlimited potential of Pasifika students. If Pasifika enter education environments where they are constantly and consistently made to feel they belong in education, educators collaboratively build positive academic selfconcept and belief in students about their potential and ability. Pasifika students' academic results are likely to be congruent with how they see themselves and what they believe about themselves in education. Educators should also try to incorporate as best they can Pasifika content within the learning and environments. Pasifika students should see themselves as being part of the school in more than just sport and music but they should feel they belong academically, and see their relevance to the learning. 


\section{Pasifika engaging consistently in reflection}

One of the key strategies in developing academic resiliency for Pasifika is for the students to reflect on their lives and their learning. A key component of the experiential learning cycle (Kolb, 2014) is the importance of reflection on experiences as a key part of learning. Teachers need to generate spaces for students to reflect on the learning, how they are learning, the "gaps" in their learning, their experience of the teaching, what worked well, what did not, and thinking in terms of how they want to develop their learning for the future. Dewey (1933) stated that individuals do not learn from an experience but from the reflection on the experience. When students consistently reflect on their learning, they understand their own learning process better but also develop skills, abilities, and habits that come with critical reflection (Zubizaretta, 2009). Below is an adapted list from Porter and Cleland's (1995) benefits to students in consistent reflection during the learning process.

- $\quad$ Improved examination of their learning process.

- $\quad$ Builds responsibility towards their learning.

- Identifies the "gaps" in their learning.

- $\quad$ Gives evidence to strategies that supported their learning.

- $\quad$ Celebrates risk taking and inquiry.

- $\quad$ Sets goals for future experiences.

- $\quad$ Shows changes and development over time.

The development of a reflection space in classes not only benefits the student but also the teacher. Teachers can have immediate feedback on their teaching practice and, in addition, attain crucial feedback on where the students feel they are in terms of the learning. Teachers can use this data to change, adapt, and incorporate new teaching strategies into their practice as well be proactive and place support around those student identifying as not understanding some of the learning.

Getting students to write down reflections only serves one type of student. Educators need to be creative in the process by getting students to express how they feel orally in reflective circles, using reflective games, emotive cards and symbols to represent 
feelings, artwork, post-it notes, and so forth. Reflection needs to be multidimensional and fun so that it becomes a central part of the learning experience.

In addition, it is important for young people to reflect on life as well. The participants in this research only reflected on their life after major life events, this reflective space was the beginning of their personal transformation. The development of a culture of reflection within schools and classes should also incorporate times of reflection about what it is like to be young people in New Zealand. Often educators ask students "what they want to be?” but are often met with the answer "I don't know”, because how and why should they know. Better questions for developing further inquiry around their lives are "What type of legacy do you want to leave?", "How do you want to be remembered by your family and friends?”, and "Your last name, has been transferred down from your ancestors to you. How are you leaving that name for future holders of the name?"

\section{Goal setting and visualisation}

Goal setting and visualisation are quite different processes. However, when someone reflects on goals or thinks about goals and where they want to be, in effect they are visualising a better future for themselves. Goal setting is a time-tested strategy that is said to benefit individuals' lives more than if they did not set goals (Locke \& Latham, 2006). Educators need to incorporate goal setting into the students' academic lives and consistently set and monitor goals for themselves. Goal setting, according to Locke and Latham (2006), is more than just thinking about a different outcome in someone's future; there are strategies for doing goal setting strategically and more effectively. SMART goals are a strategy to make sure goals are more effective and increase the likelihood of achieving them.

- $\quad$ Specific

- $\quad$ Measureable

- $\quad$ Achievable

- $\quad$ Realistic

- $\quad$ Time bound 
SMART goals should be written down, to be viewed by the student frequently, and monitored in terms of progress. An example of a non-smart goal would "I want to pass school”. While any goal is better than no goal, this one is not specific, measureable, or time bound. This can be turned into a SMART goal: "I want to pass all my subjects with a B grade average or higher by the end of the year”. This goal is specific, measurable, achievable, realistic, and time bound. The next step would be to work with students to create action plans to develop the necessary steps to attain the goal.

According Porter and Foster (1990) the mind does not know the difference between the real and the imagined, meaning that when you "imagine yourself perform to perfection and doing precisely what you want, you are in turn physiologically creating neural patterns in your brain, just as if you had physical performed the action” (p. 17). Ranganathan, Siemionow, Liu, Sahgal, and Yue's (2004) study on the influence of the mind on muscle power also found similar results that show that "patients can use their minds to maintain or enhance the neural signal to maintain or even increase muscle strength (p. 955). Consequently, through setting goals, seeing oneself as successful in the future develops similar neural responses as being successful in reality. Students with limited academic achievement, negative self-concepts, and beliefs about education who can set goals towards academic achievement and really visualise the outcomes consistently are, in effect, creating successful results in their body and mind before they actually experience success.

The Pasifika Resiliency Framework, above, illustrates that results influence selfconcepts. Enabling the students to set goals and see results can shape how students see themselves in education. In addition, this study has shown the enormous influence of self-concept on academic resiliency, achievement, and wellbeing. Therefore, if positive self-concepts can be enhanced through goal setting and visualisation, goal setting should be an integral education strategy when working with Pasifika.

\section{Limitations of the Study}

This research provides a set of common trends and patterns of Pasifika resiliency stories that are relevant and align with existing literature on Pasifika in education. However, there are some limitations to the study. The sample of Pacific participants selected were all graduates from Victoria University of Wellington. This was not intentional and the students studied many different degrees and majors; however, because they have all 
experienced the same institution there will be difficulty in generalising across the general population of Pasifika students in New Zealand. In addition, while the sample size of eight participants came from different areas of the Pacific such as Samoa, Niue, Fiji, Cook Islands, and Tonga this is only a small representation of Pacific students, thus the wider perspectives and views of Pasifika could have been overlooked and again generalisation may not be applicable.

\section{Conclusion}

When looking back at the stories of these participants, it is remarkable to see how transformation happens. The goal of the research was to find and understand the factors that made the difference in the education journeys of Pasifika postgraduate students that had previously failed secondary school. These students have "tasted" both sides of the education spectrum - both academic success and failure. They left secondary school with little to no qualifications and with very limited/negative self-concept in education. The majority of their secondary school teachers had made them feel and believe they would probably amount to nothing and go nowhere in education. However, the participants not only came back to education but became very successful postgraduate students and graduates.

The majority of the research into Pasifika in education is geared towards external influences that shape Pasifika students. The researcher understands the importance of these factors but felt that this focus may unintentionally depower Pasifika student's selfdetermination. For instance, if the barriers to Pasifika success in education are lack of understanding of NCEA, balancing of church commitments, financial barriers, and negative teacher interactions, the underlying message that this sends is that a lot of external factors have to be right or "fixed up" or Pasifika are more than likely to fail. These barriers are relevant and important; nevertheless, the chance of transformation and addressing these issues for every Pasifika student is unlikely in a small education timeframe.

The constant underperforming of Pasifika in education highlights the "current" system does not work as well for Pasifika people and needs to change. Yet the question that always appears at the back of the mind of the researcher is "How long will it take for total systemic change to come in New Zealand?” In an ideal world this would occur in a few years, but after years of consistent underperforming, with minimal improvement 
despite numerous Pasifika education plans it does not appear to be realistic any time soon. In reality, the system changes that Pasifika desire and need are probably not coming fast enough. However, this does not mean that Pasifika cannot achieve as well as or better than everyone else in a "broken” education system.

Although the Talanoa findings from this research do not claim to be the saving grace for Pasifika in education, they do show that Pasifika students can be equally successful in the same system that originally did not work for them. The findings show the participants transformed an education system that failed them into a system they now "get” very easily. When asked about their potential now in education, most of them frankly believed it was limitless. In addition, the findings have the ability to empower Pasifika by illustrating that they are powerful contributors to their academic achievement, they do not need wait for the perfect education climate and experiences before they can be successful within education.

This study showcases Pasifika students who did not wait for the academic environment to be "perfect" before they "gritted their teeth" and "fought" for their future and education. It was not an easy road for the participants; their stories are littered with obstacle after obstacle, the biggest being failing secondary school. Yet they were able to overcome and thrive in education. Pasifika students and educators need to hear more stories of such empowerment and resilience. Pasifika students must have the courage to start, but also the courage to endure, in their academic pursuits. Educators need to change their line of thinking and believe in and feel responsible to every student that walks in their doors. Pasifika need to know that the conditions for education for Pasifika persons will probably never be faultless; however, when they believe in themselves they can not only succeed in this system, but flourish. 


\section{References}

Airini, Anae, M., \& Mila-Schaaf, K. (2010). Teu le va: relationships across research and policy in Pasifika education. Report to the Ministry of Education. Wellington: Ministry of Education.

Allen, P., Taleni, L. T., \& Robertson, J. (2009). In order to teach you, I must know you. The Pasifika initiative: A professional development project for teachers. New Zealand Journal of Education Studies, 44(2), 47-62.

Bandura, A. (1994). Regulative function of perceived self-efficacy. Personnel selection and classification, 261-271.

Bandura, A. (1997). Self-efficacy: The exercise of control. New York, NY: W.H. Freeman.

Bartelt, D. (1994). On resilience: Questions of validity. In M. C. Wang \& E. W. Gordon (Eds.), Educational resilience in inner-city America: Challenges and prospects (pp. 97-108). Hillsdale, NJ: Lawrence Erlbaum Associates.

Baumeister, R. F. (1994). The crystallization of discontent in the process of major life change. In T. F. Heatherton \& J. L. Weinberger (Eds.), Can personality change? (pp. 281-297). Washington, DC: US: American Psychological Association.

Basseches, M. (1984). Dialectical Thinking and Adult Development. Norwood, N.J.: Ablex.

Benseman, J., Coxon, E., Anderson, H., \& Anae, M. (2006). Retaining non-traditional students: Lessons learnt from Pasifika students in New Zealand. Higher Education Research \& Development, 25(02), 147-162.

Bishop, R. (2008). Freeing ourselves from neo-colonial domination in research. In N.K. Denzin \& Y.S. Lincoln (Eds.) The Landscape of Qualitative Research (pp. 145183). London, UK: Sage.

Bishop, R., Berryman, M., Tiakiwai, S., Richardson, C., Mitai, R. \& Savill, S. (2002). Improving the educational achievement of Maori students in mainstream classrooms: Strategies for effective professional development. Paper presented at New Zealand Association for Research on Education Annual Conference, Massey University, Palmerston North.

Bourdieu, P., \& Passeron, J. C. (1970). La reproduction éléments pour une théorie du système d'enseignement. 
Broadbent, J., \& Poon, W. L. (2015). Self-regulated learning strategies \& academic achievement in online higher education learning environments: A systematic review. The Internet and Higher Education, 27, 1-13.

Bronfenbrenner, U. (1979). The ecology of human development: Experiments by nature and design: Harvard University.

Brookover, W. B., \& Lezotte, L. W. (1979). Changes in school characteristics coincident with changes in student achievement: Executive summary. Institute for Research on Teaching, Michigan State University.

Bryman, A. (2008) Social Research Methods. 3rd Ed. Oxford: Oxford University Press. Burnett, J. (2015). Collecting data: Qualitative methods. In SAGE Study Skills: Doing your social sciences dissertation. (pp. 154-171). London: SAGE Publications Ltd.

Bushe, G. R., \& Coetzer, G. (1995). Appreciative inquiry as a team-development intervention: A controlled experiment. The Journal of applied behavioural science, 31(1), 13-30.

Cappella, E., \& Weinstein, R. S. (2001). Turning around reading achievement: Predictors of high school students' academic resilience. Journal of Educational Psychology, 93(4), 758.

Carr, M. (2001). Assessment in early childhood settings: Learning stories. Sage.

Cefai, C. (2008). Promoting resilience in the classroom: a guide to developing pupils' emotional and cognitive skills. Jessica Kingsley Publishers.

Charmaz, K. (2006). Constructing grounded theory. London: Sage.

Chu, C. M. (2009). Mentoring for leadership in Pacific education (Unpublished PhD thesis). Wellington, New Zealand: Victoria University of Wellington.

Chu, C., Abella, S., \& Paurini, S. (2013). Educational practices that benefit Pacific learners in tertiary education. Wellington: Ako Aotearoa, National Centre of Tertiary Teaching Excellence.

Chu, C., Glasgow, A., Rimoni, F., Hodis, M., \& Meyer, L. H. (2013). An analysis of recent Pasifika education research literature to inform improved outcomes for Pasifika learners. Wellington: Ministry of Education.

Cooperrider, D., \& Srivastva, S. (1987). Appreciative Inquiry in organisational life. In and D. W. D. Cooperrider, P. F. Sorensen, T. F. Yaeger (Ed.), Appreciative Inquiry: Rethinking Human Organization Toward a Positive Theory of Change. Champaign IL: Stipes. 
Cooperrider, D., \& Whitney, D. D. (2005). Appreciative inquiry: A positive revolution in change. Berrett-Koehler Publishers.

Coxon, E., Anae, M., Mara, D., Wendt-Samu, T., \& Finau, C. (2002). Literature Review on Pacific Education Issues. Wellington: Ministry of Education

Craven, R. G., \& Marsh, H. W. (2004). The challenge for counsellors: Understanding and addressing indigenous secondary students' aspirations, self-concepts and barriers to achieving their aspirations. Australian Journal of Guidance \& Counselling, 14(1), 16-33.

Creswell, J. (1994). Research Design: Qualitative and Quantitative Approaches. Thousand Oaks, CA: Sage Publications.

Creswell, J. (1998). Qualitative inquiry and research design: Choosing among five traditions. London: Sage.

Creswell, J. (2003). Research Design; Qualitative, Quantitative, and Mixed Method Approach. Thousand Oak, CA: Sage.

Creswell, J. (2008). Educational research: Planning, conducting, and evaluating quantitative and qualitative research (3rd ed.). Upper Saddle River, NJ: Pearson Education.

Denscombe, M. (2010). The Good Research Guide: for small-scale social research projects (4th ed.). Maidenhead: McGraw-Hill Open University Press.

Dewey, J. (1933). A restatement of the relation of reflective thinking to the educative process. DC Heath.

Dweck, C. (2006). Mindset: The new psychology of success. Random House.

Dweck, C. S. (2010). Mind-sets. Principal Leadership, 10(5), 26-29.

Dweck, C., Walton, G. M., \& Cohen, G. L. (2011). Academic tenacity: Mindsets and skills that promote log-term learning. Paper presented at the Gates Foundation, Seattle, WA.

Education Counts. (2015). Progress against Pasifika education plan targets. Retrieved October 3, 2015, from https://www.educationcounts.govt.nz/statistics/pasifikaeducation/progress_against_pasifika_education_plan_targets.

Education Review Office. (2013). Making connections for Pacific learners' success, November 2013. Retrieved from http://www.ero.govt.nz/National$\underline{\text { Reports/Making-Connections-for-Pacific-Learners-Success-November-2013 }}$ 
Eggens, L., Van der Werf, M. P. C., \& Bosker, R. J. (2008). The influence of personal networks and social support on study attainment of students in university education. Higher Education, 55(5), 553-573.

Erickson, F. (1979) Mere ethnography: some problems in its use in educational practice. Anthropology and Education Quarterly, 10(3), 182-188.

Erlandson, D. A., Harris, E. L., Skipper, B. L., \& Allen, S. D. (1993). Doing naturalistic inquiry: A guide to methods. Newbury Park, CA: Sage.

Farrelly, T., \& Nabobo-Baba, U. (2012, 3-5 December). Talanoa as empathic research. Paper presented at the International Development Conference: Integrating Research, Policy and Practice, Auckland, New Zealand.

Farruggia, S. P., Bullen, P., Solomon, F., Collins, E., \& Dunphy, A. (2011). Examining the cultural context of youth mentoring: A systematic review. The Journal of Primary Prevention, 32(5-6), 237-251.

Finn, J. D., \& Rock, D. A. (1997). Academic success among students at risk for school failure. Journal of applied psychology, 82(2), 221.

Fletcher, J., Parkhill, F., Fa'afoi, A., \& Taleni, L. T. (2006). Pasifika students' perceptions of barriers and support to reading and writing achievement in New Zealand schools. New Zealand Journal of Educational Studies, 41(2), 163-182.

Fletcher, J., Parkhill, F., Fa'afoi, A., Taleni, L. T., \& O'Regan, B. (2009). Pasifika students: Teachers and parents voice their perceptions of what provides supports and barriers to Pasifika students' achievement in literacy and learning. Teaching and Teacher Education, 25, 24-33.

French, W. L., \& Bell, C. H. (1984). Organization Development: Behavioral Science Interventions for Organization Improvement (3rd ed.). Englewood Cliffs, NJ: Prentice Hall.

Fry, R. \& Barrett, F. (2002). Rethinking what gives life to positive change. In R. Fry, F. Barret, J. Seiling, \& D. Whitney (Ed.), Appreciative Inquiry and organizational transformation: Reports from the field (pp. 263-278). Westport, Connecticut: Quorum Books.

Gegeo, D. W. (2008, April). Shifting paradigms in Pacific scholarship: Towards islandbased methodologies, epistemologies and pedagogies. Paper presented at Building Pacific Research Capacity and Scholarship Fono 2008, Fale Pasifika, University of Auckland. 
Glaser, B. G., \& Strauss, A. L. (1967). The Discovery of Grounded Theory: Strategies for Qualitative Research. Chicago: Aldine Pub. Co.

Goodman. L. A. (1961). Snowball sampling. Annals of Mathematical Statistics, 32. 148-170.

Gorinski, R., \& Fraser, C. (2006). Literature review on the effective engagement of Pasifika parents and communities in education. Research Division, Ministry of Education.

Graham, J., Meyer, L. H., McKenzie, L., McClure, J., \& Weir, K. F. (2010). Maori and Pacific secondary student and parent perspectives on achievement, motivation and NCEA. Assessment Matters, 2, 132-157.

Guba, E. G., \& Lincoln, Y. S. (1994). Competing paradigms in qualitative research. In N. K. Denzin \& Y. S. Lincoln (Eds.), Handbook of qualitative research (pp. 105117). London: Sage.

Halapua, W. (2008). Moana methodology: A way of promoting dynamic leadership. Talanoa Oceania. Retrieved February 4, 2012, from https://sites.google.com/a/nomoa.com/talanoa/Home/paperspresentations/halapua-moana

Hamachek, D. (1995). Self-Concept and School Achievement: Interaction Dynamics and a Tool for Assessing the Self-Concept Component. Journal of Counseling \& Development, 73(4), 419-425.

Hammond, S.A., \& Royal, C. (Eds.). (1998). Lessons from the field: Applying appreciative inquiry. Piano, TX: Thin Book / Practical Press.

Hannant, B. J. (2013). What works: Academically successful Pasifika males identify factors contributing to their educational outcomes (Unpublished master's thesis). Massey University, New Zealand.

Harms, L. (2005). Understanding human development: A multidimensional approach. South Melbourne: Oxford University Press.

Hattie, J. (2014). Self-concept. Psychology Press.

Hawk, K., \& Hill, H. (2001). Troubled transition: How to ensure that educational transition points do not interrupt student learning. set: Research information for teachers.

Hawk, K., \& Hill, J. (2004). Transition traumas, traps, turning points and triumphs: Putting student needs first. In Way Forward for Secondary Education Conference, Wellington, New Zealand. 
Hawk, K., Hill, J., \& Seabourne, T. (1996). Towards Making Achieving Cool:

Achievement in Multi Cultural High Schools (AIMHI) Report. The Ministry.

Henry, K. L., Knight, K. E., \& Thornberry, T. P. (2012). School disengagement as a predictor of dropout, delinquency, and problem substance use during adolescence and early adulthood. Journal of youth and adolescence, 41(2), 156-166.

Hettich, P. (1992). Learning Skills for College and Career. Pacific Grove: Brooks Cole.

Hulleman, C. S., \& Harackiewicz, J. M. (2009). Promoting interest and performance in high school science classes. Science, 326(5958), 1410-1412.

Irby, M. A., Ferber, T., \& Pittman, K. J. (2001). Youth action: Youth contributing to communities, communities supporting youth. International Youth Foundation.

Jette, D. U., Grover, L., \& Keck, C. P. (2003). A qualitative study of clinical decision making in recommending discharge placement from the acute care setting. Physical Therapy, 83(3), 224-236.

Johnson, B. \& Christensen, L. (2008). Educational research: quantitative, qualitative, and mixed approaches (3rd ed.). Los Angeles: Sage Publications

Johnson, B., \& Sessions, J. (2014). What schools don't teach: 20 ways to help students excel in school and life. Routledge.

Kearney, J., \& Donaghy, M. (2010, June). Bridges and barriers to success for Pacific Islanders completing their first year at an Australian university. Paper presented at The 13th Pacific Rim First Year in Higher Education Conference, 'Aspiration Access - Achievement', 27-3.

Kolb, D. A. (2014). Experiential learning: Experience as the source of learning and development. Pearson Education.

Kouzes, J. M., \& Posner, B. Z. (2007). The leadership challenge (Vol. 3). John Wiley \& Sons.

Krishnan, V., Schoeffel, P., \& Warren, J. (1994). The challenge of change: Pacific Island communities in New Zealand 1986-1993. Wellington: New Zealand Institute for Social Research \& Development.

Kruse, D. (1996). Transition and change: Early adolescence and the role of education. Learning Matters, 1(2), 59.

Lessard, A., Butler-Kisber, L., Fortin, L., \& Marcotte, D. (2014). Analyzing the discourse of dropouts and resilient students. The Journal of Educational Research, 107(2), 103-110. 
Levinson, D. J., \& Levinson, J. D. (1996). The Seasons of a Woman's Life. New York: Ballantine, 1996.

Lipene, T. (2010). Education of secondary Samoan students in New Zealand: The road to success (Unpublished doctoral thesis). Victoria University, Wellington, New Zealand.

Locke, E. A. (1975). A Guide to Effective Study. New York: Springer.

Locke, E. A., \& Latham, G. P. (2006). New directions in goal-setting theory. Current directions in psychological science, 15(5), 265-268.

Luthar, S. S., Cicchetti, D., \& Becker, B. (2000). Research on resilience: Response to commentaries. Child development, 71(3), 573-575.

Manu'atu, L., \& Kepa, M. (2002). Towards reconstituting the notion of study clinics. A Kakai Tonga Tu'a community based educational project. Invited presentation given to the First National Pasifika Bilingual Education conference, Auckland, Alexandra Park Conference Centre, 1-3 October.

Manueli, K. (2012). Pasifika tertiary students' use of information and communication technologies (Unpublished PhD thesis). Wellington, New Zealand: Victoria University of Wellington.

Mara, D. (1999, April). Why research? Why educational research for/by/with Pacific communities in Aotearoa-New Zealand. Paper presented to the Pacific Island Educators’ Conference, Auckland.

Mara, D., \& Marsters, M. (2009). Pasifika students: Supporting academic success through the provision of mentoring. Wellington: Ako Aotearoa.

Martin, A. J. (2002). Motivation and academic resilience: Developing a model for student enhancement. Australian journal of education, 46(1), 34-49.

Martin, A. J. (2009). Motivation and engagement across the academic life span a developmental construct validity study of elementary school, high school, and university/college students. Educational and Psychological Measurement, 69(5), 794-824.

Martin, A. J. (2013). Academic buoyancy and academic resilience: Exploring 'everyday' and 'classic' resilience in the face of academic adversity. School Psychology International, 34(5), 488-500.

Martin, A.J., \& Dowson, M. (2009). Interpersonal relationships, motivation, engagement, and achievement: Yields for theory, current issues, and educational practice. Review of Educational Research, 79, 327-365. 
Marsh, H. W., \& Craven, R. G. (2006). Reciprocal effects of self-concept and performance from a multidimensional perspective: Beyond seductive pleasure and unidimensional perspectives. Perspectives on psychological science, 1(2), 133163.

Martin, A. J., \& Marsh, H. W. (2008). Academic buoyancy: Towards an understanding of students' everyday academic resilience. Journal of School Psychology, 46(1), 53-83.

Maxwell, J. A. (2005). Qualitative research design: An interactive approach (2nd Ed.). Thousand Oaks, CA: Sage.

Mayocchi, L., \& Hanrahan, S. J. (1997). Adaptation to a post-athletic career: The role of transferable skills. Belconnen, ACT: Australian Sports Commission.

McKnight, K., Bernes, K., Gunn, T., Chorney, D., Orr, D., \& Bardick, A. (2009). Life after sport: Athletic career transition and transferable skills. Journal of Excellence, 13, 63-77.

Meredeen, S. (1988). Study for Survival and Success. London: Paul Chapman.

Merton, R. K. (1949). On sociological theories of the middle range [1949]. na.

Mezirow, J. (1998). On critical reflection. Adult Education Quarterly, 48(3), 185-198.

Ministry of Education. (2002). Excellence, relevance and access: An introduction to the new tertiary education system. Wellington: Ministry of Education.

Ministry of Education. (2007). Pasifika education plan monitoring report. Wellington: Ministry of Education.

Ministry of Education. (2008). A study of students' transition from primary to secondary schooling. Wellington: Ministry of Education.

Ministry of Education. (2009). Pasifika Education Plan 2009-2012. Wellington: Ministry of Education.

Ministry of Education. (2010). Pasifika in tertiary education in New Zealand in 2009. Wellington: Ministry of Education.

Ministry of Education. (2011). Progress against Pasifika Education Plan 2009-2012. Wellington: Ministry of Education.

Ministry of Education. (2012a). Pasifika Education Plan 2013-2017 Consultation. Retrieved from http://www.minedu.govt.nz/NZEducation/EducationPolicies/PasifikaEdu cation/PEP2013Consultation/ProgressToDate.aspx

Ministry of Pacific Island Affairs. (1999). Pacific vision strategy, Pacific directions 
report: A report to government on a possible pathway for achieving Pacific people's assumptions. Wellington: Ministry of Pacific Island Affairs.

Montero-Hernandez, V., Levin, J., \& Castillo, M. (2014), Academic resilience and achievement: Self-motivational resources that guide faculty participation in instructional technology training at a Mexican university. Journal of Hispanic Higher Education, 13(4), 334-358.

Morales, E. E., \& Trotman, F. K. (2004). Promoting academic resilience in multicultural America: Factors affecting student success (Vol. 29). Peter Lang.

Morisano, D., Hirsh, J. B., Peterson, J. B., Pihl, R. O., \& Shore, B. M. (2010). Setting, elaborating, and reflecting on personal goals improves academic performance. Journal of Applied Psychology, 95(2), 255-264.

Morse, Janice M. (1994). Designing funded qualitative research. In Norman K. Denzin \& Yvonna S. Lincoln (Eds.), Handbook of qualitative research (2nd ed., pp.220-35). Thousand Oaks, CA: Sage.

Murphy, D., Campbell, C., \& Garavan, T. N. (1999). The Pygmalion effect reconsidered: its implications for education, training and workplace learning. Journal of European Industrial Training, 23(4/5), 238-251.

Nakhid, C. (2003a). Comparing Pasifika students' perceptions of their schooling with the perceptions of non-Pasifika teachers using the "mediated dialogue" as a research methodology. NZ Journal of Educational Studies, 38, 207-226.

Nakhid, C. (2003b). "Intercultural" perceptions, academic achievement, and the identifying process of Pacific Islands students in New Zealand schools. The Journal of Negro Education, 72(3), 297-317.

New Zealand Education. (2015). Your New Zealand education system. Retrieved August 21, 2015 from http://www.studyinnewzealand.com/learn/oursystem?utm_source=newzealandnow.govt.nz\#slide-2

New Zealand Qualifications Authority. (2015a). NCEA qualifications and standards. from http://www.nzqa.govt.nz/qualifications-standards/qualifications/ncea/

New Zealand Qualifications Authority. (2015b). University Entrance. Retrieved June 3, 2015, from http://www.nzqa.govt.nz/qualifications-standards/awards/universityentrance/

New Zealand Qualifications Authority. (2015c). Secondary School Statistics. Retrieved June 5, 2015 from http://www.nzqa.govt.nz/studying-in-new-zealand/secondaryschool-and-ncea/find-information-about-a-school/secondary-school-statistics/ 
New Zealand Qualifications Authority. (2015d). Tertiary Education. Retrieved June 5, 2015, from http://www.nzqa.govt.nz/studying-in-new-zealand/tertiary-education/

Otsuka, S. (2006). Talanoa research: Culturally appropriate research design in Fiji. Retrieved from http://www.aare.edu.au/05pap/ots05506.pdf

Pajares, F. (1996). Self-efficacy beliefs in academic settings. Review of educational research, 66(4), 543-578.

Pajares, F. (2001). Toward a positive psychology of academic motivation. The Journal of Educational Research, 95(1), 27-35.

Pasikale, A. (2002). Pacific Education in New Zealand. In F. Pene, A. M. Taufe'ulungaki \& C. Benson (Eds.), Tree of opportunity: Rethinking Pacific education (pp. 112-124). Suva, Fiji: The University of the South Pacific.

Pasikale, A., \& George, T. (1995). 'For family first': A study of income allocation within Pacific Island families in New Zealand. Wellington: Destini.

Passi, J. (2011). To give back to the hand that fed me (Unpublished master's thesis). University of Auckland, New Zealand.

Perry, J. M., \& Jamison, S. (1997). In the Zone: Achieving Optimal Performance in Business - as in Sports. JM Perry Learning Technolog.

Pintrich, P. R. (2000). The role of goal orientation in self-regulated learning. In M. Boekaerts, P. R. Pintrich, \& M. Zeidner (Eds.), Handbook of self-regulation (pp. 452-502). San Diego, CA: Academic Press

Podmore, V. N., Sauvao, L.M., with Mapa, L. (2003). Sociocultural perspectives on transition to school from Pacific Islands early childhood centres. International Journal of Early Years Education. 11 (1), 33-42.

Polutu-Endemann, K. (2009). Fonofale model. from http://www.hauora.co.nz/resources/Fonofalemodel.pdf

Polutu-Endemann, K., Suaali’i-Sauni, T., Lui, D., McNicholas, T., Milne, M., \& Gibbs, T. (2007). Seitapu Pacific Mental Health and Addiction Cultural \& Clinical Competencies Framework. Te Pou O Te Whakaaro Nui, Auckland, New Zealand.

Porter, C., \& Cleland, J. (1995). The portfolio as a learning strategy. Portsmouth, NH: Boynton. Cook Publisher.

Purkey, W. W. (1985). Inviting student self-discipline. Theory into Practice, 24(4), 256-259.

Race, P. (1992). 500 Tips for Students. Oxford: Blackwell. 
Rice, J. (1997). Explaining the negative impact of the transition from middle to high school on student performance in mathematics and science: An examination of school discontinuity and student background variables. Paper presented at the Annual Meeting of the American Educational Research Association, Chicago.

Richardson, M., Abraham, C., \& Bond, R. (2012). Psychological correlates of university students' academic performance: a systematic review and metaanalysis. Psychological bulletin, 138(2), 353.

Ringold, D. (2005). Accounting for diversity: Policy design and Maori development in Aotearoa New Zealand. Retrieved April 23, 2015, from http://www.fulbright.org.nz/wp-content/uploads/2011/12/axford2005_ringold.pdf

Ritchie, J., Lewis, J., \& Elam, G. (2003). Qualitative research practice: A guide for social science students and researchers. In J. Ritchie \& J. Lewis (Eds.), Qualitative research practice: A guide for social science students and researchers. Sage: London; Thousand Oaks; New Delhi.

Rockoff, J. E. (2004). The impact of individual teachers on student achievement: Evidence from panel data. American Economic Review, 247-252.

Rosenthal, R., \& Jacobson, L. (1968). Pygmalion in the classroom. The Urban Review, 3(1), 16-20.

Rubie-Davies, C.M., Peterson, E., Garrett, L., Watson, P., Flint, A., O’Neill, H., \& McDonald, L., (2012). Ethnicity as a factor in student beliefs. Paper presented at the International Conference for Education and Educational Psychology, Istanbul, Turkey.

Ruvolo, A. P., \& Markus, H. R. (1992). Possible selves and performance: The power of self-relevant imagery. Social cognition, 10(1), 95-124.

Saldana, J. (2009). An introduction to codes and coding. The coding manual for qualitative researchers, 1-31.

Schumacher, D. (1998). The transition to middle school (Report No. EDO-PS-98-6). Washington, DC: Clearinghouse on Elementary and Early Childhood Education.

Schunk, D. H., \& Pajares, F. (2009). Self-efficacy theory. In K. R. Wentzel \& A. Wigfield (Eds.), Handbook of motivation at school (pp. 35-54). New York, NY: Routledge. 
Seaton, M., Parker, P., Marsh, H. W., Craven, R. G., \& Yeung, A. S. (2014). The reciprocal relations between self-concept, motivation and achievement: juxtaposing academic self-concept and achievement goal orientations for mathematics success. Educational psychology, 34(1), 49-72.

Seiuli, B. M. S. (2013). Counselling psychology from a Samoan perspective. New Zealand Journal of Psychology, 42(3), 50-58.

Seligman, M. E., \& Csikszentmihalyi, M. (2000). Positive psychology: An introduction (Vol. 55, No. 1, p. 5). American Psychological Association.

Senko, C., \& Hulleman, C. S. (2013). The role of goal attainment expectancies in achievement goal pursuit. Journal of Educational Psychology, 105(2), 504-521. doi:http://dx.doi.org.helicon.vuw.ac.nz/10.1037/a0031136

Skinner, E. A., Kindermann, T. A., Connell, J. P., \& Wellborn, J. G. (2009). Engagement and disaffection as organizational constructs in the dynamics of motivational development. Handbook of motivation at school, 223-245.

Smith, L. T. (1999). Decolonizing methodologies: Research and indigenous peoples. Zed books.

Spiller, D. (2012). Assessment matters: Self-assessment and peer assessment. Retrieved from http://www.waikato.ac.nz/tdu/pdf/8_SelfPeerAssessment.pdf

Steele, C. M. (1997). A threat in the air: how stereotypes shape intellectual identity and performance. American psychologist, 52(6), 613.

Strauss, A., \& Corbin, J. (1998). Basics of qualitative research: Grounded theory procedures and techniques (2nd ed.). Thousand Oaks, CA: Sage.

Strauss, A., \& Corbin, J. (2015). Basics of qualitative research: Techniques and procedures for developing grounded theory. Sage publications.

Tesch, R. (1990). Qualitative research: Analysis types and software tools. New York, NY: Falmer.

Thaman, K. H. (1993). Culture and the curriculum in the South Pacific. Comparative Education, 29(3), 249-260.

Thaman, K. H. (1998). Learning to be: A perspective from the Pacific Islands. Keynote address, Melbourne, UNESCO Conference.

Thaman, K. H. (2001). Towards culturally inclusive teacher education with specific reference to Oceania. Retrieved from http://ehlt.flinders.edu.au/education/iej/articles/v2n5/1Thaman/paper.pdf 
Tupuola, A. M. (2004). Pasifika edgewalkers: Complication the achieved identity status in youth research. Journal of Intercultural Studies, 25(1), 87-100.

Updegraff, J. A., \& Taylor, S. E. (2000). From vulnerability to growth: Positive and negative effects of stressful life events. In J. Harvey \& E. Miller (Eds.), Loss and trauma: General and close relationship perspectives (pp. 3-28). Philadelphia, PA: Brunner-Routledge.

Vaioleti, T. (2006). Talanoa research methodology: A developing position on Pacific research. Waikato Journal of Education, 12, 21-35.

Watkins, J.M., \& Mohr, B.J. (2001). Appreciative inquiry: Change at the speed of imagination. San Francisco, CA: Jossey-Bass/Pfieffer.

Watkins, J.M., Mohr, B.J., \& Kelly, R. (2011). Appreciative inquiry: Change at the speed of imagination (2nd ed.). San Francisco, CA: Pfieffer.

Wentzel, K. R., Baker, S. A., \& Russell, S. L. (2012). Young adolescents' perceptions of teachers' and peers' goals as predictors of social and academic goal pursuit. Applied Psychology, 61(4), 605-633.

Werner, E. E., \& Smith, R. S. (1992). Overcoming the odds: High risk children from birth to adulthood. Cornell University Press.

Wiant, A. A. (1977). Transferable skills: The employer's viewpoint. Columbus, $\mathrm{OH}$ : National Center for Research in Vocational Education.

Wigfield, A., \& Eccles, J. S. (2000). Expectancy-value theory of achievement motivation. Contemporary Educational Psychology, 25, 68-81.

Williams, R., \& Stockdale, S. (2004). Classroom motivation strategies for prospective teachers. The Teacher Educator, 39, 212-230

Wildavsky, A., \& Dake, K. (1990). Theories of risk perception: Who fears what and why? Daedalus, 119(4), 41-60.

Williams, R., \& Stockdale, S. (2004). Classroom motivation strategies for prospective teachers. The Teacher Educator, 39, 212-230

Wood, R. (2005). New frontiers for self-regulation research in IO psychology. Applied Psychology: An International Review, 54, 192-198.

Wylie, R. C. (1979). The self-concept: Theory and research on selected topics (Vol. 2). Lincoln, NE: University of Nebraska.

Zubizarreta, J. (2009). The learning portfolio: Reflective practice for improving student learning. John Wiley \& Sons. 


\section{Appendix 1: Participant Information Sheet}

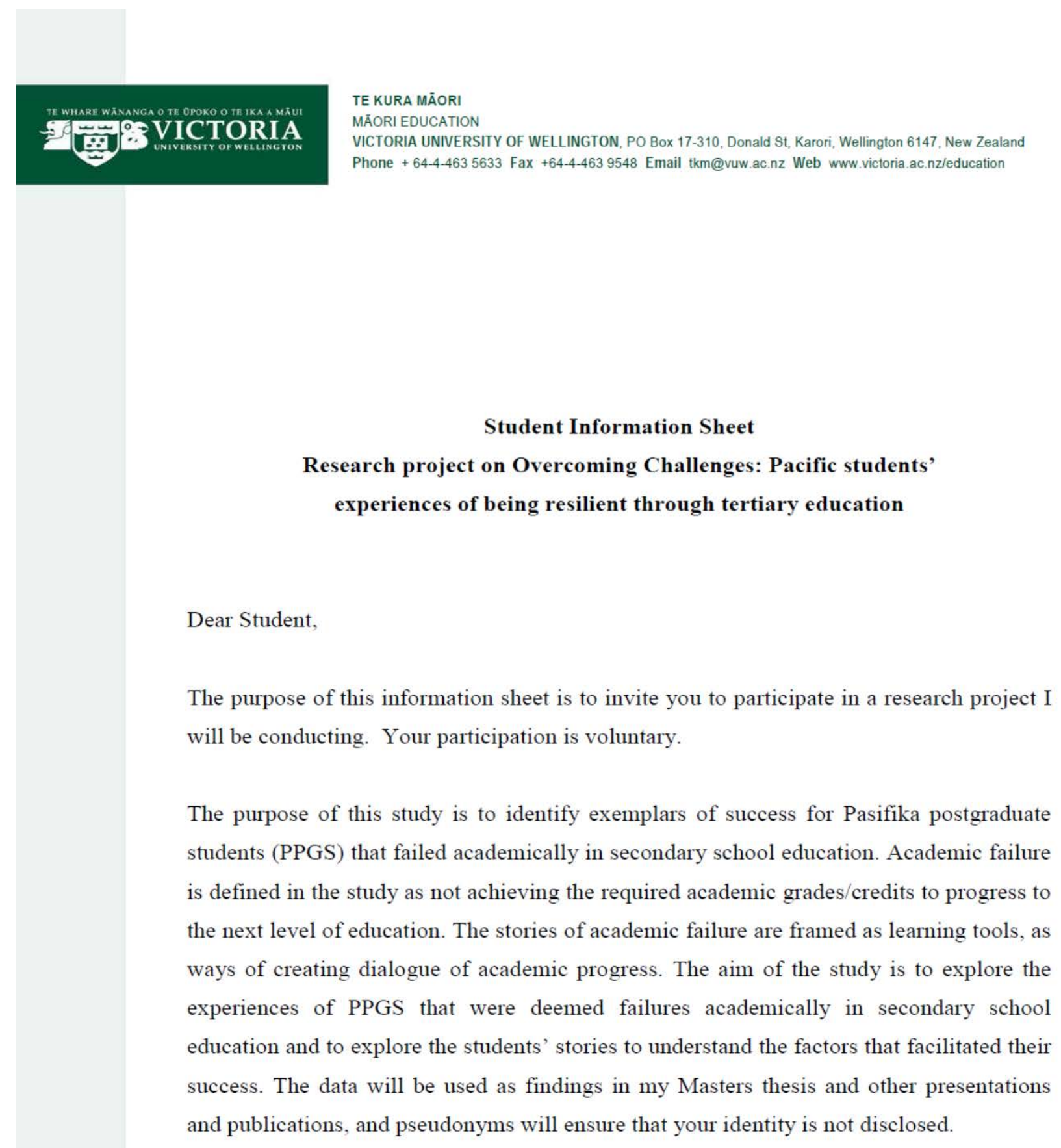

The objectives of the study are:

1) To identify, investigate, analyse and report PPGS experiences and stories of education in Aotearoa. 
2) To explore what the PPGS believe was the difference between the two educational settings.

3) To investigate, analyse and describe internal and external motivational factors that contribute to PPGS development and success.

4) To identify how PPGS stories of resilience can assist future Pasifika students in tertiary level education.

5) To identify in their stories some key factors that could enhance policy, programme and practice levels at the secondary school level to better serve the needs of Pasifika students.

It is hoped that this research will be beneficial to future Pasifika students themselves but also to inform institutional and sectoral improvements in supporting Pasifika learners in secondary schools and tertiary institutions.

The purpose of you participating in this study is to identify, understand and share your educational story. You will participate in one hour talanoa sessions. As a research tool:

1) Talanoa is a conversation;

2) Talanoa can be formal or informal in nature;

These Talanoa sessions are informal individual discussions. The discussions will be audio recorded. I will be talking with you about your positive and negative experiences in your education journey thus far. The findings from the research will be produced in a full report.

During the talanoa:

You may withdraw at any time. Audio Recordings will be made of your responses. The data files will be kept strictly confidential.

The identifying factors that will be published with consent will be:

What tertiary institute you studied with/ currently studying with including the course of study. Also personal details such as your Pasifika ethnicity, your age, gender.

By consenting you understand that: 
You have the right to withdraw at any time. The results of the research project will be written up in the form of a report. Audio recordings and transcripts will be kept until a period of three years and then destroyed. You will have your data returned as a full transcript to you so you can check for accuracy. You will be sent a copy (via email) of your stories for you to check over.

Arden Perrot and Cherie Chu (supervisor) will only have access to the data and it will be kept locked in a secure filing cabinet and/ or in a password protected storage system.

If you have any further questions or would like some more information, do not hesitate to contact me. My contact details are: Arden Perrot, School of Health and Social Services, Weltec, (Arden.Perrot@Weltec.ac.nz, 04-830-2004)\& Cherie Chu, Te Kura Maori, Victoria University of Wellington, (Cherie.Chu@vuw.ac.nz,04-463-5316). This research is approved by the Victoria University of Wellington, Human Ethics Committee.

Yours Sincerely,

Arden Perrot 


\section{Appendix 2: Consent from}

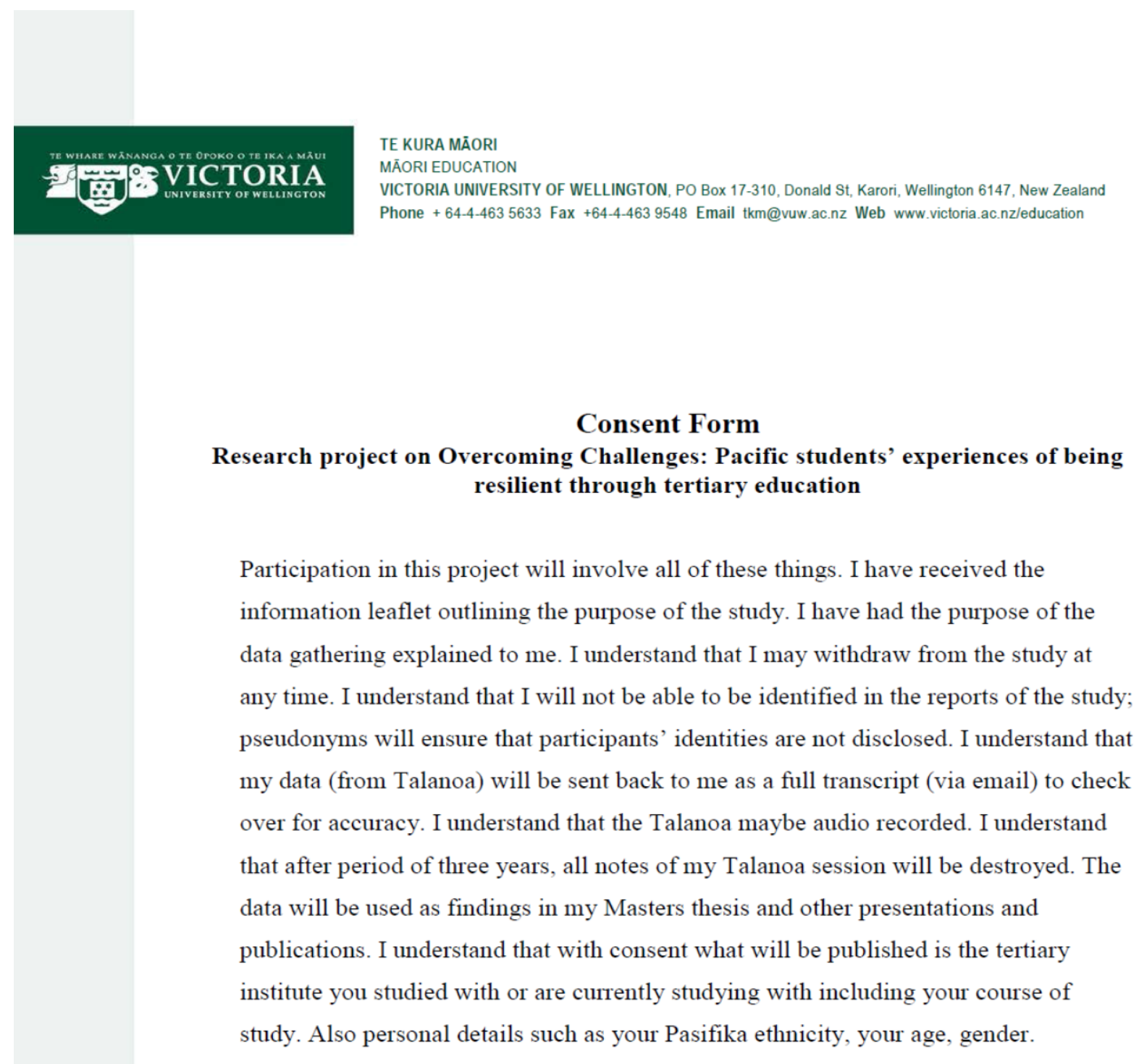

I wish to receive feedback from this project

*If you ticked yes please provide an email or address here:

Sign and confirm that you have read and agreed with the information provided here.

Student's Name:

Student's Signature:

Please complete this form and either return it to me by July $15^{\text {th }} 2015$. 


\section{Appendix 3: Talanoa Briefing Document}

VICTORIA UNIVERSITY OF WELLINGTON, PO Box 17-310, Donald St, Karori, Wellington 6147, New Zealand

Phone + 64-4-4635633 Fax +64-4-4639548 Email tkm@vuw.ac.nz Web www.victoria.ac.nz/education

\section{Talanoa Briefing document and questions}

Thank you once again for being part of my research. Here is a little bit more information so you have time to think about some of your answers so you don't feel as if you are put on the spot. This also allows us to really get to the core of your story. There a few things you can think about and bring some notes into the Talanoa.

\section{Think hard about your self from the time you left secondary school -}

- How was your thinking, what were your thoughts about education, about your ability academically?

- What do you think held you back?

- How did this shape the perceptions of yourself or your belief about your potential in education

- How was your self-talk, what phrases did you tell yourself about yourself?

- What was your mental focus at school?

- How was your physiology when you finished school, did you walk with confidence, shoulders back

\section{Think hard about yourself from the time at university}

- What made you want to come back?

- What had changed in your thinking, what were your thoughts about education now and why?

- What factors internally were driving you to shift your ability academically and the perceptions of yourself?

- What was making you persist? What stopped you from giving up?

- What was your mental focus now what was driving that?

- How was your self-talk, what phrases did you tell your self about your self?

- How was your belief system now

- What made you want to now pursue postgraduate success

What was the difference between the two contexts in your mind, were they different or did you change?

What transferable practices or skills or factors did you possess in tertiary level that made your experience different from secondary school?

Any of these skills available to Young Pasifika now at education that they should be using?

What words of advice would you give the next generation of Pacific learners? 


\section{Appendix 4: Victoria University Human Ethics Approval}
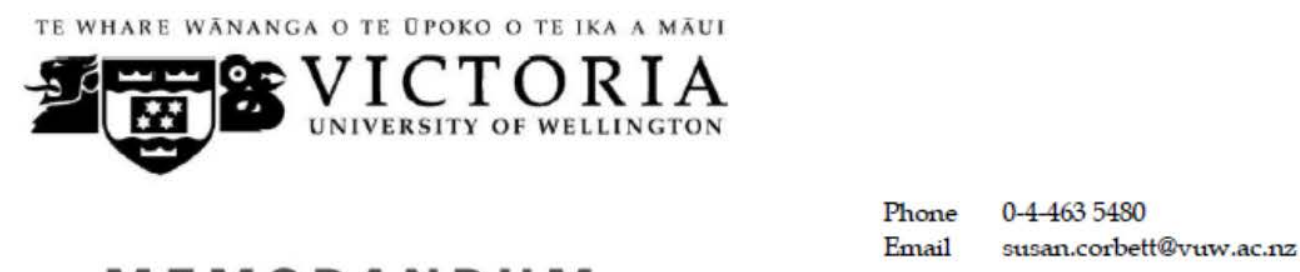

MEMORANDUM

\begin{tabular}{l|l}
\hline TO & Arden Perrot \\
\hline COPY TO & Cherie Chu \\
\hline FROM & AProf Susan Corbett, Convener, Human Ethics Committee \\
\hline
\end{tabular}

\begin{tabular}{l|l}
\hline DATE & 9 June 2015 \\
\hline PAGES & 1 \\
\hline
\end{tabular}

\begin{tabular}{l|l}
\hline SUBJECT & $\begin{array}{l}\text { Ethics Approval: } 21541 \\
\text { Overcoming Challenges: Pacific students' experiences of being } \\
\text { resilient through tertiary education }\end{array}$ \\
\hline
\end{tabular}

Thank you for your application for ethical approval, which has now been considered by the Standing Committee of the Human Ethics Committee.

Your application has been approved from the above date and this approval continues until 31 October 2015. If your data collection is not completed by this date you should apply to the Human Ethics Committee for an extension to this approval.

Best wishes with the research.

Kind regards<smiles>CCCCCCCCCCCCCC(C)(C)C</smiles> 